\title{
Informe años dos Movil.com: Evaluación de la línea final resumen de hallazgos principales
}

Annik Sorhaindo

Population Council

Xipatl Contreras

Population Council

Kate S. Wilson

Sandra G. Garcia

Population Council

Follow this and additional works at: https://knowledgecommons.popcouncil.org/departments_sbsr-rh

Part of the Community-Based Research Commons, Demography, Population, and Ecology Commons, Family, Life Course, and Society Commons, International Public Health Commons, and the Maternal and Child Health Commons

How does access to this work benefit you? Let us know!

\section{Recommended Citation}

Sorhaindo, Annik, Xipatl Contreras, Kate S. Wilson, and Sandra G. Garcia. 2011. "Informe años dos Movil.com: Evaluación de la línea final resumen de hallazgos principales." Mexico City: Population Council. 


\section{Population Council, Oficina de México}

\section{INFORME AÑO DOS MOVIL.COM}

\section{EVALUACIÓN DE LA LÍNEA FINAL RESUMIEN DE HALLAZGOS PRINCIPALES}

Agosto 2011 


\section{Contenido}

Agradecimientos .3

Introducción

Antecedentes y colaboración................................................... 5

Descripción de Movil.com ...................................................5

Descripción de actividades Movil.com ......................................6

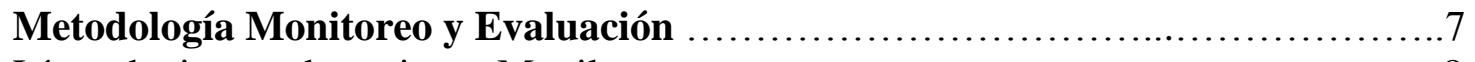

Línea de tiempo de acciones Movil.com...................................... 8

Plan para el análisis ......................................................

Actividades de evaluación y fuentes de datos...................................9

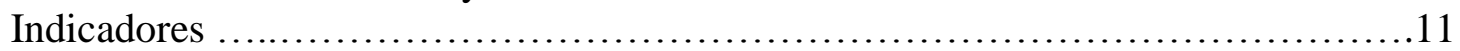

Métodos e instrumentos para recolectar los datos................................12

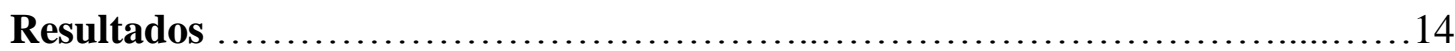

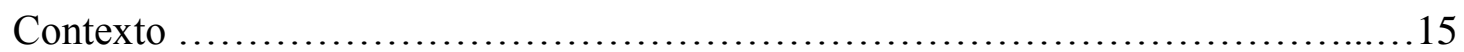

Descripción y diseño de la descripción de datos ..................................16

Líderes ................................................................. 17

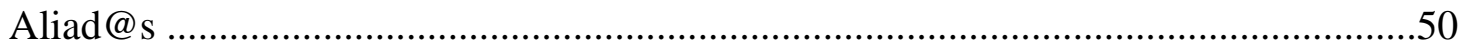

Jóvenes de la Comunidad .........................................................68

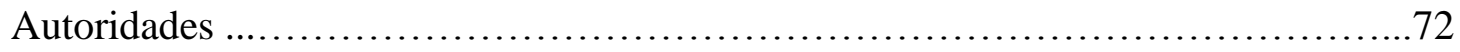

Conclusiones y recomendaciones. 


\section{Agradecimientos}

A nombre de la oficina de México del Population Council y de

la Directora de País, Dra. Sandra G. García,

Annik Sorhaindo y Xipatl Contreras, desean expresar su sincera

gratitud a las siguientes organizaciones y personas, cuya colaboración hizo posible la culminación de esta etapa de la actividad:

Grupo de Estudios de la Mujer "Rosario Castellanos"

Fundación John D. \& Katherine T. MacArthur

A todas las jóvenes líderes, a los grupos de aliadas y aliados, a la juventud y autoridades de las comunidades de Oaxaca en donde el proyecto se lleva a cabo, por su gran compromiso y entusiasmo,

y por haber compartido sus valiosas experiencias. 


\section{Introducción}
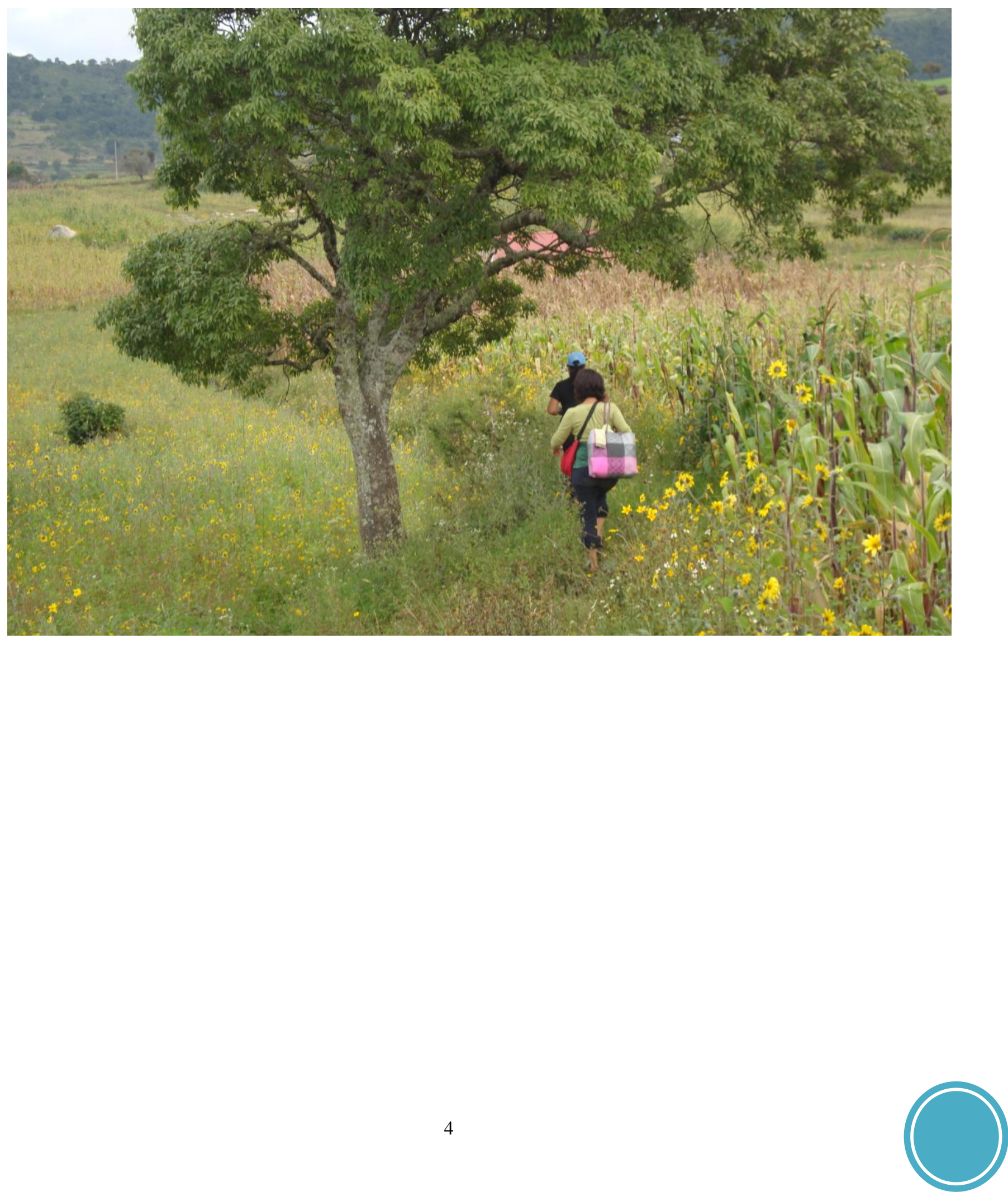


\section{Antecedentes de Colaboración}

En este informe se destacan los hallazgos de la evaluación de la línea final de un proyecto de liderazgo de dos años de duración, dirigido a la juventud indígena: Movil.com (acrónimo de "movilización comunitaria"). La oficina del Population Council en México ha evaluado el proyecto a solicitud de la organización social que lo implementa, el Grupo de Estudios sobre la Mujer Rosario Castellanos, el "Grupo", una ONG que ha trabajado durante más de 30 años con comunidades indígenas promoviendo la salud materna y los derechos sexuales y reproductivos, y cuya sede se ubica en la ciudad de Oaxaca. Ambas organizaciones comparten la meta de promover los derechos sexuales y reproductivos en México, lo que incluye a la juventud indígena.

Este informe busca resumir los hallazgos más relevantes de la línea final recolectados entre mayo y julio del 2011 respectivamente, orientados a la evaluación del proyecto. También hará un comparativo de la línea base con la final, en donde se emplearon la misma metodología, con los mismos grupos e indicadores. A continuación, describimos el contexto comunitario y el proceso de recolección de datos para la línea final, junto con los retos y las modificaciones al plan. Presentamos un resumen de los resultados claves. La sección final describe las lecciones aprendidas así como las recomendaciones finales.

\section{Descripción de Movil.com}

El Grupo desarrolló Movil.com basándose en la exitosa experiencia de un programa de becas para adolescentes indígenas (Fondo de Becas Guadalupe Musalem), y a partir también de tres décadas de actividades comunitarias de promoción de la salud y los derechos de las mujeres Oaxaqueñas. Identificó la evidente necesidad de adaptar los programas juveniles para beneficiar a las niñas y mujeres jóvenes y sus pares que no asisten a la escuela y que tienen una presencia más estable en sus comunidades.

De este modo y a partir de programas anteriores, Movil.com es un proyecto comunitario encabezado por pares y fincado en elementos de otros modelos. Es similar a un modelo de educación y entrenamiento de pares en cascada, en el cual se capacita a las líderes nucleares quienes, a su vez, capacitan a facilitadores de grupos más amplios (a los que de aquí en adelante nos referiremos como "aliados"). Las líderes y sus aliados educan a un grupo más amplio para alcanzar a segmentos mayores de la población meta de jóvenes, desarrollan actividades educativas diversas con la juventud meta de sus comunidades para validar mensajes que, en el transcurso del tiempo y de distintas formas, les sean comunes. El proyecto tiene, además, un elemento semejante al de "espacios seguros" de otras intervenciones del Population Council. Los espacios seguros son el Grupo mismo (que representa un centro de recursos y vivienda para las líderes) y un espacio físico o lugar de trabajo que las autoridades locales de cada comunidad designan para que las líderes se reúnan y planeen sus actividades durante la vigencia del proyecto. De modo similar a como sucede con el proyecto del Council, en Movil.com el espacio seguro más importante y sostenible son las mismas redes sociales de la juventud y no tanto un espacio comunitario designado.

\section{Objetivos}

La meta del proyecto fue promover la salud y los derechos sexuales y reproductivos (SDSR) de la juventud indígena a través de una movilización enraizada en los principios de la equidad de género y el respeto a la diversidad cultural. Los objetivos específicos fueron: 
- Sensibilizar a un grupo de mujeres indígenas jóvenes y capacitarlas en organización comunitaria y participación para promover la salud y los derechos sexuales y reproductivos de toda la juventud en sus respectivas comunidades

- Implementar actividades comunitarias de promoción de la SDSR que sean creativas y hayan sido diseñadas por líderes juveniles para sus pares en coordinación con autoridades locales y los sectores sanitarios y educativos

- Promover la inclusión de la SDSR en los planes de trabajo y presupuestos municipales a fin de asegurar la sostenibilidad.

\section{Descripción de actividades Movil.com}

Mes con mes, las líderes acudieron a la sede del Grupo (en la capital de Oaxaca) para un seminario de una semana (24 sesiones en total) en temas centrales: SSR (embarazo deseado y no deseado, anticoncepción, virginidad, relaciones sexuales), derechos de los adolescentes, violencia basada en género (VBG), equidad de género (EG), desarrollo de liderazgo e interculturalidad

Al comenzar el proyecto, se solicitó a cada líder integrar un equipo de por lo menos cinco amigas y amigos que les ayudarían a organizar y llevar a cabo actividades comunitarias durante cuatro períodos de dos semanas cada uno, buscando alcanzar a grupos más amplios de jóvenes, las campañas de Movil.com tendrían variantes (conservando los mensajes nucleares), en el tipo de actividades que realizarían las líderes y sus aliados. Igualmente, se distinguirían en sus habilidades para organizar y llevar a cabo dichas actividades y para definir lo que consideraran más apropiado para sus pares en las comunidades. La fortaleza de este enfoque es que la juventud tendría varias oportunidades para participar y la diversidad de actividades ayudaría a reforzar los mensajes centrales del proyecto de distintas maneras (por ejemplo, a través de la danza, de discusiones en grupos pequeños, de marchas).

Durante 18 meses, las líderes y sus aliados realizaron cuatro campañas importantes (un paquete de actividades que incluye funciones de teatro, eventos deportivos, marchas, todas ellas relacionados con los temas principales del proyecto), y "mini campañas" entre periodos, con actividades dirigidas a autoridades, funcionarios de salud y otros grupos clave. La segunda campaña, sobre SSR, se lanzó en octubre 2010, la tercera y cuarta en febrero y mayo del 2011, respectivamente. 


\section{Metodología \\ Monitoreo y Evaluación}

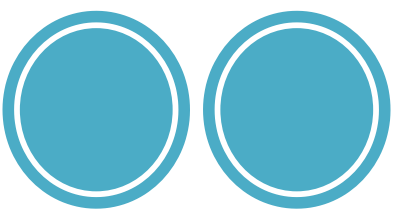




\section{Línea de tiempo de acciones Móvil.com}

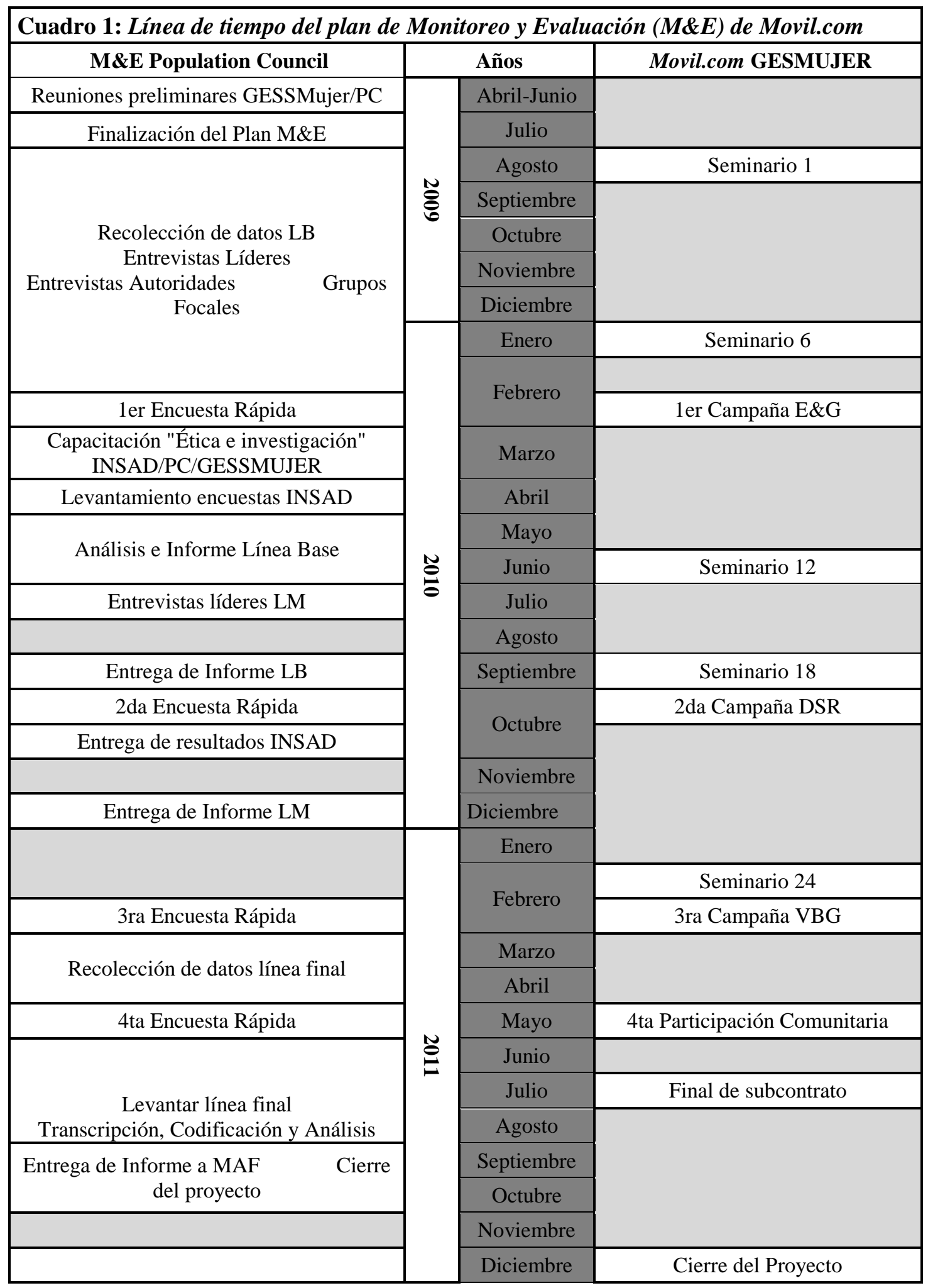




\section{Plan para el análisis}

Hicimos el análisis cuantitativo y cualitativo de los datos de la línea base y final. Para la totalidad del análisis cuantitativo desarrollamos bases de datos separadas en SPSS v. 18.0 para cada grupo, que analizamos por separado (encuestas de líderes, aliados y “encuestas rápidas"). Como el tamaño de la muestra de las encuestas a líderes y aliados era pequeño, decidimos trabajar en estadísticas descriptivas que pudieran emplearse para hacer comparaciones generales con los componentes cualitativos. Para la encuesta rápida analizamos las respuestas por sexo y grupo de edad solamente. Las muestras por comunidad (que oscilaron entre dos y 40 encuestas completas) no eran suficientemente grandes como para hacer comparaciones estadísticamente significativas entre los sitios.

Para el análisis cualitativo se transcribieron en word y codificaron en Atlas.Ti todas las entrevistas y grupos focales en documentos de Word para análisis de contenidos. Desarrollamos códigos basados en las guías para las entrevistas (Ver Anexos A instrumentos línea final). Para fines del presente informe, condensamos los hallazgos principales con citas ilustrativas de cada grupo.

Para la evaluación final, hemos pensado hacer un análisis comparativo enfocándose en los datos de los tres grupos nucleares: líderes, aliados y de autoridades de la línea base y la línea final, a fin de determinar en qué medida el proyecto alcanzó los objetivos que se propuso y los indicadores establecidos.

En resumen, para el análisis cuantitativo, por cada líder y los aliados hicimos comparaciones generales de los datos de la encuesta, entre línea base y final, dependiendo más de los hallazgos cualitativos y los datos del monitoreo para evaluar el cambio en CAP (pruebas de conocimiento pre-post de contenidos del seminario que el Grupo administró). También medimos los cambios cualitativos en base a la información que surja del grupo focal.

\section{Actividades de evaluación y fuentes de datos}

Con base en los objetivos de Movil.com y a las necesidades y solicitudes específicas de las Directoras de proyecto del Grupo, quienes deseaban ser capaces de demostrar el nivel del cambio ocurrido en la comunidad, de acuerdo con el municipio y/o los presupuestos para sustentar el programa (diseño de "espacios seguros" para las líderes), además de cambios constatados en el ámbito individual. Acordamos que requeríamos un plan de evaluación de las líneas base, media y final que pudiera medir los cambios en conocimientos, actitudes y prácticas sobre los cuatro temas centrales de Movil.com entre las líderes, los aliados y los jóvenes de la comunidad, así como en la opinión y percepción de las autoridades. Los resultados de la evaluación basal y las actividades de monitoreo que el Grupo realizó permitirían contestar las preguntas: “¿Las actividades se llevaron a cabo tal y como se habían planeado (y si no, ¿qué fue lo que cambió y por qué?)?” En la evaluación final de junio 2011 se compararían los resultados para contribuir a contestar la pregunta: “¿Logramos los objetivos de Movil.com (y si no ocurrió así, ¿cuál fue la razón?)?”

El cuadro que aparece a continuación resume, para cada grupo, los indicadores principales, las actividades de recolección de datos y las fuentes de información. Favor referirse al Cuadro 2 que ofrece el plan en forma tabulada, la lista completa de indicadores y el cronometraje 


\begin{tabular}{|c|c|c|c|c|}
\hline \multicolumn{5}{|c|}{ Cuadro 2: Plan de Evaluación } \\
\hline Grupos & Planeado & $\begin{array}{c}\text { Línea base } \\
\text { (Ago 2009 - Feb 2010) }\end{array}$ & $\begin{array}{l}\text { Línea media } \\
\text { (Julio 2010) }\end{array}$ & $\begin{array}{c}\text { Línea Final } \\
\text { (Mayo - Agosto 2011) }\end{array}$ \\
\hline Líderes & $\mathrm{N}=10$ & $\begin{array}{l}\mathrm{N}=13 \\
\text { En el } 1^{\circ} \text { seminario: } \\
\text { Encuesta CAP sobre cuatro } \\
\text { áreas de contenidos y } \\
\text { liderazgo } \\
\text { Entrevistas a profundidad }\end{array}$ & $\begin{array}{l}\mathrm{N}=11 \\
\text { En el } 12^{\circ} \text { seminario: } \\
\text { Encuesta CAP sobre cuatro } \\
\text { áreas de contenidos y } \\
\text { liderazgo } \\
\text { Entrevistas a profundidad }\end{array}$ & $\begin{array}{l}\mathrm{N}=9 \\
\text { En el } 23^{\circ} \text { y } 24^{\circ} \text { seminario: } \\
\text { Encuesta CAP sobre cuatro } \\
\text { áreas de contenidos y } \\
\text { liderazgo } \\
\text { Entrevistas a profundidad }\end{array}$ \\
\hline Aliados & $\begin{array}{l}\mathrm{N}=50 \\
\text { Mínimo cinco } \\
\text { por comunidad } \\
70 \% \text { mujeres }\end{array}$ & $\begin{array}{l}\mathrm{N}=62 \\
10 \text { Comunidades, } 45 \% \\
\text { mujeres } \\
\text { Grupos focales } \\
\text { Encuesta CAP sobre cuatro } \\
\text { áreas de contenidos y } \\
\text { liderazgo }\end{array}$ & No aplica & $\begin{array}{l}\mathrm{N}=17 \\
8 \text { comunidades, } 70 \% \text { mujeres } \\
\text { Grupos focales } \\
\text { Encuestas CAP sobre cuatro } \\
\text { áreas de contenidos y } \\
\text { liderazgo }\end{array}$ \\
\hline Jóvenes & \begin{tabular}{|l|}
$\mathrm{N}=500$ \\
Mínimo 50 por \\
comunidad \\
Muestra base y \\
final Censo \\
SSR a jóvenes
\end{tabular} & $\begin{array}{l}\mathrm{N}=270 \\
1^{\circ} \text { Encuesta rápida } \\
\mathrm{N}=361 \\
3 \text { Comunidades } \\
\text { Censo SSR de jóvenes entre } \\
15-24 \text { años }\end{array}$ & $\begin{array}{l}\mathrm{N}=207 \\
2^{\circ} \text { Encuesta rápida } \\
\mathrm{N}=0\end{array}$ & $\begin{array}{l}\mathrm{N}=374 \\
4^{\circ} \text { Encuesta rápida } \\
\mathrm{N}=0\end{array}$ \\
\hline $\begin{array}{l}\text { Autoridades } \\
\text { y o líderes } \\
\text { comunitarios }\end{array}$ & $\begin{array}{l}\mathrm{N}=30 \\
3 \text { por } \\
\text { comunidad }\end{array}$ & $\begin{array}{l}\mathrm{N}=17 \\
10 / 13 \text { Comunidades } \\
\text { Entrevistas a profundidad }\end{array}$ & Ninguna & $\begin{array}{l}\mathrm{N}=22 \\
8 / 9 \text { Comunidades } \\
\text { Entrevistas a profundidad }\end{array}$ \\
\hline
\end{tabular}

Las líderes fueron las beneficiarias "directas" del proyecto, estuvieron expuestas a los mensajes nucleares y a las actividades. Fue en éste grupo y en el de aliados, dada la metodología de cascada, donde esperábamos constatar el mayor incremento en los indicadores de conocimientos, actitudes y prácticas, al comparar la línea base con la final del proyecto. Además el proyecto estableció como meta que líderes y aliados transmitieran los mensajes claves a un tercer grupo de por lo menos 50 jóvenes en cada comunidad, este grupo habría de variar en el tiempo y entre comunidades, y no tenía un compromiso formal de participar en las actividades de Movil.com, sabemos que tendría una menor exposición y por ende experimentarían menos cambios, mayormente en conocimientos y (posiblemente) en actitudes; pero no tanto en comportamientos.

En cuanto a las autoridades locales, se beneficiarían indirectamente del proyecto, dado que Movil.com estaba dirigido a la juventud, pero estarían expuestas al proyecto directamente al participar en cuando menos una sesión informativa organizada y adaptada para las líderes y ajustada para las autoridades ${ }^{1}$, y también mediante contactos directos con las coordinadoras de proyecto del Grupo.

Acordamos que el Grupo tomaría a su cargo las actividades de monitoreo, incluyendo listas de participantes, documentación de actividades concluidas (comunitarias y seminarios), y encuestas regulares de CAP, pre y post, sobre el contenido específico de los seminarios no cubiertos por las encuestas de evaluación.

\footnotetext{
${ }^{1}$ El grupo convocó a una reunión en febrero 2011 a la que asistieron autoridades de: Santa Ana Tlapacoyan, San Pedro el Alto, Pueblo Viejo Yucuhiti, Nejapa de Madero y Santo Tomas Ocotepec. A la clausura del asistieron autoridades de Santa Ana Tlapacoyan y San Sebastián Coatlán.
} 


\section{Indicadores}

Al desarrollar los indicadores de la evaluación se buscó que fueran específicos, medibles, adecuados y realistas en función de las metas y objetivos del proyecto. El Grupo contaba ya con indicadores que deseaba usar. Nosotras incluimos otros basándonos en la literatura publicada. Los indicadores para los derechos sexuales y reproductivos y la equidad de género representaban más un desafío, ya que la comprensión de estos temas y la experiencia respectiva puede ser específica de cada cultura. Por eso fue que bosquejamos varios indicadores nuevos, suponiendo que tendríamos que revisarlos en el transcurso del proyecto. De igual modo, establecimos metas (porcentaje de cambio entre la línea base y final), basándonos en la experiencia previa del Grupo con programas juveniles y para mujeres, y también en la literatura publicada (ver Cuadro 3). Nuestro razonamiento fue que el mayor impacto de Movil.com se relacionaría con el conocimiento de los contenidos del proyecto; sería ligeramente menor en relación con actitudes, y más escaso en lo relativo a comportamientos (salvo por las habilidades de liderazgo). Fue así que establecimos metas inferiores para cambios en comportamientos saludables, considerando que la mayoría dependería de otras personas y de situaciones ajenas al proyecto (por ejemplo, uso de un método anticonceptivo consistente, denuncias de VBG). En virtud de que en la línea base carecíamos de información sobre SSR y derechos, por no hablar de otros temas, establecimos los indicadores como porcentajes de cambio, en vez de especificar un valor (desconocido) en la línea base.

En términos generales, desarrollamos alrededor de tres indicadores por cada área de contenido de Movil.com; cada grupo de indicadores abarcaba medidas de conocimiento, actitudes y prácticas. Los indicadores del nivel de la comunidad aplican al tercer grupo de jóvenes y miden el cambio en términos del grupo. Lo hicimos así porque no era factible recolectar datos individuales de los participantes jóvenes, ya que el "grupo" variaría en cada actividad y sitio. Para las autoridades y funcionarios locales, recolectamos datos e información de CAP relacionados con cambios en las políticas públicas. Como disponemos de cuando menos una fuente de datos por cada grupo (entrevistas, encuestas), y de varias preguntas por extraer de cada indicador, podemos también comprobar los resultados buscando consistencias. 


\begin{tabular}{|c|c|c|c|c|c|c|c|}
\hline \multirow{3}{*}{ 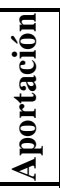 } & \multicolumn{7}{|c|}{ Cuadro 3: Plan de M\&E con indicadores } \\
\hline & \multicolumn{2}{|c|}{ Proceso Movil.com } & \multicolumn{5}{|c|}{ Resultados previstos para el final del proyecto (agosto 2011) } \\
\hline & Actividades & Indicadores & \multicolumn{2}{|r|}{ Indicadores $\mathbf{M \& E}$} & \multicolumn{3}{|c|}{$\begin{array}{c}\text { Porcentaje de aumento por } \\
\text { grupo clave }\end{array}$} \\
\hline \multirow{24}{*}{ 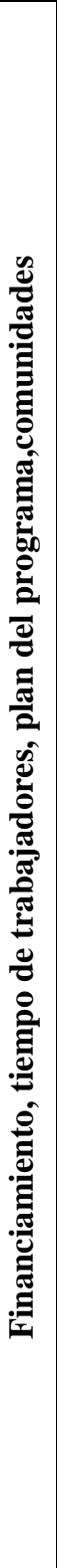 } & \multirow{5}{*}{$\begin{array}{l}\text { 1.Reclutar } \\
\text { líderes (10) }\end{array}$} & \multirow{3}{*}{$\begin{array}{l}\text { \# de líderes } \\
\text { participando } \\
\text { en los } \\
\text { seminarios }\end{array}$} & \multirow{3}{*}{ 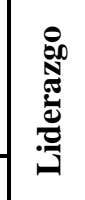 } & Aumento en conocimiento, aptitudes y habilidades sobre liderazgo & Líder & Aliados & Jóvenes \\
\hline & & & & Aumento en habilidades de liderazgo, incluyendo gestión de campañas con aliados & $50 \%$ & NA & NA \\
\hline & & & & Aumento en habilidades de liderazgo, realización de actividades grupales y gestión de campañas con aliados & NA & $50 \%$ & NA \\
\hline & & \multirow{3}{*}{$\begin{array}{c}\text { \# de aliad@s } \\
\text { con planes de } \\
\text { actividad por } \\
\text { líder }\end{array}$} & \multirow{5}{*}{$\mid \begin{array}{ll}0 \\
0 \\
0\end{array}$} & Aumento en conocimiento, aptitudes y habilidades sobre Equidad de Género (EG) & Líder & Aliados & Jóvenes \\
\hline & & & & Aumento en conocimiento de EG y raíces de desigualdad de acuerdo con el currículo de Movil.com & $50 \%$ & $30 \%$ & $30 \%$ \\
\hline & \multirow{4}{*}{$\begin{array}{l}\text { 2.Reclutar } \\
\text { aliad@s } \\
\text { (5 por líder) }\end{array}$} & & & Aumento en actitudes a favor de EG entre jóvenes y adultos & $50 \%$ & $30 \%$ & $10 \%$ \\
\hline & & \multirow{3}{*}{$\begin{array}{l}\text { \# de líderes } \\
\text { con } \\
\text { actividades } \\
\text { comunitarias }\end{array}$} & & Aumento en las que saben cómo y dónde denunciar desigualdad de género & $50 \%$ & $30 \%$ & $10 \%$ \\
\hline & & & & Al final del proyecto líderes/aliad@s habrán organizado y realizado una campaña sobre EG & $100 \%$ & $90 \%$ & NA \\
\hline & & & \multirow{6}{*}{ 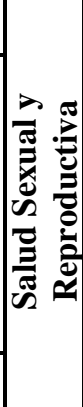 } & Aumento en conocimiento, aptitudes y habilidades sobre Salud Sexual y Reproductiva (SSR) & Líder & Aliados & Jóvenes \\
\hline & \multirow{7}{*}{$\begin{array}{l}\text { 3.Identificar } \\
\text { las personas } \\
\text { claves de las } \\
\text { comunidades } \\
\text { (autoridades) }\end{array}$} & \multirow{4}{*}{$\begin{array}{c}\text { \# de jóvenes } \\
\text { y/o recursos } \\
\text { de de la } \\
\text { comunidad } \\
\text { destinados a } \\
\text { las actividades }\end{array}$} & & Aumento en actitudes a favor de relaciones saludables (sexo protegido y derecho a no tener relaciones) & $50 \%$ & $30 \%$ & NA \\
\hline & & & & Aumento en las que pueden acudir a servicios de SSR & $50 \%$ & $30 \%$ & $30 \%$ \\
\hline & & & & Aumento de líderes/aliad@s que reportan usar métodos para prevenir embarazos, VIH e ITS siempre o casi siempre & $50 \%$ & $30 \%$ & NA \\
\hline & & & & Aumento en actitudes a favor de la promoción de SSR para jóvenes & NA & NA & $10 \%$ \\
\hline & & \multirow{3}{*}{$\begin{array}{l}\text { \# actividades } \\
\text { comunitarias } \\
\text { realizadas por } \\
\text { las líderes }\end{array}$} & & Al final del proyecto líderes/aliad@s habrán organizado y realizado una campaña sobre SSR & $100 \%$ & $90 \%$ & NA \\
\hline & & & \multirow{5}{*}{ 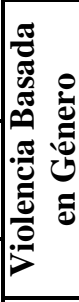 } & Aumento en conocimiento, aptitudes y habilidades sobre Violencia Basada en Género (VBG) & Líder & Aliados & Jóvenes \\
\hline & & & & Aumento en conocimiento de VBG y raíces del problema de acuerdo con el currículo de Movil.com & $50 \%$ & $30 \%$ & $30 \%$ \\
\hline & \multirow{4}{*}{$\begin{array}{l}\text { 4.Llevar a } \\
\text { cabo los } \\
\text { seminarios }\end{array}$} & \multirow{2}{*}{$\begin{array}{l}\text { \# de aliad@s } \\
\text { participando }\end{array}$} & & Aumento en las que saben dónde y cómo denunciar casos de VBG & $50 \%$ & $30 \%$ & $20 \%$ \\
\hline & & & & Aumento en actitudes a favor de prevenir y denunciar VBG & $50 \%$ & $30 \%$ & $10 \%$ \\
\hline & & \multirow{4}{*}{$\begin{array}{c}\text { \# de jóvenes } \\
\text { de la } \\
\text { comunidad } \\
\text { asistiendo a } \\
\text { actividades }\end{array}$} & & Al final del proyecto líderes/aliad@ habrán organizado y realizado una campaña sobre VBG & $100 \%$ & $90 \%$ & NA \\
\hline & & & \multirow{5}{*}{$\stackrel{\frac{a}{0}}{\stackrel{\mathscr{n}}{2}}$} & $\begin{array}{l}\text { Aumento en conocimiento, actitudes y habilidades sobre Derechos Humanos (DH) } \\
\text { Derechos Sexuales y Reproductivos (DSR) }\end{array}$ & Líder & Aliados & Jóvenes \\
\hline & \multirow{4}{*}{$\begin{array}{c}\text { 5.Capacitar a } \\
\text { líderes y } \\
\text { aliad@s en } \\
\text { gestión de } \\
\text { proyectos } \\
\text { comunitarios }\end{array}$} & & & Aumento en conocimiento de DH y DSR de acuerdo con el currículo de Móvil.com & $50 \%$ & $30 \%$ & $30 \%$ \\
\hline & & & & Aumento en las que saben como y donde se puede denunciar casos de violación de DH/DSR & $50 \%$ & $20 \%$ & $20 \%$ \\
\hline & & \multirow{2}{*}{$\begin{array}{l}\text { \# de eventos } \\
\text { conducidos } \\
\text { por los } \\
\text { jóvenes }\end{array}$} & & Aumento en actitudes a favor de la exigencia y protección de DH/DSR & $50 \%$ & $20 \%$ & $10 \%$ \\
\hline & & & & Al final del proyecto líderes/aliad@s habrán organizado y realizado una campaña sobre DH7DSR & $100 \%$ & $90 \%$ & NA \\
\hline
\end{tabular}




\section{Métodos e instrumentos para recolectar datos}

Las encuestas de CAP (ver Anexo A) que administramos a las líderes y sus aliados abarcan los cuatro temas principales de Movil.com (que describimos posteriormente), además de información sociodemográfica, redes sociales (amistades, actividades sociales) y experiencia de liderazgo.

Las entrevistas a profundidad a líderes y los grupos focales (ver Anexo A) complementaron las encuestas estructuradas; se abocaron a los ejes temáticos y a las habilidades de liderazgo, sondearon los cambios en percepciones, actitudes, experiencias y prácticas, revisando logros, retos y lecciones aprendidas. Los instrumentos fueron desarrollados durante la línea base junto con el Grupo apoyándonos en una revisión de la literatura y enriquecidos en la línea final para los tres grupos, para medir el cambio con base en los indicadores (ver Cuadro 3). También incluimos algunos resultados de la línea media (julio 2010) entrevistas en profundidad y encuestas realizadas a las líderes.

Los instrumentos para líderes y aliados incluyen preguntas nuevas sobre crecimiento personal, habilidades adquiridas, experiencias al trabajar en grupo y en la comunidad, el cambio en sus percepciones, actitudes y prácticas, así como las fortalezas y limitaciones de Movil.com. Para las líderes planteamos preguntas específicas sobre las habilidades de liderazgo adquiridas a lo largo de su participación, así como las que faltaron por desarrollar. También se agregaron varias preguntas destinadas a conocer la forma de trabajar con los aliados y de bajar la información adquirida durante los seminarios. El tema de la SSR contempló entender el acceso a servicios de salud, el conocimiento de métodos para prevenir embarazo, VIH e ITS, las actitudes y prácticas relacionadas con el uso de métodos y la toma de decisiones sobre su uso. Las preguntas vinculadas con la equidad de género exploraron los roles de género en su comunidad así como su experiencia en diversos ámbitos (trabajo, hogar, escuela, vida política y religiosa, etc.); también explora las diferencias entre hombres y mujeres en la toma de decisiones y oportunidades dentro de sus comunidades. Las preguntas sobre VBG se refirieron a sus percepciones y actitudes, así como a su experiencia personal como testigos o víctimas de algún tipo de violencia. En términos generales, la sección sobre DSR y derechos humanos se enfoca a conocimientos adquiridos a lo largo de los seminarios y cambios en la percepción. Finalmente, averiguamos sobre identidad cultural y respeto a la diversidad cultural, buscando que en palabras propias desarrollaran una definición del término "interculturalidad".

Por su parte, la guía para entrevistar a las autoridades (ver Anexo A) planteó preguntas sobre los procesos comunitarios de la toma de decisiones, cambios significativos en el sistema de Usos y Costumbres, la aplicación de derechos humanos y las necesidades de jóvenes y mujeres. También indagó acerca de los servicios, recursos y políticas públicas para favorecer la SSR, contrarrestar la desigualdad entre hombres y mujeres, la violencia basada en género y la mortalidad materna. La parte central de la entrevista sondeó el conocimiento, las actitudes y percepciones respecto de Movil.com, así como las posibilidades de que retomaran y dieran continuidad al proyecto.

Para intentar medir el cambio entre los miembros del tercer grupo (jóvenes) generado por las actividades de Movil.com, incluimos dos estudios: la Encuesta de necesidades de SSyR (realizada durante el primer año y registrada en el informe de la línea base) y cuatro ${ }^{2}$ Encuestas Rápidas (ver Anexo A), levantadas durante las campañas.

\footnotetext{
${ }^{2}$ Sólo se levantaron tres encuestas rápidas. La encuesta correspondiente a la tercera campaña no se realizó
} 
Resultados

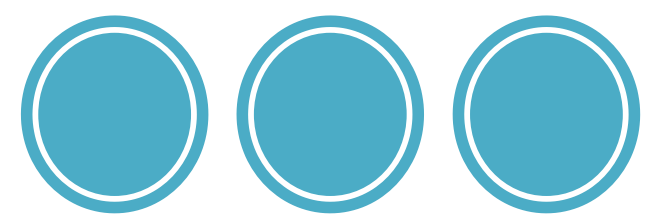




\section{Contexto}

Inicialmente, el Grupo reclutó a 12 líderes de 12 comunidades, en el supuesto de que pudieran concluir el programa por lo menos 10 de ellas. Sin embargo para febrero 2010 el proyecto se había cancelado en tres comunidades (San Antonio Cuajimoloyas, San Miguel Chimalapas y Santo Domingo Tepuxtepec), la primera por problemas de salud y las otras dos no informaron el motivo; había cambiado de líder en Santa María Quiegolani, porque al parecer la primera desertó debido a que su familia pertenecía a un grupo conservador y reaccionario, opuesto a generar cambios en los usos y costumbres de su comunidad y había sumado dos nuevas (Santo Tomás Ocotepec y San Juan Guelavía).

A partir del sexto mes el grupo de líderes se conformó de once integrantes que asistieron regularmente a los seminarios y llevaron a cabo las actividades de diseminación en sus comunidades durante casi un año. Sin embargo, en el primer trimestre de 2011 desertaron líderes de tres comunidades (San Pedro el Alto, San Mateo del Mar y Santa María Quiegolani) la primera para continuar sus estudios en la ciudad de México, la segunda por razones familiares (nunca ofreció explicaciones precisas) y la tercera porque consiguió un empleo en la comunidad como responsable del centro de computo, pero tras del consejo (regaño) de la autoridad comunitaria, después de tres meses de ausencia se reintegró previa aceptación de las representantes del Grupo y de sus compañeras.

Figura 1: Nombre y ubicación de las comunidades participantes en Movil.com

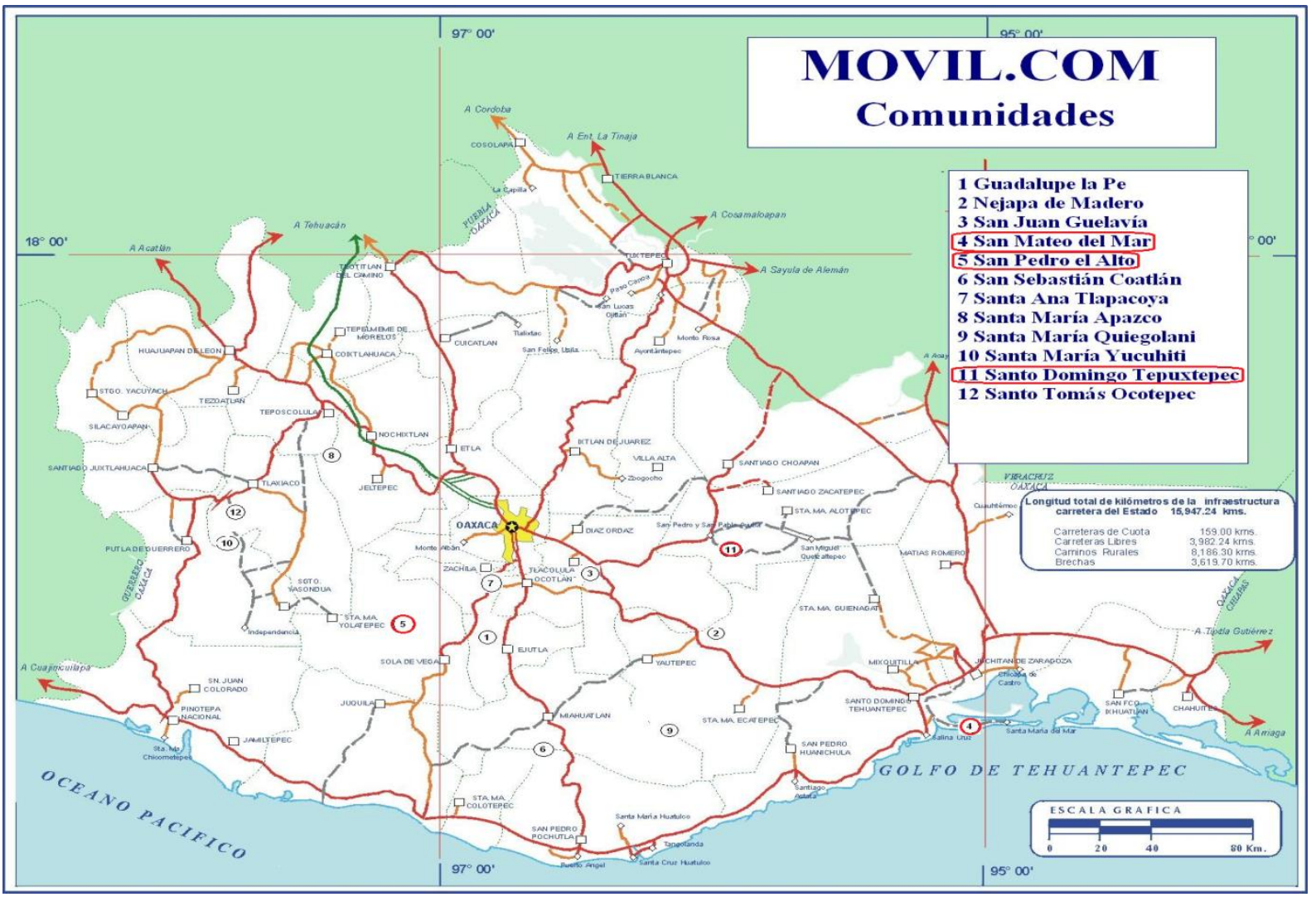

En mayo de 2011, nueve de las 12 líderes iniciales, cerraban actividades comunitarias así como la movilización de jóvenes en cada comunidad y en julio concluían su formación en la ciudad de Oaxaca. 


\section{Descripción y diseño de la recolección de datos}

La recolección de la línea final, al igual que en la línea base estuvo a cargo de la antropóloga Xipatl Contreras, apoyada de la psicóloga Cecilia Castro, investigadora técnica y consultora del Population Council respectivamente. Ambas se establecieron durante dos meses en la ciudad de Oaxaca para facilitar el trabajo de campo en el cual realizaron las entrevistas a profundidad de las líderes y las visitas a las comunidades. Para el análisis de la línea final ofrecemos los datos de las nueve entrevistas con las líderes, de las ocho entrevistas con autoridades comunitarias, de seis grupos focales y de una entrevista con una aliada-becaria.

En coordinación Xipatl y líderes programaron la visita a sus comunidades para encuestar y entrevistar aliados (grupos focales) y entrevistar a autoridades. Las coordinadoras del Grupo por su parte, formalizaron las visitas a través de oficios entregados por las líderes un mes antes de las visitas. Los datos de la línea final se recolectaron entre mayo y junio 2011.

Se recorrieron aproximadamente $3000 \mathrm{~km}$. El levantamiento de la línea final se hizo en una sola visita por comunidad, con excepción de San Juan Guelavía (donde se triplicaron las visitas), siguiendo el diseño de recolección a partir de tres rutas establecidas: Valles Centrales y Coatlanes (Santa Ana Tlapacoyan, Guadalupe la Pe y San Sebastián Coatlán), Sierra Sur (San Juan Guelavía, Nejapa y Quiegolani), Mixteca (Santa María Yucuhiti, Santo Tomás Ocotepec y Santa María Apazco). El diseño del trabajo de campo permitiría optimizar tiempos y recursos, lograr en una visita a cada comunidad la recolección total de datos, iniciar de manera simultánea la transcripción de las entrevistas y el análisis. Todo lo cual nos permitiría cumplir con la entrega puntual del informe final a finales de octubre. Los tiempos y lógicas de la recolección de datos fueron acordados previamente con el Grupo, sin embargo una semana antes de empezar el levantamiento en la zona de la Mixteca, un par de líderes nos avisaron que viajarían a un taller en Chiapas, lo cual entre otras cosas, implicó aplazar un mes la visita a tres comunidades y reprogramar las citas con las respectivas autoridades.

Lo anterior además tuvo implicaciones relevantes en un par de comunidades: en una, posponer la 4ta Campaña desató un conflicto líder/aliada y en otra causó molestia y desconcierto de las autoridades sobre la seriedad de la cita solicitada para la entrevista, quienes recibieron mal el aplazamiento y pese a avisarles el día de la cita que íbamos retrasadas por problemas en el camino, salieron de la comunidad y nos cruzamos en el camino. Una vez en la comunidad nos presentamos con el Síndico, quien ofreció una cita con él y el presidente municipal al día siguiente en la ciudad de Oaxaca, pero ya no respondieron las llamadas y en el mes siguiente pese a insistir ya no se logró concretar una cita.

\footnotetext{
"Bueno, se molestó conmigo porque este... según la fecha la teníamos para el 23 para realizar la actividad, pero como salió eso de irnos a Chiapas, entonces le dije que las cambiábamos para el 21 ique era sábado! me dice: "no”, dice, "porque ¿cómo crees?, si ya tenemos la fecha y todo" y le digo "es cierto" le digo, "pero todavía no tenemos nada, nada seguro, o sea, nada nada seguro, todo nada más planeado pero no estaba... o sea ningún ya compromiso de que alguien si iba a poder en esa fecha”, y entonces pues se molestó (...) Pues ya después al otro día este... pues casi casi como que me arruinó mi actividad porque unos jóvenes me iban a apoyar a presentar un bailable, pero (...) los había como amenazado y diciéndoles que si no iban a ir pues, las faltas que tuvieran ya no iban a asistir al catecismo (...) pues los chavos con el miedo de eso pues mejor fueron al catecismo y ya no presentaron el bailable..."
} 


\section{Líderes}

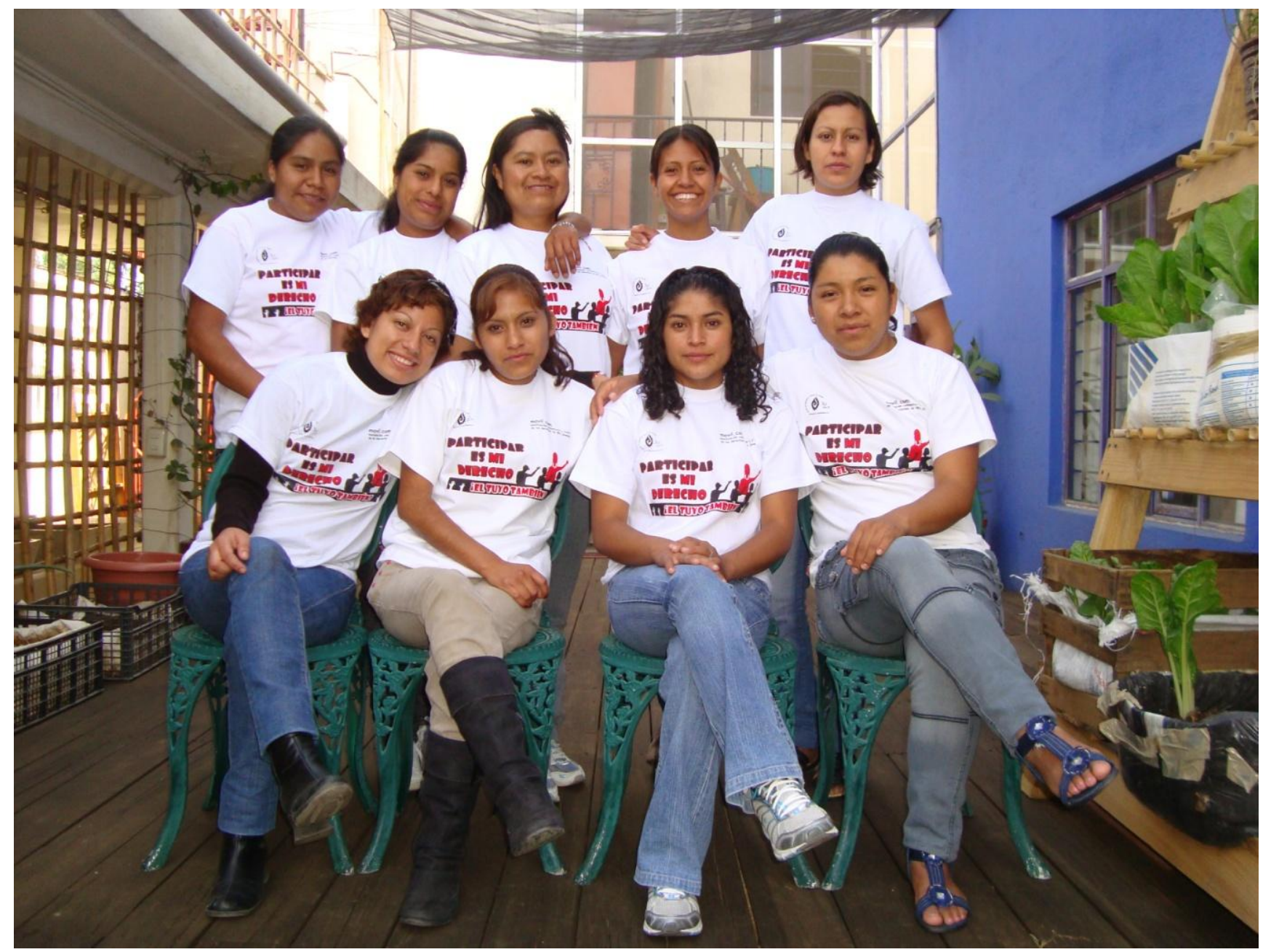




\section{Recolección de datos}

\section{Datos socio-demográficos}

Todas las participantes (ver Cuadro 4) tenían entre 19 y 27 años de edad, eran solteras, dos habían terminado su educación secundaria y siete el bachillerato. Es importante indicar que por lo menos una líder retomó los estudios de preparatoria antes de concluir, dos iban a empezarlos al concluir el programa y dos más pretendían iniciar estudios profesionales. Para lo cual la gran mayoría tenía planeado mudarse a Oaxaca.

"Pues en la pareja no, pero en lo educativo tenía como esa expectativa de estudiar la prepa, por lo menos abierta porque no la he terminado y a partir de enero para acá ya la comencé”

\begin{tabular}{|r|r|l|l|}
\hline \multicolumn{5}{|c|}{ Cuadro 4: Datos socio-demográficos (líderes) } \\
\hline \multicolumn{1}{|c|}{ Líder } & Edad & Escolaridad & Estado Civil \\
\hline $\mathbf{1}$ & 19 & Bachillerato & Soltera \\
\hline $\mathbf{2}$ & 20 & Bachillerato & Soltera \\
\hline $\mathbf{3}$ & 21 & Bachillerato & Soltera \\
\hline $\mathbf{4}$ & 21 & Secundaria & Soltera \\
\hline $\mathbf{5}$ & 22 & Bachillerato & Soltera \\
\hline $\mathbf{6}$ & 23 & Secundaria & Soltera \\
\hline $\mathbf{7}$ & 26 & Bachillerato & Soltera \\
\hline $\mathbf{8}$ & 27 & Bachillerato & Soltera \\
\hline $\mathbf{9}$ & 27 & Bachillerato & Soltera \\
\hline
\end{tabular}

\section{Encuestas y entrevistas a profundidad $(n=9)$}

Durante el seminario 23, las nueve líderes auto-aplicaron las encuestas, lo cual permitió que fuera un ejercicio de autoevaluación, realizado con calma y de forma personal. Además ayudó a agilizar el análisis de los datos recabados.

Las entrevistas a profundidad abordaron los temas principales del proyecto: actitudes y experiencias sobre liderazgo, derechos sexuales y reproductivos, igualdad de género, violencia de género, salud sexual y reproductiva. Además revisaron exhaustivamente la aplicación comunitaria del programa, los logros, retos y dificultades, así como las lecciones aprendidas a lo largo del trabajo realizado con sus aliados, con los jóvenes y el vínculo establecido con la comunidad en general y la autoridad en particular.

El grupo apoyó y facilitó la realización de las encuestas y permitió que las entrevistas a profundidad se realizaran durante el último seminario (24). La gran mayoría de las entrevistas se realizaron en la Casa de la Mujer, las primeras dos tuvieron lugar el día en el que regresaron del taller en Chiapas, cinco durante las tardes, una más el sábado después de concluir actividades y antes de que regresara a su comunidad. La última entrevista se llevó a cabo el domingo en la plaza de su comunidad. Realizar entrevistas de cierre de proyecto después de largas jornadas de trabajo y con una importante carga de tareas vespertinas tuvo un impacto negativo en la calidad de algunas respuestas, ya que las líderes en general mencionaron sentirse exhaustas.

A continuación ofrecemos los hallazgos cuantitativos y cualitativos principales así como algunas citas para ilustrarlos. 


\section{Cambios significativos debidos a su participación en Movil.com}

\section{Impacto personal}

El objetivo de sensibilizarlas y capacitarlas en la organización comunitaria y participación para la promoción de la salud sexual y los derechos reproductivos de la juventud en sus respectivas comunidades tuvo importantes logros (con sus respectivas observaciones), información que dan los datos sistematizados de las entrevistas individuales. Todas mencionan haber obtenido más herramientas, conocimientos y habilidades que las hacen sentir fortalecidas, capaces, informadas, responsables y empoderadas en los temas. En general expresan ser diferentes, contar con más confianza y seguridad en sí mismas para la toma de decisiones, evento que se venía dando desde el año 2010 (línea media).

\footnotetext{
"Sí, porque a veces digo ¿ahora qué vamos a ver? Y como que tenía yo esa curiosidad de saber qué es lo que vamos a ver las veces próximas o que es lo que va a pasar al día siguiente con las compañeras, que hay que hacer, a donde vamos a ir, que cosas vamos a aprender, bueno, eso es lo que me motiva a seguir viniendo, pues, y luego a las licenciadas de la Casa y luego como nos tratan, bueno, eso es lo que me anima a mí a venir"
}

En su percepción respecto a ser mujer y una mujer indígena todas comentan entender su origen y raíces indígenas expresando orgullo y reconocimiento a sus culturas, comentarios que no expresaron de tal manera en el 2010 y 2009. Al respecto cabe aclarar que ha existido reconocimiento del ser

\footnotetext{
“...de hecho esa vez me acuerdo que todas dijeron que no eran mujeres indígenas, cuando nos preguntaron ¿son mujeres indígenas? todas dijimos que no y ya cuando..., de hecho creo que a mí me preguntaron primero que si me sentía yo mujer indígena y les dije que no, porque no hablaba yo la lengua, no vestía yo la ropa típica de mi comunidad y no tenía yo casi los usos y costumbres que manejan en mi comunidad y tampoco mi papás hablaban la lengua materna ni se vestían y todas las cuestiones y las costumbres se habían perdido”, y me decían "¿pero por qué?, ¿por qué no te consideras mujer indígena?, y les digo pues por eso, y ya me empezaron a explicar eso de que no solamente eres mujer indígena si te vistes o hablas la lengua, sino porque perteneces a esa comunidad"

"Fue como que (...) te abrieron tanto los oídos como los ojos, decir “¿sabes qué?, si eres mujer indigena y quizás tú vas a tardar en aceptarlo por lo mismo, de que muchas cosas se perdieron en tu comunidad pero realmente sí eres indígena" y fue como el aceptar"
}

Las nueve líderes que concluyeron el proyecto continuaron por la motivación de aprender nuevos temas y experimentar cosas diferentes. En el año 2010 una de ellas menciona que continuaba en el proyecto por el pago de la beca y ahora menciona que se interesó más por aprender y convivir con el resto de las líderes/amigas, incluso se manifestó deseosa de continuar sus estudios. 
"Y a mí no me gustaba que hablaran eso de mi, por eso siempre no salía yo, me gustaba yo mas estar dentro de mi casa. Y ahora que entré aquí pues ya empecé a... ya, ya cambió mi vida, mi vida cambió totalmente"

Dos de las líderes tuvieron problemas familiares motivo que les hizo pensar en dejar el proyecto, una de ellas se ausentó por casi cuatro meses sin realizar actividad alguna, ambas concluyeron el programa. Otra líder quiso dejar de participar debido a que no lograba integrar a los jóvenes en sus actividades y otras dos por la falta de apoyo de las autoridades a lo largo del programa.

\section{"Porque...por lo mismo, como le decía, de los jóvenes (que no participaban), me desanimé, por eso en un momento decidí ya no volver a regresar aquí a la organización pero, no sé, algo... me dio, este, por aprender más cosas y convivir con diferentes personas y aprender más de los temas que aquí nos daban, por eso, eso como que me dio como ánimo de volver a regresar a la organización”}

Algunas mencionan haberse sentido desanimadas y en ocasiones poco acompañadas por sus familias, sin embargo no fue motivo para abandonar el programa $(n=2)$.

“... una de mis hermanas se salió de la casa y fue por un pequeño problema mío y de ella y fue como que mis papás, mi mamá, mi papá, mis hermanos, mis hermanas, fue como que más apoyo para ella, (...) y era como decirme, echarme la culpa a mi, y decir “ ¿sabes qué? por tu culpa se fue tu hermana, (...), por lo mismo de que nos peleábamos a cada rato con ella, porque no estaba de acuerdo con los temas que yo trataba, como que muchas veces era el roce de decir (...) sobre todo en cuestión de equidad de género y de derechos sexuales y reproductivos, era como que topaba yo con pared con mi hermana, que no estaba de acuerdo en los temas, que no estaba de acuerdo en nada conmigo, de ahí decidió salirse ..."

\section{Impacto familiar}

Sumado a lo anterior, ahora los cambios que perciben de sí mismas los ven reflejados en sus familias sintiéndose más respetadas. Opinan que se han modificado conductas familiares como el compartir tareas de la casa o del campo entre todos los/as integrantes, además de poder hablar de lo que piensan, sienten y participar en la toma de algunas decisiones $(\mathrm{n}=2)$.

\footnotetext{
"Casi muy poco, yo lo veía muy poco, porque yo siempre tenía que obedecer a mi mamá por lo mismo que decían "pues la mujer nomás a obedecer y el hombre a mandar "y siempre como era eso, si, si, como mi mamá o mi papá lo indiquen, y ahora como que no, yo he sentido que como que ahora cada quien da su punto de vista y es respetable"
}

En lo familiar, excepto una, mencionan que se sienten con más seguridad y confianza de expresar sus ideas, opiniones y sentimientos, principalmente ante sus padres/madres. Se consideran capaces de tomar sus propias decisiones y comentan que la opinión de su familia sigue siendo importante pero no es definitiva para lo que planean hacer a futuro.

\footnotetext{
“Pues... sí, ha cambiado un poco porque pues antes que yo entrara a Móvil, pues este como que(...) no me dejaban salir así sola, no me dejaban tomar
} 
Muchas hablaron del reconocimiento por parte de sus familiares de todos los conocimientos y capacidades adquiridas y si bien no las reconocen abiertamente como líderes si las apoyan y animan a seguir adelante

"...y me decía mi hermana: "es que yo te veo con tanta capacidad, porque antes yo te discriminaba como decía yo, no te creía lo que me decías cuando me hablabas de equidad o me hablabas de derechos sexuales o me hablabas de violencia, yo no te creía y ahora que te veo ocupada, haciendo tantas actividades y sobre todo esa capacidad que tienes de hablar ante la gente y estar segura de los temas que tú manejas, era como decir si te veo capaz”

\section{Sus relaciones personales (reflejo de autoestima)}

En general expresan tener nuevas amistades y haberse relacionado con más gente a partir del proyecto ya que sus amigos/as de infancia o generación en su mayoría han migrado $(n=6)$, consideran no haber hecho nuevas relaciones y mantener las mismas $(n=3)$. Actualmente solo tres comentan tener novio. Este apartado en general refleja mejoría en establecer vínculos afectivo/amistosos, reflejados en que ocho se sienten más capaces en hacer nuevos amigos, siete en expresar su opinión ante padres, maestros y adultos en general, seis en expresar su punto de vista con sus pares y cinco con su pareja. Resalta además una percepción de mejoría en relacionarse con hombres y mujeres jóvenes de su comunidad y los comentarios confirman que se debe a su participación en Movil.com.

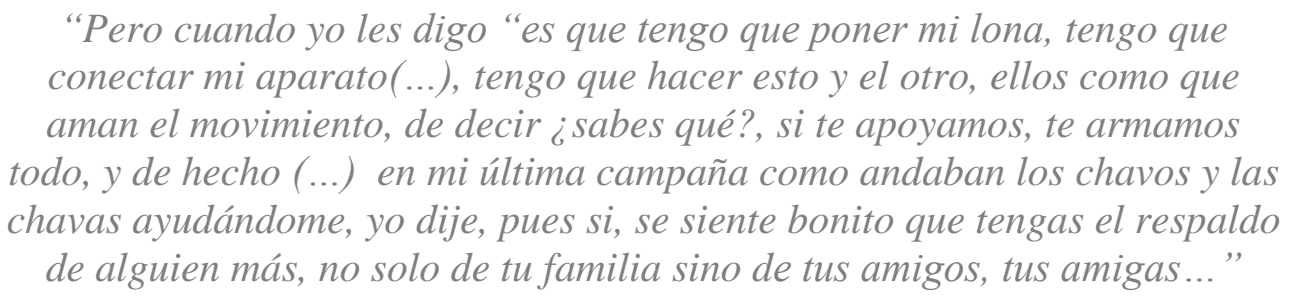

La gran mayoría, ocho, reconocen tener más amigas jóvenes y una igual que antes, mientras siete más amigos jóvenes y dos igual que antes. Las frecuencias no son tan prometedoras para las amistades con adultos ya que cuatro consideran que tienen más amigas adultas y cinco más amigos adultos. Es importante resaltar que una refiere menos amigos hombres y mujeres de los que tenía en el principio, sin embargo no es posible cruzar en todos los casos esta cifra con su participación en el programa.

\footnotetext{
"Pues ya tengo más, este, amigos y amigas que antes por ejemplo para organizar nuestras actividades llegan, aunque no sean nuestros aliados y aliadas llegan y nos ponemos a platicar o hacer cosas diferentes que no sea con el proyecto, pero es como establecer una relación con otras personas"
} 


\title{
Planes para el futuro
}

Algunas expresaron su expectativa de vivir con alguien (casadas o en unión libre) o bien tener hijos en algún momento de su vida $(\mathrm{n}=4)$, sin embargo no es su meta principal, incluso solo dos mencionaron tener novio actualmente y ninguna mencionó planes de boda o vida en común inmediata.

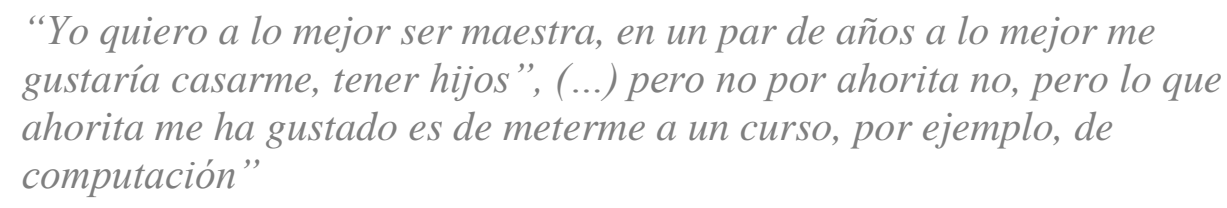

En esta etapa final del proyecto mencionan querer seguir estudiando, terminar el bachillerato o bien iniciar una carrera universitaria $(n=5)$. Siete expresan querer trabajar, salir de su comunidad y ser más independientes aunque las familias no estén en total acuerdo. El resto menciona que quieren seguir adelante, ser alguien en la vida pero aún no definen lo que harán $(\mathrm{n}=2)$.

\begin{abstract}
"Pues sí(...) pues digo que sí porque hemos recibido mucha capacitación y es una forma en la cual, este, he ido fortaleciéndome y, siendo más segura de mi misma, de las cosas que necesito yo hacer, y pues es como que nos dieron más armas para seguir adelante y ver más posibilidades de buscar otros medios para seguir estudiando, para buscar, este... un trabajo, pero ya como que nos fortalecieron más, entonces ya como que tenemos, digamos, ya tenemos la base ..."
\end{abstract}

En relación al proyecto Móvil.com solo dos líderes mencionan su deseo por continuar trabajando en su comunidad o en alguna organización respecto a los temas que aprendieron, puntualizan que necesitan más apoyo para poder lograrlo.

\footnotetext{
"Sí este, una de ellas (metas) es trabajar en todas las comunidades en las que no pude trabajar con jóvenes, hombres y mujeres, y otra es, este, trabajar y seguir estudiando"
}

Las otras pese a que reconocen la necesidad y la importancia de seguir sensibilizando a la comunidad en estos temas desean salir de la comunidad, de hecho tres mencionaron que se establecerán en la ciudad de Oaxaca a partir de julio 2011 y una ya lo hizo. Las cinco argumentan buscar oportunidades laborales y/o becas que les permitan continuar los estudios.

\footnotetext{
"Pues ahorita estoy pensando en seguir estudiando, no podría decir que trabajar y en no, todavía seguir trabajando ah (comunidad), pero ya después de que, bueno, si dios quiere, en este año pueda yo empezar a estudiar, que termine la carrera o que termine de estudiar, que vea la forma de cómo apoyar a mi comunidad, seguir trabajando con la comunidad, pero ya sería después, pero si, este... si no se pudiera, si yo no pudiera estudiar, yo intentaría regresar a la comunidad y ver en qué forma podría dar los talleres y seguir trabajando con los y las jóvenes"
} 


\title{
Relación con "El Grupo"
}

En general todas mencionan haber tenido una relación de comunicación y confianza con el equipo de del Grupo. La mitad comenta que fueron apoyadas con llamadas telefónicas a las autoridades y en la elaboración de oficios para algunas gestiones $(n=5)$, dos líderes dijeron que les hubiera gustado más presencia por parte de las coordinadoras de "Grupo" en el desarrollo del proyecto, evento que también mencionan algunos grupos de aliados en las entrevistas grupales y refuerzan las autoridades que no hablaron en su mayoría de no haber tenido vínculos directos con el Grupo. Por otra parte es importante resaltar que las líderes expresaron haber recibido apoyo y acompañamiento a nivel personal por parte del equipo de Gesmujer, llegando a considerar la Casa como su segunda Casa, un espacio seguro y teniendo la claridad de contar con el Grupo durante y después del programa Movil.com.

$$
\begin{gathered}
\text { “...antes de que yo entrara a Móvil yo ya estaba en la Casa de la Mujer, yo } \\
\text { fui becaria, entonces pues es, yo conozco la institución, (...)aunque siento } \\
\text { que he fallado bastante, les he fallado un poco pero, pero ellas siempre } \\
\text { están ahí apoyándome, animándome (...) entonces ahí están, pues, al } \\
\text { pendiente y pues son como mi segunda familia porque con eso y las conozco } \\
\text { y han sido las que me han dado, me han dado mucha información, digo, } \\
\text { todo me han, este, ayudado a forjar nuevas cosas” }
\end{gathered}
$$

En este sentido es importante resaltar que cuando una de las líderes fue agredida por medio de una pinta en su comunidad, en la cual ventilaba su vida íntima, manifestó un fuerte apoyo por parte de las integrantes del Grupo.

\author{
"Me dijo que, este, le tomara yo fotos y que fuéramos a levantar una \\ demanda que porque era... como que estaban violando uno de mis derechos \\ y ya, este, y la Licenciada pues me dijo que, que lo viniera a borrar (un \\ insulto que pintaron en su comunidad) para empezar para que no estuviera \\ ahí, para que yo tampoco me sintiera mal y de ahí, este, pues que si yo \\ quería proceder (legalmente) con eso pues que adelante pero que sino pues \\ que no (...) Ella todavía me dijo que (...) que si teníamos que venir que \\ venía"
}

Es importante resaltar que una líder menciona que no sabían la agenda de cada seminario, que desconocía por completo lo que se trabajaría en las sesiones siguientes y que cada sesión llegaba a "Casa" sin saber que información recibiría. Todas mencionan haber obtenido información que desconocían por completo, resultándoles un reto el compartir la información para que fuera entendida por la comunidad y los/as jóvenes durante las campañas.

\section{Seminarios en la Casa}

Las temáticas que más llamaron la atención de las líderes fueron Violencia en el Noviazgo, Equidad de Género, Derechos Sexuales y Reproductivos e Interculturalidad, en el mismo orden de prioridad los señalan. Mencionan haberles gustado el trabajo en equipo $(n=3)$ exponer y como les fueron 
expuestos los temas $(n=3)$ y las dinámicas vivenciales así como los diferentes ejercicios en los talleres.

\begin{abstract}
“...quizá era como exponer los temas, los diferentes temas que nos mandaban, porque muchas veces era como que armabas equipos y tenias que exponer de equis tema y muchas veces como era la presión tanto de GESMUJER, por lo mismo de que ellas tienen más conocimientos de los temas y pararte ahí enfrente y como que te estaban poniendo la mirada así, de eso de que a ver si lo podías lograr, era como un reto para nosotras, para mí sobre todo, porque muchas veces si se me hace fácil hablar de cualquier cosa, pero muchas veces de los temas que nos ponían si era como complicado, porque decía yo "¿qué tal si me equivoco y me van a calificar mal? y era como la presión, era como...para mí fue como un logro impartir o exponer los temas tanto a mis compañeras como a las del GES”
\end{abstract}

\title{
Vínculo con autoridades
}

\section{Autoridades comunitarias}

El objetivo de promover la inclusión de la Salud y de los Derechos Sexuales y Reproductivos en los planes de trabajo y presupuestos municipales a fin de asegurar la sostenibilidad y continuidad del proyecto Móvil.com no se cumplió del todo ya que el cambio de autoridades municipales durante el segundo año del proyecto modificó la relación con las líderes. Sin embargo la mayoría $(\mathrm{n}=5)$ logró vincularse y tener una relación más participativa por parte de las autoridades en el segundo año del proyecto.

\footnotetext{
“No, esta a todo dar este presidente (...) me dice “qqué vas hacer?” dice, “cómo te está yendo?” y ya se pone, me hace como preguntas (...) creo que es lo que más le interesa (el tema de igualdad) este porque me dijo, "que se puede hacer para que los chavos participen, hombres y mujeres", dice, "porque no quiero que nada más tengas un grupo de mujeres" dice "también hay jóvenes que son muy inteligentes"
}

Existe un reconocimiento abierto por la autoridad en tres comunidades, destinándoles un espacio seguro cerca de la presidencia municipal exclusivo para el proyecto Movil.com, espacios que se ubican en el kiosco y en cuartos que pertenecen a la presidencia; sin embargo necesitan ser acondicionados y equipados para su funcionamiento.

\footnotetext{
"No, hasta ahorita la autoridad si está muy interesada en el proyecto"

"Pues siento que ha habido un cambio y que me ha favorecido, pero el año pasado pues como que me ponían muchos, este... muchas... no sé, como que... trabas ¿no? de decir "no te vamos a apoyar por esto y lo otro", pero ahorita ya no, ya es diferente (...) Sí, me ha favorecido y pues él me comprende mucho y aunque dicen que no sabe mucho de lo que es equidad y género y todo, pero él ha demostrado su interés"
} 
El cambio continuo de autoridades también implicó altas y bajas en el apoyo al programa en algunas comunidades, pocas hablaron incluso de obstaculizar el proyecto sobre todo por desacuerdo con las temáticas que trataban en las Campañas.

"P: ¿Cuál fue la razón pues que no apoyaba tu trabajo? R: Creo que porque no estaba de acuerdo con lo que hacíamos, con los temas que impartíamos nosotros en lo de Móvil”

"Yo siento que el desinterés de la autoridad actual, porque que yo quizá, quizá nada más yo he visto como el interés en el regidor de educación, que si nos estuvo apoyando en las dos actividades que hicimos con el cabildo nuevo, pero yo veía más el interés de parte de la autoridad pasada, porque

quizá... de hecho, la autoridad pasada nunca me pidió un papel o un requisito para presentar un proyecto o para presentar alguna actividad que teníamos (...)como que no te creían en lo que estabas haciendo"

\section{Autoridades educativas}

Es importante resaltar que en la mayor parte de las comunidades las líderes establecieron vínculos exitosos con los maestros, quienes colaboraron activa y permanentemente a lo largo de los años que duró el programa.

“...de hecho, casi he tenido la, ahora sí, la fortuna de contar con todo en cuestión de las autoridades educativas, porque yo he visto el interés"

No obstante es importante también resaltar que algunas tuvieron problemas importantes en sus comunidades vinculados a malos entendidos sobre el tipo de relación que establecían con los maestros.

\section{Liderazgo}

Respecto a su liderazgo cuatro de ellas aseguran haber logrado más presencia en la comunidad, principalmente entre los/as jóvenes de las Instituciones Educativas (IEBO, Secundaria), quienes las buscan, preguntan sobre el proyecto y en ocasiones piden ayuda para resolver dudas y tareas escolares sobre sexualidad.

“...y como le digo, nunca tuve ningún problema al realizar mis actividades, entonces fue como una fortaleza a seguir adelante y sobre todo porque me siento apoyada por mis aliados y aliadas y por las autoridades educativas, de salud y municipal, entonces es como una motivación"

La mayoría reconoce más la importancia de haber trabajado con un grupo de manera democrática y participativa, escuchando su opinión y fomentando la comunicación y el trabajo en equipo $(n=7)$. Algunas se reconocen como líderes y dos expresaron abiertamente no serlo, ya que "ser líder" tiene un peso moral y de respeto en su comunidad. Sin embargo mencionan, al igual que el resto de las chicas haber dirigido con respeto y consenso de sus grupos de aliados. 


\section{"Es que bueno, este allá en mi comunidad no entienden qué es líder, y yo sí sé que es ser líder, pero, este, en mi comunidad a los que ven que son líderes son a las autoridades municipales, como ellos son los que dirigen, o los que dicen que es lo que tiene uno que hacer en la comunidad"}

En la autoevaluación la información recabada sobre su experiencia en liderazgo, no revela cambios sustanciales con respecto a la línea base ya que exceptuando una líder, todas se sentían capaces, o algo capaces de convencer y motivar a sus pares para llevar a cabo una tarea. La diferencia importante se observan en que ocho se sienten más capaces en planear y gestionar actividades con los aliados, convocar a un evento y persuadir a jóvenes, mientras que en la línea base solo 4/12 dijeron poseer las habilidades para ello.

\section{"Pues yo creo que si, porque al principio pues no sabía yo así como no me sentía así capaz de dirigir a un grupo de personas, pero con el transcurso del proyecto y todo, pues ya aprendí más como dirigir a un grupo de personas y como expresarme enfrente de ellos"}

En cuanto a escribir informes y levantar encuestas siete se sienten más capaces y dos igual que antes. Para persuadir adultos y hacer entrevistas con miembros de la comunidad seis se sienten más capaces y tres igual que antes. En cuanto a presentaciones en público, la diferencia es contundente ya que en la línea base cerca de la mitad nos dijeron haberlo hecho, mientras en la línea final todas habían realizado diversas presentaciones públicas: en los seminarios, las actividades dirigidas a jóvenes, las campañas comunitarias y ante autoridades políticas, educativas y de salud en sus comunidades.

\section{Habilidades de liderazgo a desarrollar}

\section{Cuadro 5: Habilidades de liderazgo a} desarrollar $n=9$

\begin{tabular}{|l|r|r|}
\hline Habilidades: & \multicolumn{1}{|l|}{ Si } & \multicolumn{1}{l|}{ No } \\
\hline Gestión de actividades con aliados & 5 & 4 \\
\hline Planeación de actividades con aliados & 6 & 3 \\
\hline Escribir informes & 7 & 2 \\
\hline Persuadir jóvenes & 8 & 1 \\
\hline Persuadir adultos & 8 & 1 \\
\hline Levantar una encuesta & 7 & 2 \\
\hline Hacer entrevistas en la comunidad & 7 & 2 \\
\hline
\end{tabular}

La mayoría, ocho, coincide en que necesitan desarrollar la habilidad de persuadir a jóvenes y adultos, por otra parte siete consideran que hay que mejorar las habilidades de escribir informes, levantar encuestas y entrevistar a miembros de la comunidad. Seis opinan que hay que desarrollar la habilidad de planeación de actividades y cinco lo consideran necesario en la gestión de actividades con aliados. (ver Cuadro 5)

\section{Las líderes y sus aliados}

En cuanto a la meta de conformar un grupo de aliados y mantenerlo hasta el final del proyecto fue difícil cumplirla para todas. En el último año siete de las líderes cuentan con la participación de sus aliados aunque el número fue disminuyendo con el avance del proyecto. Una terminó el proyecto con el grupos más grande conformado por cuatro aliados, dos concluyeron con tres aliadas, tres con dos y dos con una becaria del fondo de becas "Guadalupe Musalem”. Solo una de las líderes, como se menciona anteriormente terminó trabajando sola ya que los aliados dejaron de participar después de la primera campaña. 
“...nunca tuve aliados, no, nomás estuve trabajando con una chava que es becaria”

En comparativo con la línea base el número de aliados referidos difiere del reportado en la encuesta CAP de agosto 200972 en vez de 62, además, el total de aliados disminuyó el $46 \%$ en el caso de los varones y el $60 \%$ en el de las mujeres. Los motivos de la deserción pueden clasificarse en cinco según los comentarios de las líderes. Tres consideran que los estudios los limitaban para seguir colaborando, una el trabajo, otra la migración, dos mencionaron la falta de interés y una de ellas agregó la negativa de los padres para que sus hijas continuaran debido a que pasaban mucho tiempo fuera de casa y regresaban muy tarde.

“Mm... pues sí, un poco de problema en ellas porque, bueno, al principio cuando iniciamos, eh y cuando empezamos a preparar la primera campaña nos reuníamos pero salíamos muy noche, y ya de ahi de... como son menores de edad ya pues sus papás les llamaban la atención, que ya no las iban a dejar salir"

Algunas mencionaron la negativa de los padres como razón por la cual se desintegró su grupo de aliados.

\footnotetext{
"Pues no sé, a lo mejor porque... pues le digo, a la primera actividad que tuvimos y todo pues sí, bien todo, pero pues ya después yo digo que por una parte no, no les gustó el proyecto porque teníamos que hacer diferentes actividades y que este (...) bueno, por lo menos a lo mejor veían que como íbamos a gastar esto y lo otro pensaban que iba yo a pedirles también a ellos que me apoyaran, yo pienso que a lo mejor también por el recurso económico pensaron que pues no"
}

Es importante mencionar que hubo la modalidad de "colaboradores" de campaña (amigos y/o familiares) que se integraban exclusivamente para ayudarles en la realización de las campañas. Todas mencionan haber trabajado con sus aliados de manera solidaria, en equipo, con respeto y comunicación, se sintieron acompañadas y apoyadas durante el proceso.

$$
\begin{aligned}
& \text { “... yo desde ese momento los entendí a los chavos y a las chavas que } \\
& \text { empezaron a salirse, por lo mismo de que muchas veces iban, muchas veces } \\
& \text { no iban por lo mismo de las tareas, todo lo escolar, y de hecho, ahora así } \\
& \text { aliados y aliadas así no tengo, pero si tengo un grupo de chavos y chavas } \\
& \text { que me apoyan en todo, inclusive para lo que les comenté, que iban a } \\
& \text { hacerles las entrevistas, ellos están de acuerdo, ellas también me dijeron } \\
& \text { que si, que no había problema, por lo mismo de que al cien por ciento } \\
& \text { quizás no han estado, pero si en la mayoría del tiempo que pueden, hacen lo } \\
& \text { posible pues sí, me han apoyado en las actividades" }
\end{aligned}
$$

Pese a todo lo anterior las líderes en general consideran que lograron transmitir la información y los mensajes claves del programa a sus grupos de aliados. Considerando las respuestas de los aliados podemos indicar que esto efectivamente sucedió en los temas de equidad de género y violencia en el noviazgo 
Sin embargo, las respuestas que dieron los aliados en las encuestas demuestran vacíos de información y confusión en los temas principales. Además las respuestas de las líderes no demuestran una sistematización y metodología precisas para capacitar a su grupo y en ocasiones reflejan que no lograron socializar los conocimientos teóricos necesarios. (ver Cuadro 6)

Cinco explicaron, siempre o casi siempre, a sus aliados lo que el programa esperaba de ellos y en igual número consideran que éstos cumplieron siempre sus expectativas. También cinco mencionan que solo a veces distribuían las tareas y dos nunca, lo cual se ve reflejado en que seis mencionaron que decidían en conjunto (líderes-aliados) las actividades para la campaña, distribuían tareas, se motivaban para realizar actividades y la hacían sentirse apoyada y respaldada.

“...lo mismo estaba yo diciendo, porque ella (una de las líderes) dice que cuando dice algo es porque más o menos se va a hacer y le digo, "pero a mí

es que me gusta es que todos participen, no sé, me gustan los puntos de

opinión de las personas" y es lo que me estaban diciendo las chamacas, quizás tal vez por lo mismo, que les daba mucha libertad de opinar, de decir

estoy de acuerdo, esto no estoy de acuerdo, era como que dejar al grupo libre y que cada quien hiciera su santa voluntad"

\begin{tabular}{|c|c|c|c|c|}
\hline \multicolumn{5}{|l|}{ Cuadro 6: Capacitación y desempeño del grupo de aliados } \\
\hline Preguntas para la líder sobre el desempeño de sus aliados: & \begin{tabular}{|l|} 
Siempre \\
Casi siempre
\end{tabular} & A veces & Nunca & NC \\
\hline ¿Les explicabas a los aliados lo que Movil.com esperaba de ellos? & 5 & 2 & & 2 \\
\hline ¿Distribuías las tareas & & 5 & 2 & 2 \\
\hline ¿Los capacitabas en los temas de cada seminario? & 2 & 5 & & 2 \\
\hline ¿Los aliados cumplían tus expectativas? & 5 & 2 & & 2 \\
\hline ¿Les comunicabas el trabajo a realizar en Movil.com? & 5 & 2 & & 2 \\
\hline ¿Los aliados asistían a las reuniones? & 4 & 2 & 1 & 2 \\
\hline ¿Se ponían de acuerdo sobre funciones de equipo? & 4 & 3 & & 2 \\
\hline ¿Planeaban en conjunto actividades para las campañas? & 6 & 1 & & 2 \\
\hline ¿Les Distribuías tareas? & 6 & 1 & & 2 \\
\hline ¿Tomaban decisiones en grupo? & 5 & 2 & & 2 \\
\hline ¿Resolvían malentendidos entre ellos? & 5 & 2 & & 2 \\
\hline ¿Se Motivaban a realizar una actividad? & 6 & 1 & & 2 \\
\hline ¿Reclutaban a jóvenes en lo cotidiano? & 4 & 3 & & 2 \\
\hline ¿Reclutaban y motivaban a jóvenes dentro de las campañas? & 5 & 2 & & 2 \\
\hline ¿Comunicaban mensajes claves de Movil.com? & 4 & 3 & & \\
\hline ¿Representaban a Movil.com en la comunidad? & 2 & 4 & 1 & 2 \\
\hline ¿Te hacían sentirte apoyada y respaldada? & 6 & 1 & & 2 \\
\hline
\end{tabular}

Sin embargo sólo cuatro consideran que siempre o casi siempre asistían a las reuniones, se ponían de acuerdo en las funciones de equipo y comunicaban los mensajes claves del programa y solamente dos consideran que siempre o casi siempre lo representaban ante la comunidad. Es importante resaltar 
que solamente dos refieren haberlos capacitado siempre o casi siempre en los temas de cada seminario.

\author{
"Pues este, a pesar de... bueno, en todas mis actividades que he realizado \\ siempre ellas, siempre ahí están conmigo, siempre me apoyan en todas mis \\ actividades, y este... y más cuando se trata de la escuela ahí están siempre \\ conmigo apoyándome, y es creo que es lo mejor, que me apoyaron en todos \\ los tiempos que estuve, que cuando las necesitaba así para que me \\ ayudaran, ahí estaban conmigo"
}

En cuanto a la diferencia por sexo solo una menciona que los varones hacían tareas diferentes (responsable del equipo de audio, cargar cosas pesadas, etc.) y tres reportaron que los hombres no responden igual a su liderazgo, sin especificar en qué sentido.

El tiempo destinado a trabajar con los aliados fue muy variado y dependió de la disponibilidad de éstos, cabe aclarar que no hubo indicaciones precisas que especificara la forma y los tiempos de trabajo, dos líderes mencionaron que se reunían tres veces al mes, otras dos cuatro veces y tres más cinco veces; un par mencionó además que sólo se reunían para la campaña.

\title{
Espacio Seguro y puntos de reunión
}

Es importante reconocer que las líderes se esforzaron por mantener un espacio seguro que les permitiera reunirse con sus aliadas/os, igual que el año pasado la mitad del grupo se reunía en las canchas, auditorio y el kiosco de la comunidad. Cuatro de ellas mantuvieron un espacio privado cerca de las oficinas municipales llamándoles cuarto y biblioteca. Hubo líderes que nunca tuvieron espacio seguro durante todo el proyecto ocupando las canchas, el parque de la comunidad o sus casas o la de algún aliado $(n=4)$.

Los tiempos de utilización de los espacios seguros variaron entre una vez al mes y tres veces a la semana $(n=3)$. Por lo general las actividades que ahí realizaban, consistían en preparar las actividades para las campañas. Tres mencionaron haber utilizado el espacio para compartir información, ver videos y platicar sobre los temas, es decir, como un espacio de capacitación, cabe resaltar que a algunos grupos se les complicó mantener el espacio activo ya que no se reunían periódicamente. Solo un espacio seguro permaneció a lo largo de todo el programa (a pesar de haber sido subutilizado). Al respecto es importante anotar que éste espacio fue otorgado por la comunidad de la asamblea y probablemente sea a este órgano un mejor interlocutor para dichos fines.

\footnotetext{
"Si ahorita la autoridad, esta autoridad, porque la anterior no. (...) estos fueron los que me dieron mi oficina (...)en la planta baja del municipio (...) y son dos, dos departamentitos (...) solo que hace falta escritorio, compu, o sea, no tengo nada solamente los papeles de aquí, yo tengo ahí una mesa donde tengo las cosas, un material que me han dado aquí y mi lona, pero hasta ahí, también tengo todo para hacer el aseo la cubeta, el trapeador y todo, el recogedor también me lo otorgo la autoridad (...) Las llaves... también baño, en si tiene todo (...) Pues lo he abierto tres veces a la semana, porque eso nos pidieron aquí, pero yo quisiera abrirlo diario, pero si no llegan jóvenes también te aburres al estar ahí, entonces lo que hago es ir abrir un rato y al rato ya cierro y lo abro tres veces a la semana"
} 
Los demás grupos $(\mathrm{n}=5)$ se reunían en lugares públicos (auditorio, centro de la comunidad, canchas deportivas). En general fue muy difícil lograr que las autoridades les proporcionaran un espacio seguro..

“...no de hecho estaba todavía en planes, de hecho fueron a platicar con la
autoridad municipal actual para que me dieran un espacio, pero yo le fui a
insistir y le fui a insistir y nada. De hecho antier se fue a buscar a la
licenciada y luego ella (trabajadora del Grupo) para sensibilizar a la
autoridad municipal que me dieran un espacio, pero como siempre decían
"es que no tenemos, no tenemos" y luego según me dijeron que me iban a
dar el palacio donde estaban anteriormente porque se iban a cambiar a
otro lado(...) hay veces que nos reuníamos en el parque o en la cancha y
más, lo más seguro era en las escuelas... en el receso."

\section{Ejes temáticos}

\section{Equidad e inequidad de género}

Seis líderes opinaron que lograron transmitir el mensaje de que hombres y mujeres valen lo mismo y que debe existir igualdad de oportunidades entre ambos, pudieron hablar y trabajar el tema y lograron que los jóvenes opinaran diferente sobre las desigualdades de género. En sus comunidades fue un tema que despertó interés, "fue el que más sonó". Una de ellas menciona además que el mayor reto fue haber podido hablar el tema en familia, otra haber dejado una herramienta a la comunidad con la pinta del mural y por último otra comenta que tuvo temor a que la violentaran o hicieran algo por hablar del tema ante la comunidad

"Pues al menos en lo personal platicar con mi mamá, porque mi mamá
antes decía, "son mujeres y se tienen que buscar su pareja y se tienen que
hacer su vida" y yo le decía "no mamá, porque todavía podemos hacer
nuestras cosas" y dice "pero si nos morimos ¿quién va a ver por ustedes?",
le digo "pues si se mueren pues ya quedamos solitos, por lo menos
casarnos no" (ahora dice) que es decisión de nosotras (mis hermanas y yo)
pues que ya decidamos que queremos o nos depara”"

Todas lograron identificar desigualdades de género en sus comunidades, dos mencionaron que las mujeres no van a la escuela, no pueden practicar deporte ni tener diversión después de ciertas horas $(n=2)$, no participan en la política y asambleas ejidales para la toma de decisiones $(n=2)$, no son heredadas y tienen más cargas de trabajo en la casa y en el campo $(n=2)$, Una en particular utilizó el término machismo mencionando que aun existe en su comunidad y en la sociedad en general. Esto hace evidente que lograron una amplia comprensión de los conceptos y un cambio de percepción en torno a los usos y costumbres de sus comunidades.

“...si, porque yo antes me acuerdo que tanto en mi familia como en la comunidad yo veía normal lo que es el machismo, y ya en cambio ahora no. En mi casa, por ejemplo, como que he intentado meter eso de la igualdad, ya sea en las labores de la casa, en labores educativas, en cuestión familiar, todo, siempre que veo siempre es en cuestión de igualdad (...) en mi casa más o menos lo he visto, lo he visto el resultado, porque igual siempre 
La mayoría expresó la dificultad que vivieron para lograr que la comunidad entendiera los mensajes y los conceptos, consideran que necesitan aprender más sobre el manejo de la información y cómo bajarla a sus comunidades para que quede claro $(n=4)$

"Que, por ejemplo, buscar una forma de se pueda trabajar más con las
comunidades porque eres tú, es como meter un tema bien difícil y buscar la
manera de que las personas logren, logren entenderlo, porque es difícil
cambiarlo de la noche a la mañana cuando ya traen las creencias de que
como mujeres debemos obedecer lo que los hombres digan"

Dos opinaron que es necesaria más información sobre leyes y derechos, otras materiales didácticos y nuevas técnicas de trabajo $(n=2)$, por último consideraron que no es suficiente el tiempo y la duración de las campañas para abordar el tema por lo que es necesario trabajarlo más ampliamente.

\section{Yo diría en cuestión de leyes, porque hay muchas leyes que lo mencionan, pero muchas veces quizá nomas nosotras vamos con ese fin de decir “'sabes qué? somos iguales y todo”, pero nunca decimos en qué ley o en que articulo lo menciona de que somos iguales, yo siento como que eso me falta. Porque inclusive la otra vez alguien me dijo eso, que en qué ley lo menciona, yo dije, "ups, yo según yo quiero estudiar derecho y yo no sé las leyes”, y fue como el interés de decir “¿sabes qué? voy a estudiar más y más de eso”}

Al igual que en la línea base dos terceras partes, seis, señalaron que en sus hogares, lugares de trabajo y vida cotidiana podía constatarse la inequidad de género (ver Cuadro 7). En el mismo sentido cinco reconocen que no existe igualdad en la vida religiosa ni en la política. A diferencia de la línea base en donde la mayoría consideraba equitativo el trato en la escuela, durante la línea final la mitad (cinco) lo consideraba así. Por lo que hace a sus valores sociales, la totalidad tenía actitudes bastante abiertas similares a las expresadas en la línea base. Todas estaban a favor de que la mujer puede escoger a sus amistades aunque a su esposo o pareja no le gusten y en que mujeres solteras y casadas escojan su plan de vida, diferenciándose un poco de la línea base en donde 2/13 estaban en desacuerdo en que las casadas lo escogieran. Al igual que en la línea base la mayoría estaban a favor de que la mujer o ambos miembros de la pareja tomaran las decisiones sobre la administración del dinero en el hogar, salvo una que se pronunció porque el hombre tuviera mayor poder de decisión al respecto. Ninguna estuvo de acuerdo en que la mujer se responsabilizara exclusivamente del cuidado de los hijos, ni en la obligatoriedad de tener relaciones sexuales.

\section{Cuadro 7: Opiniones de las líderes sobre equidad de género}

\begin{tabular}{|c|c|c|c|}
\hline En tu opinión: & Acuerdo & Igual & Desacuerdo \\
\hline La mujer puede escoger a sus amistades aunque al esposo /pareja no le gusten & 9 & 0 & 0 \\
\hline El hombre debe administrar el dinero de la casa & 1 & 1 & 7 \\
\hline La mujer casada puede escoger su plan de vida & 9 & 0 & 0 \\
\hline La mujer soltera puede escoger su plan de vida & 9 & 0 & 0 \\
\hline La mujer debe responsabilizarse del cuidado de los hijos & 0 & 1 & 8 \\
\hline La mujer debe tener relaciones sexuales con su pareja aunque no quiera & 0 & 1 & 8 \\
\hline La mujer u hombre puede expresar libremente su preferencia sexual & 8 & 1 & 0 \\
\hline
\end{tabular}




\section{Violencia basada en género}

Respecto a la violencia de género reportan que los jóvenes lograron identificarla en el noviazgo, en las campañas y talleres hablaron y explicaron los tipos de violencia $(n=4)$. Comentan que no fue fácil explicar el tema ya que en sus comunidades se piensa que es natural violentar a las mujeres $(n=3)$,



Sumado a lo anterior, está el hecho de que ellas han vivido violencia en sus hogares o bien experimentado algún tipo de relación amorosa que las ha violentado. Es importante resaltar que una de las líderes dice que no pudo hablar sobre el tema ya que ella vive situaciones violentas que no ha logrado romper/superar. Solo una dijo espontáneamente sentirse capaz de exponer el tema después de lo aprendido en Movil.com.

\footnotetext{
“...¿¿los retos? pues quizás que obviamente uno como mujer que por ser hija, por ser hermana, por ser todo, lo vivías (la violencia) en tu casa, quizás no físicamente o en ocasiones si, quizás porque no lo veías que te golpeaban así hasta ponerte morada, simplemente muchas veces te daban un zape, o te hacían algo que tú no querías, pues yo lo veía normal, o que te decían una palabra o un insulto ah, pues era porque no le caes bien a alguien o porque no le obedeciste a alguien y ya cuando empiezas a conocer todo esto, pues ya no lo vez normal, (...) pues si era como un reto decir... ir a impartir un taller o hacer alguna actividad y tú decir "¿sabes qué?, esto es violencia" y cuando la gente te miraba te decía "tú lo estás viviendo y tú no haces nada para que me vienes a hablar a mí”
}

Mencionan los tipos de violencia que identifican en la cotidianidad de sus comunidades como el hostigamiento a las mujeres, verlas con un sentido de propiedad, celarlas y obligarlas a tener relaciones sexuales sin su consentimiento (dentro del matrimonio), también obligarlas a tener los hijos con la creencia religiosa respecto a "tener los hijos que dios les de" $(n=3)$. Comentan que es común la violencia física, los golpes, empujones y actos que agredan por el hecho de no complacer a sus parejas, ser acusadas de infidelidad por comentarios de la comunidad o simplemente por no servirle a los esposos cuando éstos lo solicitan $(n=3)$. Comparten que la violencia de tipo psicológica es frecuente y antes no la detectaban, eventos como los gritos, insultos y chantaje, acompañado de control económico por parte de los padres/madres $(n=3)$. Otro tipo de violencia que identificaron es que las madres son ignora en la toma de decisiones por parte de la pareja en otorgar permisos a hijos e hijas. Todos estos ejemplos visibilizan el manejo de información que ahora tienen las líderes.

\footnotetext{
"Pues yo creo que el tema de violencia es bien complicado trabajar también en las comunidades porque al menos yo siento que las personas como hombres se sienten ofendidos a que nosotras como mujeres este no permitamos que nos sigan este agrediendo, ya sea con golpes, insultos o
} 
En este tema mencionan además, la necesidad de aplicar y difundir la información con la que cuentan, pero aún no identifican las estrategias $(n=3)$. Consideran necesario tener más materiales didácticos que permitan la comprensión del tema y contar con información para referir y canalizar a las mujeres que viven estas situaciones a otras instancias ya que las autoridades de su comunidad no siempre ayudan a la solución del problema $(n=2)$. Tres de ellas no manifiestan ninguna necesidad con respecto al manejo del tema.

\section{"Pues no, no sé, tal vez como algunos juegos didácticos que se puedan, este, trabajar con las diferentes personas, pero también como en una parte trabajar con las personas mayores para que de ahí vayan entendiendo de la problemática que tienen en cuestión de violencia"}

La mayoría de las líderes, siete, cree que la violencia hacia mujeres y niñas en sus comunidades es un problema no muy frecuente, solo una considera que es muy frecuente y otra que no es un problema en lo absoluto. La diferencia más visible con la línea base es que antes igual número de líderes creían que era muy o más o menos frecuente a las que señalaban que no era un problema muy frecuente.

Si bien durante la línea base 8/13 habían sido testigos de violencia basada en género (física o sexual), para la línea final solo tres de nueve lo afirman. La mayoría durante la línea base 11/13 y en la final siete de nueve señalaron que en sus respectivas comunidades no hay servicios para mujeres y niñas víctimas de esta violencia; pero dos líderes mencionaron que una mujer puede acudir al Regidor en turno o al Síndico para denunciar y en caso de que ésta instancia no pueda resolver la denuncia se turna al Ministerio Público.

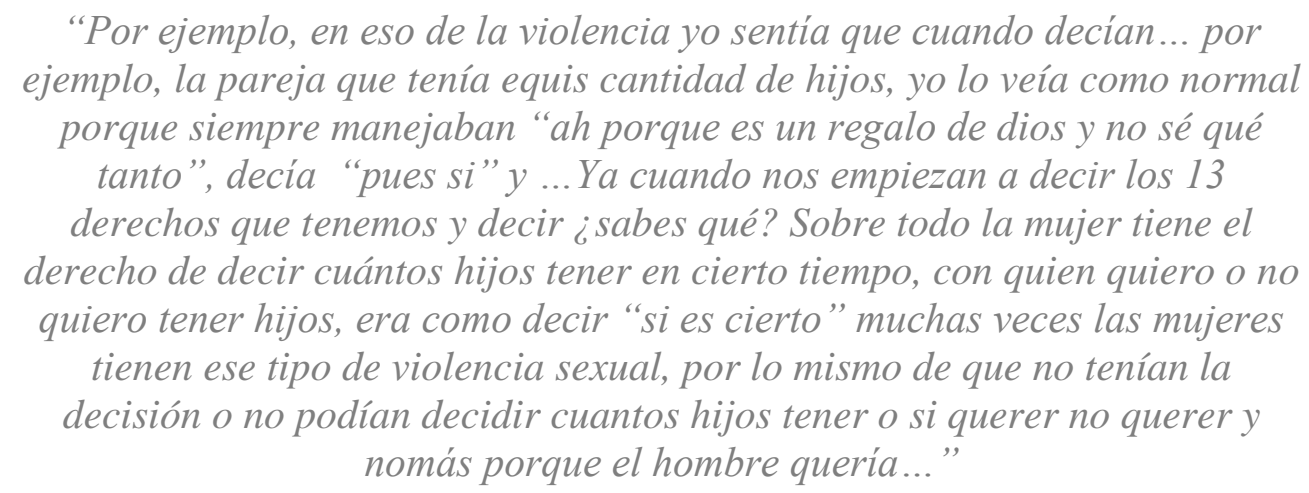

Resulta importante contrastar las respuestas anteriores a las obtenidas de su experiencia personal en violencia basada en género (ver Cuadro 8), ya que a dos el novio y en casa las han hecho sentir menos por ser mujeres y casi a todas en la calle. A una el novio la ha hecho sentir incomoda con chiflidos, palabras y albures y en la calle todas han sufrido éste tipo de violencia. En cuanto a abuso físico una ha sido amenazada y agredida por el novio, dos en casa y en la calle dos han sido amenazadas y una agredida. Una ha sido agredida sexualmente en casa. Ninguna habló de amenaza de abuso sexual pese a que en las entrevistas a profundidad de línea base y final, por lo menos tres lo reconocen abiertamente. Nadie reconoció haber sido forzada a tener relaciones sexuales, sin embargo en la línea base dos chicas mencionaron presión de sus respectivos novios para tener relaciones sexuales. 


\begin{tabular}{|c|c|c|c|c|c|c|c|c|c|}
\hline \multicolumn{10}{|l|}{ Cuadro 8: Experiencia en violencia (líderes) } \\
\hline \multirow[b]{2}{*}{ Alguna vez: } & \multicolumn{3}{|c|}{ Tú Pareja } & \multicolumn{3}{|c|}{ En tú casa } & \multicolumn{3}{|c|}{ En la calle } \\
\hline & Si & No & NC & $\mathbf{S i}$ & No & NC & Si & No & NC \\
\hline ¿Te ha hecho sentir 1 & 2 & 1 & 6 & 2 & 4 & 3 & 8 & 1 & 0 \\
\hline $\begin{array}{l}\text { ¿Te ha hecho sentir incomoda con chiflidos, palabras y } \\
\text { abures? }\end{array}$ & 1 & 0 & 8 & 0 & 2 & 7 & 9 & 0 & \\
\hline ¿Te ha hecho amenazas de abuso físico? & 1 & 2 & 6 & 2 & 3 & 4 & 2 & 5 & 2 \\
\hline ¿Te ha hecho amenazas de abuso sexual? & 0 & 4 & 5 & 0 & 6 & 3 & 0 & 8 & 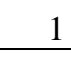 \\
\hline ¿Te ha agredido físicamente? & 1 & 3 & 5 & 2 & 4 & 3 & 1 & 6 & 2 \\
\hline ¿Te ha agredido sexualmente? & 0 & 3 & 6 & 1 & 5 & 3 & 0 & 7 & 2 \\
\hline ¿Has tenido relaciones sexuales aunque no q & 0 & 6 & 3 & 0 & 1 & 8 & 0 & 2 & 7 \\
\hline
\end{tabular}

Las respuestas de la frecuencia en que ocurre la violencia contra niñas y mujeres, en sus comunidades y de ser testigos de la misma, contrastadas a su experiencia personal nos habla claramente de la normalización de la violencia, las líderes después de dos años de formación siguen viviendo una serie de eventos de violencia de género que no identifican como tal, lo cual se ve reflejado claramente en las entrevistas a profundidad.

\begin{abstract}
"...al término del taller ya me vine para mi casa y él (joven) me venía siguiendo atrás y ya me dice "¿podemos platicar?" le digo "sale”, y ya veníamos platicando de ese tema y el chavo fue que entonces como que se abrió a mí, y me dijo "¿sabes qué? es que mi mamá yo siento que sufre de violencia”, "no es que sientas, sufre de violencia, que es distinto”, dice "porque con toda la información que tú me diste, yo cuando me empezaste a hablar de violencia yo sentía un nudo en la garganta, quería yo gritar y

decir "pues ¿sabes qué? yo sufro de violencia, mi mamá la sufre, mi hermanita la sufre”, y yo pues sí, y ya fue como que el chavo... ah, porque el chavo me dijo "no sé cómo le voy a hacer pero yo le voy a decir a mi mamá toda la información que tú me transmitiste”, y cuando... yo eso lo sentía yo normal porque la gente siempre decía "es que se lo busca porque la mujer no le cumple o porque la mujer no hace lo que el señor quiere”, yo sentía como normal eso, veía yo la violencia o que te golpeaba dándote un zape era como muestra de cariño ¿por que tú no lo hiciste?, por eso era como que la gente te golpeaba o que te decía una palabra o algo. Ya cuando llegas acá y que te dicen "es que todo eso, tanto física o sexual o sicológica es violencia”, era como decir "si es cierto" y que yo lo veía normal en mi comunidad"
\end{abstract}

\title{
Sexualidad y Salud sexual y reproductiva (SSR) Opiniones y percepciones sobre el tema
}

Consideran que su percepción ha cambiado en cuanto a la sexualidad pues antes creían que solo tenía que ver con reproducción o tener hijos, ahora pueden hablar de sentimientos, placer, deseos, conocimiento del cuerpo y cambios del mismo $(n=4)$. Dicen de manera clara que cada quien decide cuándo y con quién tener relaciones sexuales, lo asumen como un derecho y sobre todo ahora saben protegerse con un método anticonceptivo $(n=3)$. Dos de ellas no opinaron nada. 
“...pues sí, porque para mí antes la sexualidad era como la reproducción, era como nomas tenias relaciones sexuales para tener hijos o hijas, y en cambio ahora como que entendi de que no es eso, sino que la sexualidad se maneja en cuestión al placer, de los sentimientos, de que tienes el derecho a exigir un método anticonceptivo, de tener o no tener hijos, no solo se trata de "¿sabes qué?, tengo relaciones sexuales para la reproducción en sí”, sino que también es el placer, el goce de la persona"

Lo que las líderes identifican como salud sexual y reproductiva (SSR) tiene que ver con el uso de métodos anticonceptivos y la decisión de tener o no relaciones sexuales $(n=3)$, con las infecciones de transmisión sexual, el embarazo no deseado, embarazo adolescente, la violencia sexual y la muerte materna $(n=4)$. Todos ellos son temas que consideran conocer y que desconocían antes de ingresar al programa, sobre todo el cuidado de sí mismas y la prevención de embarazo e ITS/VIH. El resto $(n=2)$ no respondió y al parecer no tenían claro las especificaciones del tema, es decir hubo confusión entre éste apartado y el referente a DSyR.

“A la salud reproductiva? pues sí, sí tengo bien claro en que yo puedo
decidir en qué momento puedo tener mis hijos y con quien, yo creo que si"

Además, compartieron haber sido criticadas por hablar del tema, la comunidad las juzgó dando por hecho que tenían experiencia y relaciones sexuales, una de ellas tuvo propuestas de tener relaciones sexuales lo cual hizo que modificara su conducta para no estar expuesta. Tres mencionaron que les hizo falta tener más habilidades y herramientas para tratar el tema ya que en algunas ocasiones se vieron expuestas a juicios sobre su vida sexual $(\mathrm{n}=2)$ y una incluso mencionó tener miedo a "ser linchada" por hablar públicamente del tema

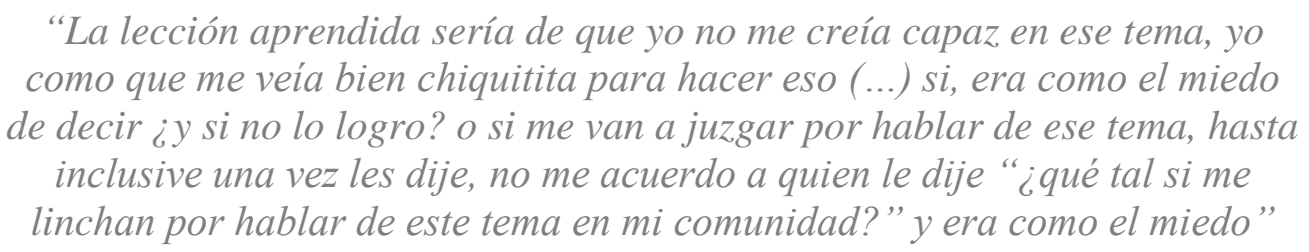

"yo siento como que el reto más de decirle a la gente “ ¿sabes qué?, yo si sé de esos temas, no porque ya los puse en práctica o no porque ya tuve relaciones sexuales, sino porque a mí me han dicho o me han dado información o me han dado la armas para decirles, transmitirles esa información y no necesariamente se necesita ponerlo en práctica para saber de los temas, sino que si tu interés es el conocimiento hacia esos temas"

Es importante resaltar que algunas líderes también coinciden en la importancia de adaptar el lenguaje y los mensajes sobre este tema para que sean comprendidos por la comunidad en general y para evitar juicios negativos sobre ellas.

\footnotetext{
"Pues trabajar el tema de los derechos sexuales y reproductivos, porque para realizar esa campaña nos costó como adaptar el lenguaje a las personas de la comunidad, porque no les podemos hablar en términos de lo que nosotros aprendemos aquí porque a lo mejor se van a ofender y ya ni caso nos iban hacer, entonces (...) Pues por ejemplo que las mujeres teníamos 'ora si que el derecho de experimentar una relación sexual antes
} 


\section{Principales problemas de SSR en sus comunidades}

Las líderes identificaron como problemas principales de SSR la falta de información sobre el uso adecuado de métodos anticonceptivos para prevenir embarazo e infecciones de trasmisión sexual y el embarazo adolescente. No obstante solo 2/9 mencionaron que el embarazo adolescente es muy frecuente. Es importante resaltar que una de las líderes mencionó que en su comunidad persisten los embarazos forzados. La mayoría $(n=5)$ menciona que en sus comunidades es frecuente que las mujeres no planifiquen a los hijos/as, que asuman tener muchos o ser madres solteras, no cuidarse ni protegerse de infecciones de transmisión sexual y tener embarazos no deseados.

“Sobre esos temas ya muchas... en el Centro de Salud ya dan esos temas, y
los jóvenes ya saben en cómo protegerse, que me... ya saben más de los
métodos, saben esto del embarazo a temprana edad pues eso, eso, este... sí
saben la información, sobre la información, pero hay algunas chavas que,
que siguen embarazándose a pesar de que haya información y todavía se
siguen embarazando (...) Porque tal vez, este, no usan algún método o en
algunas veces les da miedo acercarse al Centro de Salud a pedir algún
método”"

\section{Acceso a información y servicios}

A diferencia de la línea base, la mayoría 7/9 reportó no haber recibido educación sexual, las que lo mencionaron refirieron en Movil.com y en la escuela. Es posible que gracias a los conocimientos adquiridos durante los seminarios hayan distinguido que la información hasta entonces recibida no era precisamente educación sexual.

Diferenciando de la línea base, donde dos mencionaron la falta de servicios en su comunidad, en ésta ocasión todas mencionaron que hombres y mujeres acuden a las unidades de salud de sus comunidades para recibir información y servicios de SSR (tenemos que considerar que probablemente al principio no entendían los conceptos y las preguntas referentes al tema). En la línea final fue común la mención sobre el programa CARA de oportunidades como fuente de información permanente pero repetitiva.

\section{“...los temas no, o el CARA, pero lamentablemente dice mi hermano y mi hermanita que siempre van a las pláticas, que es como repetición de los mismos temas todo el año, y ya no... es lo mismo, dice, "porque la información que te dan es lo mismo que te dan diario y siempre dan platicas, pero de lo más aburridas porque solo dan pláticas, y nada más vas forzosamente porque tienes que recibir el apoyo de Oportunidades, sino te descuentan"}

Es preciso resaltar que sólo una mencionó a Movil.com como lugar donde los jóvenes acuden por información, sin embargo varias hicieron hincapié en que la información proporcionada por el programa favoreció en algunos casos la capacidad de los jóvenes de solicitar información y servicios (ejercer sus DSR)

“...había una pregunta (en la encuesta rápida) si tenían como la capacidad de exigir un método o sus derechos sexuales y reproductivos y me decían 
En cuanto a los lugares para obtener los métodos $(n=4)$ mencionaron farmacias y solo una en la tienda. Las nueve coinciden en que los anticonceptivos se pueden obtener con parteras o médicos tradicionales y en Centros o Clínicas de Salud. En el caso de los servicios públicos algunas mencionaron que se proporcionan después de llenar un formato, lo que significa para los jóvenes exponer públicamente su vida sexual. Es importante resaltar que solo una mencionó a Móvil.com como un lugar seguro y confidencial en donde los jóvenes pueden solicitar condones sin exponerse públicamente a pesar de que todas recibieron condones para repartir en sus comunidades.

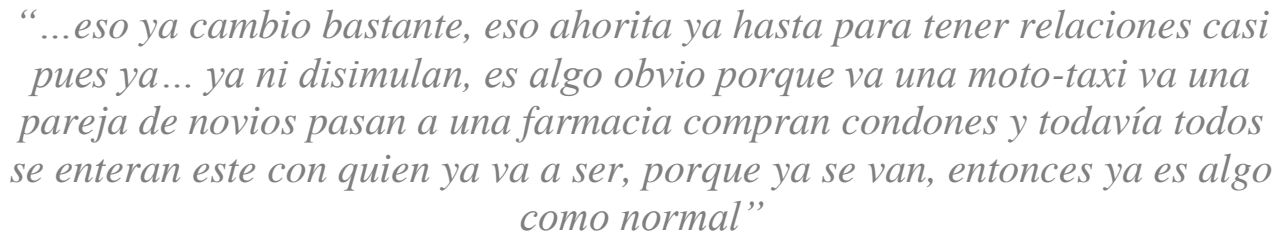

A diferencia de la línea base ocho se reconocen más cómodas buscando información y siete solicitando servicios de SSR. En lo que respecta a ITS/VIH, seis se sienten más cómodas al buscar información y cuatro al solicitarlos. En igual número, tres, se reconocieron más cómodas al buscar información y solicitar pruebas ginecológicas.

\section{Métodos para prevenir embarazo, ITS y VIH}

Cinco consideran necesario saber más sobre infecciones de transmisión sexual, métodos anticonceptivos y sus efectos en el cuerpo ya que la información con la que cuentan no es suficiente y dicen que a los/as jóvenes no les quedo claro ya que en las encuestas hubo respuestas confusas y equivocadas $(n=4)$. Una de ellas tiene la inquietud de conocer más sobre las personas que deciden la abstinencia sexual total, las razones por las que las personas inician su vida sexual y todos los factores que influyen esta decisión. Ella en particular mostró gran interés por continuar trabajando en el proyecto.

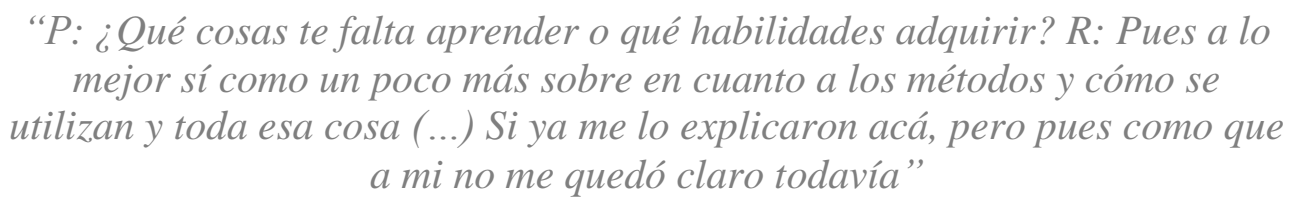

A diferencia de la línea base en la que sólo una se refirió a la abstinencia como método para prevenir embarazos, en la línea final (ver Cuadro 9) ésta opción fue reconocida por ocho como método muy efectivo, siendo que en la línea base habían mencionado los condones masculino y femenino, de los cuales ahora seis los considera muy efectivos y dos más o menos efectivos. Resalta además que una no sabe o no contestó acerca de la efectividad de éstos. En cuanto a los hormonales solo una lo considera muy efectivo, siete más o menos y una nuevamente no contestaron. El DIU tres lo consideran muy efectivo, cuatro más o menos y dos no contestaron. En el caso de PAE la información varió ligeramente con respecto a la línea base, ya que en esa ocasión muy pocas la conocían y ahora poco menos de la mitad, cuatro, la considera muy efectiva, tres más o menos y una no contestó. 


\begin{tabular}{|c|c|c|c|c|c|c|c|c|}
\hline \multicolumn{9}{|c|}{ Cuadro 9: Conocimiento sobre la efectividad de los métodos (líderes) } \\
\hline \multirow{2}{*}{$\begin{array}{l}\text { ¿Cuál es la efectividad de los } \\
\text { siguientes métodos para } \\
\text { prevenir: Embarazo, ITS y VIH? }\end{array}$} & \multicolumn{2}{|c|}{ Muy efectivo } & \multicolumn{2}{|c|}{$\begin{array}{c}\text { Más o menos } \\
\text { efectivo }\end{array}$} & \multicolumn{2}{|c|}{ No efectivo } & \multicolumn{2}{|c|}{ NC/NS } \\
\hline & Embarazo & \begin{tabular}{|l} 
ITS \\
VIH
\end{tabular} & Embarazo & $\begin{array}{l}\text { ITS } \\
\text { VIH }\end{array}$ & Embarazo & \begin{tabular}{|l} 
ITS \\
VIH
\end{tabular} & Embarazo & $\begin{array}{l}\text { ITS } \\
\text { VIH }\end{array}$ \\
\hline No tener relaciones sexuales & 8 & 7 & 1 & 1 & 0 & 1 & 0 & 0 \\
\hline Condón masculino & 6 & 7 & 2 & 1 & 0 & 0 & 1 & 1 \\
\hline Condón femenino & 6 & 7 & 2 & 1 & 0 & 0 & 1 & 1 \\
\hline Hormonales & 1 & 0 & 7 & 0 & 0 & 8 & 1 & 1 \\
\hline DIU & 3 & 0 & 4 & 0 & 0 & 8 & 2 & 1 \\
\hline PAE & 4 & 0 & 3 & 0 & 1 & 7 & 1 & 2 \\
\hline Ritmo & 0 & 0 & 1 & 0 & 6 & 7 & 2 & 2 \\
\hline Coito interrumpido & 0 & 0 & 1 & 0 & 6 & 7 & 2 & 2 \\
\hline No tener más de una pareja a la vez & 0 & 0 & 0 & 0 & 6 & 6 & 3 & 3 \\
\hline $\begin{array}{l}\text { Tomar medicamento después de } \\
\text { tener sexo no protegido }\end{array}$ & 0 & 0 & 1 & 0 & 0 & 6 & 8 & 3 \\
\hline $\begin{array}{l}\text { Bañarse después tener } \\
\text { sexo no protegido }\end{array}$ & 0 & 0 & 0 & 0 & 7 & 6 & 2 & 3 \\
\hline Tomar té o infusión & 0 & 0 & 0 & 0 & 7 & 6 & 2 & 3 \\
\hline $\begin{array}{l}\text { Lavado vaginal con infusión de } \\
\text { hierbas }\end{array}$ & 0 & 0 & 0 & 0 & 7 & 6 & 2 & 3 \\
\hline Otros & 0 & 0 & 0 & 0 & 0 & 0 & 9 & 9 \\
\hline
\end{tabular}

El ritmo y el coito interrumpido fueron considerados por las dos terceras partes, tres, como no efectivos, una como más o menos y dos no contestaron. En el caso de no tener más de una pareja los valores fueron muy similares solo que tres no contestaron en torno a la efectividad. Los métodos que la mayoría, siete, consideraron no efectivos fueron bañarse inmediatamente después de haber tenido sexo no protegido, tomar té o infusión y los lavados vaginales. A diferencia de la línea base en donde una mencionó métodos tradicionales y tés, en ésta ocasión y desde la línea media nadie volvió a mencionarlos (ver Cuadro 9). Por otra parte, casi la mitad, pensaba que los jóvenes con vida sexual activa no suelen usar anticonceptivos, y quienes si los utilizan no muy frecuentemente. A diferencia de la línea base en donde la mayoría (diez) consideraba que no usaban. Los comentarios a estas respuestas describen la persistencia de embarazo adolescente por no uso de preservativos relacionado a: falta de información, negativa de uso por parte de los hombres y dificultad en el acceso.

\section{Inicio de vida sexual}

A diferencia de la línea base, en donde solamente una dijo haberse iniciado sexualmente, para la línea final tres lo reconocen abiertamente, afirman que usan o han usado anticonceptivos, (condón masculino, DIU y PAE o la combinación de los mismos). Dos de ellas afirman que lo usan siempre o casi siempre y una de vez en cuando. Las tres reconocen que las decisiones de tener relaciones y de usar anticonceptivos la toman en pareja, afirman que la primera vez no fue planeada y sólo dos usaron condón masculino. De manera distinta a lo que responden en el párrafo anterior. Solo una se siente más cómoda solicitando servicios de SSR, pruebas ginecológicas y de prevención de ITS/VIH, así como solicitando a su pareja que se realice dichas pruebas mientras dos se sienten más cómodas que antes comprando condones y pastillas. En cuanto a la edad de inicio dos dicen 20 y otra 23 años. En la línea base una de ellas dijo haber tenido su primera relación sexual a los 18 años, en su caso es importante hacer notar que cambió favorablemente la frecuencia de uso de anticonceptivos, de casi nunca a de vez en cuando. 
Las demás, seis, señalaron que no habían tenido relaciones sexuales argumentando varias razones: tres no estaban listas, una por miedo a embarazarse, una por miedo a contagiarse del VIH y la última porque no quiere. Desapareció por completo la respuesta de la línea base de miedo al regaño de los padres.

\section{Valores sobre Salud Sexual y Reproductiva}

\begin{tabular}{|c|c|c|c|c|c|c|c|c|}
\hline \multicolumn{9}{|c|}{ Cuadro 10: Percepción de los valores comunitarios y valores personales en SSR (líderes) } \\
\hline \multirow[b]{2}{*}{ Valores sobre SSR: } & \multicolumn{2}{|c|}{\begin{tabular}{|c|} 
Acuerdo \\
\end{tabular}} & \multicolumn{2}{|c|}{ Igual } & \multicolumn{2}{|c|}{ Desacuerdo } & \multicolumn{2}{|c|}{ NS/NR } \\
\hline & Comunidad & Líder & Comunidad & Líder & Comunidad & Líder & Comunidad & Líder \\
\hline $\begin{array}{l}\text { Los hombres deben } \\
\text { ser vírgenes hasta el } \\
\text { matrimonio }\end{array}$ & 0 & 3 & 2 & 2 & 8 & 5 & 1 & 1 \\
\hline $\begin{array}{l}\text { Las mujeres deben ser } \\
\text { vírgenes hasta el } \\
\text { matrimonio }\end{array}$ & 8 & 2 & 0 & 2 & 3 & 6 & 0 & 1 \\
\hline $\begin{array}{l}\text { Las mujeres solteras } \\
\text { pueden tener hijos }\end{array}$ & 2 & 8 & 1 & 1 & 8 & 1 & 0 & 1 \\
\hline $\begin{array}{l}\text { Las parejas pueden } \\
\text { vivir juntas antes del } \\
\text { matrimonio }\end{array}$ & 2 & 9 & 3 & 1 & 6 & 0 & 0 & 1 \\
\hline $\begin{array}{l}\text { La mujer puede } \\
\text { decidir el número de } \\
\text { hijos y el periodo entre } \\
\text { cada embarazo }\end{array}$ & 3 & 10 & 2 & 0 & 6 & 1 & 0 & 0 \\
\hline $\begin{array}{l}\text { La mujer pueda usar el } \\
\text { método anticonceptivo } \\
\text { que quiera }\end{array}$ & 4 & 11 & 3 & & 4 & & & \\
\hline
\end{tabular}

\section{Percepción sobre los valores comunitarios sobre SSR}

Las respuestas socialmente esperadas (ver Cuadro10), más "conservadoras", tiene que ver por una parte con la virginidad, en donde siete líderes consideran que su comunidad está de acuerdo en que la mujer sea virgen hasta el matrimonio, mientras cinco creen que sus comunidades estan en desacuerdo en que los hombres lo sean. Otra respuesta "conservadora" se refleja en que seis afirman que su comunidad está en desacuerdo en que las mujeres solteras tengan hijos. También encontramos respuestas más "liberales", que podrían estar hablando de mayor apertura comunitaria como que cinco líderes perciben que sus comunidades están de acuerdo en que las parejas vivan juntas antes del matrimonio, en que sólo dos están en desacuerdo en que la mujer elija el método anticonceptiva que quiera y finalmente que se equiparan las comunidades que están de acuerdo en que la mujer decida el número de hijos y el periodo entre cada embarazo a las que están en desacuerdo

\section{Valores personales sobre SSR}

Las respuestas más relevantes y más alejadas de los valores comunitarios (ver Cuadro 10) mencionados anteriormente son que ocho coinciden en que una mujer pueda usar el método anticonceptivo que desee y decida el número de hijos y el periodo entre cada embarazo, valores que no cambiaron significativamente comparándolos a la línea base y al igual que entonces las restantes coinciden en que debería ser una decisión tomada en pareja. Ninguna está de acuerdo en que mujer y hombre lleguen vírgenes al matrimonio, lo cual contrasta con la opinión recabada en la línea base en donde la mayoría (9/13) consideraba que mujeres y hombres deberían llegar vírgenes al matrimonio. Otra respuesta que discrepa es que mientras seis líderes están de acuerdo en que las mujeres solteras tengan hijos, seis consideran que sus comunidades están en desacuerdo en que lo hagan. La 
diferencia con la línea base también es significativa (por el aumento) ya que antes eran (5/13) las que estaban en desacuerdo con que una mujer soltera tuviera hijos. Todas las respuestas fueron argumentadas en sus comentarios desde una perspectiva del derecho. Es importante resaltar la similitud en el acuerdo con sus comunidades sobre el hecho de que las parejas vivan juntas antes de casarse.

En el tema de la virginidad todas coinciden que no es importante y que es decisión de cada una tener o no relaciones antes del matrimonio, cuatro de la líderes reconocieron no ser vírgenes y dos quieren llegar vírgenes al matrimonio.

\section{"Pues que en eso de virginidad yo creo que sería así como que yo tengo el derecho de decidir cuándo tener relaciones sexuales y pues que eso no debe de ser pues tan importante, ya que pues, porque ve que luego dicen que debes de ser virgen hasta el matrimonio y pues yo diría que no"}

\section{Aborto}

En cuanto al aborto, no encontramos diferencias importantes con relación a la línea base en la cual un poco más de la mitad 6/13 dijeron que debe permitirse cuando la mujer lo decida o ante la presencia de ciertas circunstancias, mientras que en la línea final nuevamente la mitad, 5/9 están de acuerdo por malformaciones del feto, por violación y cuando bebé o madre estén en peligro de morir. Si bien en la línea base 7/13 estaban en desacuerdo en ésta ocasión cuatro no se manifestaron en contra pero tampoco a favor, simplemente no respondieron. En cuanto al lugar al que acuden las mujeres a practicarse un aborto mencionaron con doctores o enfermeras privados o servicios públicos para que concluyan un aborto inducido en evolución. Dos aseguran que en su pueblo nunca ha habido un aborto y otra que en el suyo no hay un sitio donde las mujeres puedan solicitarlo. Cinco sabían que el Cytotec es una "pastilla abortiva", solo una mencionó que además se usaba para problemas de la gastritis.

\section{Derechos humanos}

Sus opiniones, en la entrevista a profundidad, fueron limitadas, siete no tenían claridad sobre el tema ${ }^{3}$ y dijeron no tener logro alguno en el manejo del mismo. Solo dos comentan lo importante que es ejercer los derechos humanos. Lo importante a resaltar en éste punto con respecto a la línea base, es que en ese entonces solo expresaron opiniones muy generales y en la línea final algunas dieron explicaciones muy puntuales que reflejan gran interés y una visión crítica sobre lo que acontece en sus comunidades, de hecho hay que resaltar que una de las líderes se encuentra tomando un Diplomado sobre Derechos Humanos en su comunidad, lo cual comenta, le ha dado más herramientas y conocimientos.

Sin embargo en la encuesta encontramos importantes diferencias en relación a la línea base, como el hecho que todas conocían el término "derechos humanos", respondieron que conocían los derechos a la libertad de pensamiento y de religión, a la salud, a la igualdad, a la vida, a la libertad de opinión y expresión de ideas. Todas nombraron además el derecho a decidir cuándo casarse y sobre el número de hijos que desea, en contraste a la línea base en donde sólo una lo había hecho. Además dos mencionaron derechos a participar en las políticas públicas, una el derecho a la educación y otra a vivir libremente su sexualidad.

\footnotetext{
${ }^{3}$ De sus posteriores respuestas podemos suponer que existe la claridad de la existencia de diferentes derechos, sobre todo de los derechos sexuales y reproductivos, pero no el entendimiento global de "los derechos humanos". Por lo que algunas mencionan faltó desarrollar actividades y conocimientos sobre el tema
} 
"Este, sobre... eh, que tenemos muchos derechos pero muchas de las veces que... no podemos ejercerlos o no sabemos cómo ejercerlos (...) derecho a la participación, derecho a la educación, derecho a, este...derecho a... no, no, me acuerdo ¿a la no discriminación? Creo y... entre otras que ya no me acuerdo"

Tres identifican como un acto de desigualdad en su comunidad el que las mujeres no participen en las asambleas para la toma decisiones, que las hermanas mayores estén al cuidado de las menores y que no se respeten los usos y costumbres como parte de las obligaciones al pertenecer a una comunidad. El resto $(n=6)$ no identifica alguna falta a los derechos humanos en sus comunidades. Sin embargo es importante resaltar que algunas líderes expresaron que las mujeres empiezan a participar/opinar públicamente. Y en este sentido cuatro mencionaron que falto información sobre el ejercicio de los derechos y la participación de las mujeres, que sobre el tema no hubo actividades en las campañas y no se sintieron seguras para hablarlo.

\section{"Pues yo veía antes que no había mucha participación de la mujer y ahora yo veo que si participan mas, aunque no dan su opinión muchas mujeres, pero ya participan mas y la opinión sí, ya las mujeres ya están dando opinión y antes yo no lo veía”}

En lo que respecta a la aplicación de los derechos humanos en sus comunidades cuatro consideran que podría causar problemas con los usos y costumbres, básicamente por desconocimiento por parte de las autoridades y padres, así como por la fuerza de la costumbre; contrario a esto tres creen que no causarían problemas y dos no sabían o no contestaron. Al igual que durante la línea base, cuatro se han sentido discriminadas por ser mujeres, indígenas o jóvenes, sin embargo dado que el número de líderes es menor la proporción es más grande.

\section{Derechos sexuales y reproductivos}

La mayoría reconoció tener antes de Movil.com opiniones erróneas en torno a los DSR, emitir juicios de valor sobre las mujeres que "no se cuidaban, es decir las madres solteras, y reconocen en primer instancia el cambio que Movil.com generó en su forma de pensar, de expresarse de los demás y sobre todo de entender la realidad comunitaria desde una perspectiva de derechos y en ese sentido reconocer la violación permanente de los DSR.

\footnotetext{
"Yo lamentablemente era mi cerebro muy incapaz y yo siempre juzgaba a la gente, porque le decía a mi mamá, "porque se lo buscó por eso tuvo un hijo o porque quiso o porque no se cuidó o porque no le exigió al hombre”, era como el juzgar a las chavas, por ejemplo, eran madres solteras, pues es su problema por no aguantarse y en cambio ahora me ha llegado la mentalidad de que debemos de respetar, ahora sí, en cuestión de la sexualidad de las personas, en cuestión de su vida sexual, no tanto de decir “'sabes qué?, hasta el matrimonio”, si alguien quiere llegar hasta el matrimonio virgen, pues adelante, y si no pues también es su derecho si no quiere, si quiere tener relaciones sexuales antes del matrimonio también
} puede" 
Las líderes abordaron el tema en sus comunidades explicando los 13 derechos sexuales y reproductivos, La gran mayoría $(n=8)$ consideran haber transmitido los mensajes, principalmente a la juventud, respecto a expresar libremente sus afectos, decidir cuándo y cuántos hijos tener así como decidir cuándo y con quién tener relaciones sexuales, así como el uso de los métodos anticonceptivos. La líder restante no considera algún logro en el tema.

\footnotetext{
"Yo pensaba que era normal que obviamente que las mujeres querían tener muchos hijos porque no tenían nada que hacer en su casa por eso tenían hijos o hijas y después de ver los 13 derechos que dice pues el acceso a un método anticonceptivo, yo decía, "pues si es un derecho que siempre se ha estado violando en mi comunidad", al igual que todos los derechos por lo mismo de que(...) yo lo viví con una de mis tías, que su mamá murió por cáncer, o sea, un cáncer cervino-uterino creo que se llama, por lo mismo de que su esposo pues no, no la no dejaba ir al doctor a checarse, y yo decía "pues si es un derecho que todas las mujeres tenemos porque es un derecho a la salud"
}

Identifican que en sus comunidades los servicios de salud no ofrecen información a los jóvenes ni acceso al uso de los métodos anticonceptivos si no están casados $(n=3)$, que las mujeres se ven obligadas a tener hijos/as sin planearlos porque no pueden utilizar algún método anticonceptivo sin consentimiento de la pareja $(n=3)$ y que las parejas en el noviazgo no pueden expresar sus afectos y las chicas no pueden tener relaciones sexuales antes del matrimonio $(n=2)$. Una no mencionó nada.
“ahorita en mi pueblo pues sí sabemos que tenemos el derecho de... decidir cuántos hijos queremos tener, y hay, este, los que hacen en Centros de Salud de esos que muchas de las mujeres quieran tener hijos, pero con un hijo que tienen van a la clínica y les ponen un método, pero no les avisan, no les piden permiso, (...) sabemos que tenemos derechos, pero a las personas que van no les dan el derecho de elegir..."

También comentaron sobre la importancia de incluir a los padres/madres, relacionarlos y compartirles la información sobre los temas $(n=2)$. Tres insisten en necesitar más herramientas metodológicas para poder abordar los temas ya que fue complicado transmitir los mensajes porque son temas difíciles de abordar en sus comunidades. El resto no opinó.

\section{Interculturalidad}

Siete opinan que aprendieron sobre diversidad cultural, el respeto a las costumbres, creencias, tradiciones y a reconocer las lenguas maternas de cada cultura. Todas asumen una parte indígena en cuanto a su origen, creencias o simplemente por pertenecer a un pueblo, a diferencia de la línea base en donde pocas se reconocían indígenas.

\footnotetext{
"P: ¿Después de todo este tiempo tú te consideras mujer indígena? E: si, orgullosamente (...) fue como que (el Grupo) te... ahora sí que como que te abrieron tanto los oídos como los ojos, decir “¿sabes qué?, si eres mujer indígena y quizás tú vas a tardar en aceptarlo por lo mismo, de que muchas cosas se perdieron en tu comunidad pero realmente sí eres indígena" y fue como el aceptar"
} 
"Porque estábamos buscando de hecho, que por ejemplo en su comunidad decían "es que yo no soy indígena porque ahi nunca se hablo una lengua materna” y ya fue como volver a retomar ese tema y decir “ ¿sabes qué?”,

dando, buscando información y esto y el otro y al final pues todas

aceptamos que si éramos mujeres indígenas, y hasta el momento todas en

cualquier momento que nos pregunten, cualquier persona, pues si decimos que somos indigenas"

Es interesante mencionar que pese a que en la línea final todas se reconocen indígenas, la mayoría habló de la pérdida de costumbres e identidad indígena, incluso muchas mencionaron que sus familiares y amigos no se identifican como tales

"Entonces ahorita por eso ya no me burlo de los Yopes que decía, ya hasta el contrario hasta los voy a buscar cuando voy a su pueblo y hablan zapoteco si y trato de y ya, ya no los discrimino, no los veo así como diferentes, o sea, ya todos iguales"

“...un día les estaba yo cuestionando a mi mamá, que fueron los de INEGI y una de mis hermanas..., porque cuando a mi me hicieron la encuesta y me dijeron “'te consideras mujer indigena?”, y yo dije si, y cuando le preguntaron a mi hermana ella dijo que no y yo me pelee mucho con mi hermana y le digo, pero porque y ya me empezó a decir esto y el otro, y

luego cuando yo le explique al final me dijo "si es cierto, soy mujer indigena, y fue como aceptar y decir si"

En algunos casos fue evidente que permanece una forma peyorativa de nombrar al indígena (indio/yope) y que al parecer dicha discriminación está fuertemente arraigada a ciertas comunidades.

"Pues así le dicen Yope o indio, le dicen por que pertenece a Salinas una cultura indígena, porque es este... habla, porque habla zapoteco, zapoteco... mixe, creo que es y luego por su forma de vestir que luego es manga larga y se cierran acá como se vestían antes"

"...le presente al chavo (indígena) y el chavo le dio la mano y Pedro no se la dio, no se la dio y me enojé tanto y le deje de hablar, le dije "no te voy hablar, este, por lo que le hiciste a mi amigo y ya, hasta que le pidas perdón a él" le dije "entonces no me voy a ir contigo pues no me importa" dice "si quieres a tu amigo vete con él" dice, "yo darle una mano a uno de esos" dice "que ni me llega" dice "que a ese negro, chaparro" no sé que me dijo, "entonces discriminas el color, la estatura" le digo "si yo estuviera morena, negrita" le digo "de hecho no estoy alta" le digo "me hace falta tener un color más oscuro” digo “ ¿ya no te llevarías conmigo?”,

"ah, pero eres diferente es que no eres de allá" entonces le digo "si viene una de allá, alta, güera, pelo rubio y habla muy bien el inglés", digo "pero es de ese pueblo"

En este sentido y con base a lo aprendido durante los seminarios dos consideran importante promover el rescate de su cultura en sus comunidades, sobre toda en aquellas en donde se está perdiendo la identidad indígena y los conocimientos sobre sus raíces, y cuatro opinan que en sus comunidades se 
están perdiendo las fiestas que promueven la convivencia y resaltan las costumbres, también las lenguas maternas entre los jóvenes, quienes se avergüenzan o lo niegan.

"Yo diría que hay en ocasiones que... pues como que a los jóvenes les da
pena decir que son de una comunidad indígena (...) Pues porque yo creo
que a veces se sienten así, como que se quieren sentir de la ciudad o algo
así y pues si como que..., por ejemplo, si van así a un lugar y le preguntan
de dónde es o... y que le diga "no, pues soy de tal lugar", pero que le digan
¿eres indígena?” pues que digan que no"

Una comenta que se está perdiendo el trabajo y conocimiento de las parteras y las curanderas ya que el sector salud, les niega reconocimiento y critica fuertemente sus prácticas. En el mismo sentido dos líderes mencionan que no deberían de conservarse algunos usos y costumbres, como aquellos que promueven la desigualdad entre hombres y mujeres, ya que limitan el acceso de las mujeres a ser "ciudadanas", ejercer su derecho al voto y participar en la toma de decisiones.

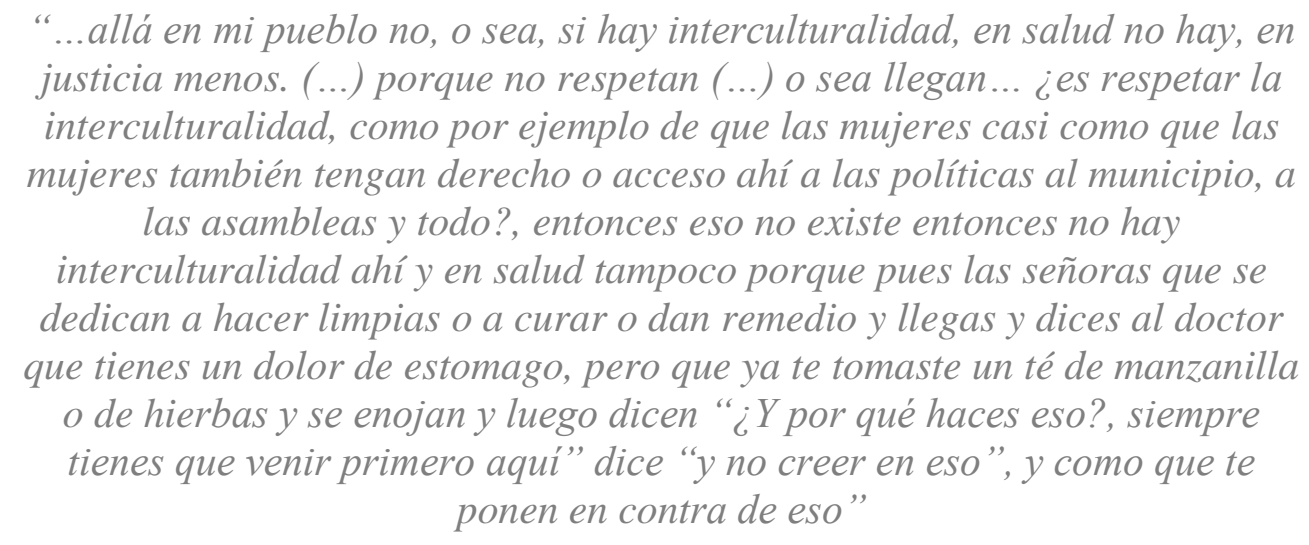
"Entonces ellos (sector salud) no están de acuerdo para nada en esos casos, (prácticas de salud tradicionales) entonces fue difícil yo llegar a decirle al promotor y hacer eso de interculturalidad y todo asi'”.

Cinco de las lideres comparten la dificultad de hablar del tema ya que hay poco interés por parte de los/as jóvenes y de la comunidad en general, que necesitan más información, conocimientos y técnicas para mejorar la forma de comunicar el tema pues creen que es mejor hablar de este tema si se tiene la misma lengua/idioma. Todas coinciden en que hubiera sido necesario realizar una campaña específica, y no solo una mención del tema. En este sentido solo dos mencionaron que lo abordaron a través de bailables y música durante el desarrollo de las otras campañas

“Sí porque...es que no le entendí bien, porque nada más tengo... lo que tengo es lo que significa interculturalidad, eso es lo que nada más tengo en la mente, que es, este... eh, respetar las diferentes culturas. Eso es nada más lo que tengo, pero así en enfocarme así en ... bueno, más bien, este... no, no"

"Entonces lo que quiero es darle a conocer eso a los jóvenes, a los y las, porque si se lo doy a las señoras, a las señoras y no les interesa, digo, es mejor a las y a los jóvenes porque ellos se (...), tendrían el conocimiento y darían a conocer, porque salen se van estudiar o algo así y estarían 


\section{Impacto comunitario del programa}

De manera general todas comentan que las comunidades aceptaron el proyecto y las identificaron por las actividades realizadas. En cinco comunidades los jóvenes las buscan para pedir información y asesoría, ya que las consideran "expertas" en el tema. Algunas incluso hablaron de haber promovido, entre este grupo, el ejercicio de sus derechos sexuales y reproductivo. Las mujeres adultas no se involucraron mucho pero mencionan que hubo comentaros positivos y de apoyo a continuar con los temas y las actividades de las campañas $(n=3)$. Los hombres adultos en realidad no tuvieron mucha participación ni realizaron comentarios respecto a su trabajo, solo una líder comenta que en algún momento les incomodo que se dijera que hombres y mujeres valen lo mismo.

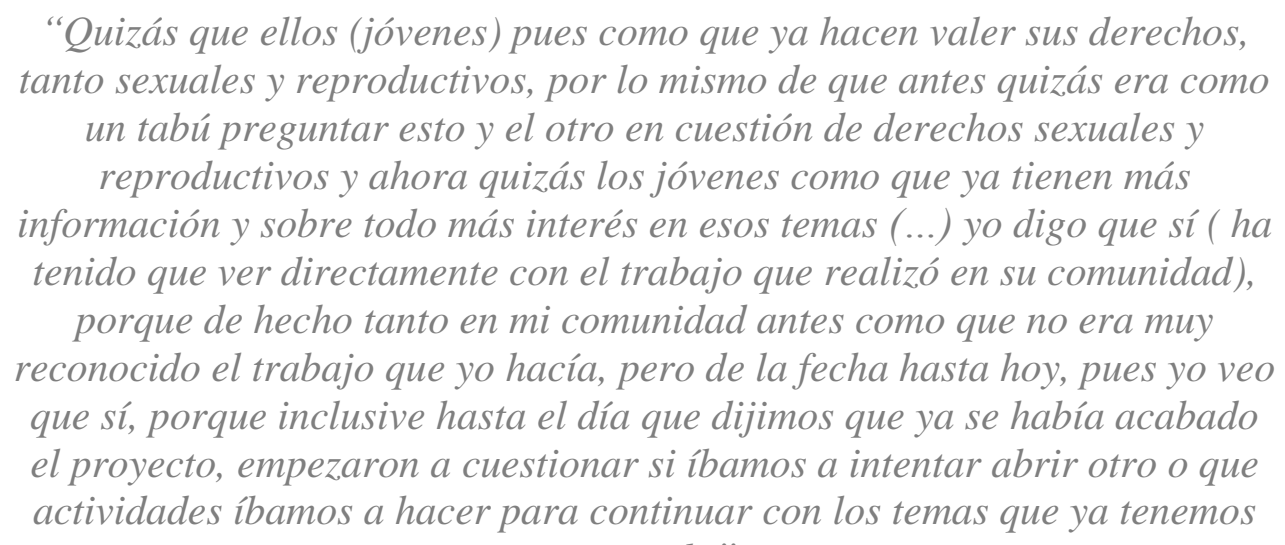
avanzado"

"Pues yo creo diferente, porque antes nos juzgaban de que andábamos perdiendo el tiempo o que si no teníamos que hacer en nuestras casas y ahora ya no" creo que si, por lo mismo de que yo terminando el bachillerato era como encerrarme en mi casa y decir “ ¿sabes qué? los libros ya no son lo mío, en la calle tampoco”, de vez en cuando salía, y ahora por lo mismo de que... yo siento como que ellos me ven ahora si con mas conocimiento, porque hay temas que ellos y ellas lo ven en la escuela y hay cosas que no les quedan claro y hay veces por miedo que no van a la unidad médica a preguntar si no siempre han acudido conmigo, de hecho yo muchas veces les he facilitado información de todos los temas que nos han dado, por lo mismo de que llegan a la casa le preguntan a mis hermanos o a mi hermana si yo tengo esa información y es como... me ven como con más capacidad en los temas que tratamos en el proyecto"

Sin embargo el impacto del proyecto también incidió en la estigmatización de algunas líderes, quienes recibieron juicios y opiniones negativas las cuales tuvieron un peso significativo en sus decisiones y vidas cotidianas, esto lleva a resaltar que tres líderes dijeron haber recibido comentarios negativos respecto a su integridad moral, sobre todo en torno al tema de sexualidad, salud reproductiva y derechos sexuales y reproductivos, pero también al tema de equidad de género. Estos 
eventos las expusieron ante la comunidad de manera violenta. Incluso una de ellas mencionó querer salir de la comunidad por los juicios elaborados hacia su vida sexual.

“...cuando fue lo de la campaña de derechos sexuales y reproductivos (...) escribieron algo por ahi de mi (...) en la pared por ahí, por donde está el mural (...) pues que yo tenía relaciones sexuales con tal persona y cosas así y eso me deprimió mucho y si como que me dieron ganas de decir "no pues aquí, ya no voy”, (...), y ya voy llegando atrás del municipio y voy viendo así y ya me hice la disimulada (...) el lunes me regresé en la tarde para borrarlo, (...) una de mis aliadas ya lo había borrado"

Cabe resaltar que cuatro líderes mencionaron que no hubo un impacto significativo en sus comunidades por diversas causas, entre las que resaltaron falta de apoyo de las autoridades, falta de interés hacia los temas por parte de los temas y falta de jóvenes en las comunidades.

"Porque... bueno, porque como ahi, este... son personas mayores, porque jóvenes muchos ya están fuera de, del pueblo, salen a estudiar fuera del pueblo, y eh... las personas mayores pues unas están, sí, bueno siempre con gentes que están siempre en las casas, y los jóvenes también. Y en mi pueblo nada más salgo a lo que voy y así regreso y siento que en las actividades que he realizado como que no les interesa"

"Unas amigas me dicen, que... que no hago nada, dicen que no se ve el trabajo que no, no se ha visto un cambio, (...) Porque como ven, por ejemplo, voy a dar una plática o proyecto un video y no, no se ve mucha gente, no hay muchos jóvenes. Por ejemplo, ahorita en las encuestas solo

levanté 28 de los que asistieron ahí y pues son muy poquitas, son 28 personas y digo si después de tanto tiempo y que lleguen al final 28, 9 en las campañas como que te desanimas"

En contraparte, el resto $(n=5)$ resaltaron que el impacto positivo en sus comunidades se debió al apoyo de aliados, amigos y familiares, para la realización de campañas, al apoyo de maestros y directores de espacios escolarizados (secundaria y IEBO) así como a la participación de alumnos y padres de familia de los niveles preescolar y primaria. También las líderes concuerdan en la importancia de realizar actividades en las escuelas

"Bueno, primero que nada pues que ahí si tuve bastante apoyo de jóvenes, del presidente municipal, del agente municipal, de los profesores de diferentes instituciones como primaria, secundaria”.

"Y siempre mi meta ha sido juntar 50 jóvenes y cuando veo mis listas y veo que son mas, "no manches, si lo logre”, y quizá, pues si, gracias a la ayuda de mis amigos, de mis amigas o de las personas que me han apoyado era como difundir de todas las actividades, y al final, si yo sentía, primero me iba yo con la meta de decir ¿y si no lo logro?, y ya después, de hecho la maestra me aconsejaba "vamos por 50", yo decía, "50 son muchos", me decía "vamos por 50", yo decía bueno, pues yo que, y cuando veo y regreso y veo mis listas de asistencia y eran más de cien, yo decía "no manches, ¿yo logré esto?", y dice la maestra "pues sí, son tus logros"..." 


\section{Campañas}

\section{"Ni más ni menos hombres y mujeres valemos lo mismo"}

Para algunas de las líderes la realización de la primera campaña resultó un logro personal, mencionan que nunca habían realizado actividad alguna en donde hablaran en público, convocarán gente y fueran responsables de un evento $(n=4)$. Todas lograron la participación y asistencia de los jóvenes, lo cual les permitió cubrir la meta del programa. Cuatro de ellas consideran que fue importante la participación de los maestros por parte de las escuelas ya que se sintieron apoyadas por ellos/as para la realización de las actividades.

La mayoría $(n=6)$ identifica algunos eventos que suponen dificultaron el desarrollo de las campañas, tales como que la autoridad les cobrara el apoyo brindado (reciprocidad) o que no llegara al evento, no hubo suficiente convocatoria para la asistencia de los/as jóvenes, algunas actividades no tuvieron impacto ya que consideran que no fueron entendidas y aceptadas. Las demás opinan que su campaña fue exitosa. Cinco tuvieron retos como movilizar a la gente, trabajar en equipo entre aliados/as, maestros/as y autoridades, pero principalmente dar a conocer el proyecto Movil.com a la comunidad. Pese a esta visión un tanto crítica todas coinciden en que ha sido la más significativa a lo largo del programa y la de mayor impacto. Cabe anotar que esta opinión es compartida por los aliados.

"Como era la primera campaña era como darle a conocer a la gente de que
se trataba, era como el logro de decir "voy a sensibilizar a la gente en este
tema", y no solo eso, sino les voy a dar a entender lo que es mi proyecto, en
qué trabajamos o con quienes trabajamos, era como el reto de decir "si
puedo juntar de perdis 20, 30 personas era como ya algo, que si lo
logramos"

\section{"X ti, por mi me informo y decido"}

Esta campaña para cinco de las líderes no tuvo mucho impacto ya que no reconocen logro alguno. Sin embargo tres afirman haber logrado la participación de las autoridades, los maestros y los jóvenes. El resto menciona que sirvió para avanzar con la participación de las escuelas, ya que se desarrollo al interior de estas, con los alumnos y bajo la aprobación y colaboración de maestros y directores.

\section{“La segunda campaña (...) Mm... no,creo que no tuve ahí logros de (...) \\ Las dificultades que encontré fue... pues que no tuve apoyo del agente municipal, tampoco de los profesores de las instituciones, y... pues no asistió este...personas a mi actividad"}

Los retos para algunas $(n=3)$ tuvieron que ver con una deficiente convocatoria, reflejada en la baja asistencia y poco interés, para otras dos la realización de los juegos didácticos no tuvo ningún impacto porque algunos estaban incompletos y no fueron comprendidos por los jóvenes. Otras dos mencionan que no funcionó porque se llevó a cabo cuando la comunidad tenía otra actividad. Finalmente dos más mencionan que no dar regalos y trabajar con grupos pequeños puede mejorar las condiciones y desarrollo de las actividades.

"Como que no dimos mucha difusión, lo veo yo así. Porque sí hubo este... o tampoco no el interés, también de los jóvenes porque era como concurso de 
cartel y como tenían nada más edad a que edad, y pues algunos si, si saben pintar y todo, pero pues a lo mejor ya, ya no era la edad que pedían ahí”

\begin{abstract}
"Yo siento que eran como los juegos que nos habían puesto, porque nos pusieron varios juegos que muchas veces no le entendimos, y luego había unos juegos que estaban incompletos, que no teníamos todas las tarjetas o todo el material, no estaban completas, y era como la burla de los chavos y las chavas, decian "mmm, no venía bien preparada para su actividad"
\end{abstract}

Seis líderes comentan que no hubo suficiente participación, asistencia e interés por parte de los jóvenes, una líder comenta que no tuvo el suficiente apoyo por parte del equipo de "Casa" para la realización de su campaña, por lo cual no fue tan exitosa. En lo que respecta a esta Campaña solo una dijo no haber tenido complicaciones. Cabe resaltar que la mayoría de las líderes mencionó mayor apoyo por parte de su familia que a partir de esta Campaña.

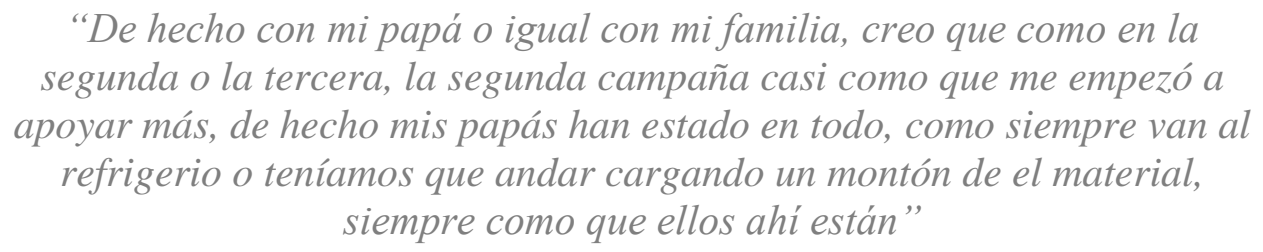

También es imprescindible resaltar que algunas compartieron haber sentido miedo a ser juzgadas. Durante el levantamiento de la línea media, cuando empezaban a trabajar el tema todas se sentían poco preparadas para manejarlo en sus comunidades sobre todo porque estaban conscientes de que dichos temas no se hablaban públicamente en sus comunidades. A raíz de empezar a difundir estos temas en sus comunidades por lo menos cuatro de las líderes sufrieron algún tipo de ofensa.

\title{
"Yo te amo tu me amas, nos respetamos"
}

Esta campaña fue más concurrida que las anteriores, siete de las líderes comentan que hubo asistencia y participación de los jóvenes, apoyo por parte de las escuelas (IEBO, Secundaria) y de las autoridades logrando transmitir el mensaje clave, las dos restantes no menciona logro alguno.

"El mayor logro yo creo que fue (...) la tercera campaña que hicimos. Si,
porque no solo..., de hecho había yo tenido la oportunidad de trabajar con
otra comunidad, otra... aja con otra comunidad cercana, pero esa vez,
cuando hice mi evento deportivo en cuestión del tema, llegaron una, dos,
tres comunidades, y llegaron como alrededor de más 70 jóvenes de las tres
comunidades vecinas, y yo si me sorprendí por lo mismo de que eran dos
maestras que me habían cuestionado de eso, me preguntaban del proyecto y
esto y el otro y era como la seguridad de decir "¿sabes qué? en esto trabajo
y son estos temas los que trabajo" y fue como mi mayor logro al decir "si lo
logré"

Para la mayoría $(\mathrm{n}=5)$ no hubo muchos retos que enfrentar, las otras cuatro dicen que fue complicado convocar a las autoridades, dar por primera vez un taller en secundaria y transmitir el mensaje a los jóvenes. Las dificultades más evidentes para cuatro de ellas fueron los "recursos económicos" así como el poco impacto de algunas actividades, principalmente el periódico mural y el no cumplir la meta de la campaña en relación al número de jóvenes y encuestas aplicadas. El resto (n=4) no 
considera no haber tenido complicaciones. La líder restante no realizó la campaña ya que estuvo fuera del programa por más de cuatro meses.

“...de hecho ese taller me encantó por lo mismo de que interactué más con los chavos y las chavas, era como más personal, de que me decían " ¿sabes qué?, yo tengo ese problema" y esto y el otro, ¿cómo me podrías ayudar tu? ", o te preguntaban de toda la información que tu tenias, en que artículo te basabas o en que te basabas para decir todo eso, y era como el interés de los chavos y las chavas de decir “'sabes qué?, si me interesa el tema”, y

“ ¿sabes qué?, no solo me interesa sino que también en la comunidad se vive eso"

\section{"Participar es mi derecho el tuyo también"}

La última campaña fue el cierre del programa Móvil.com, cinco líderes consideran haber logrado la participación de jóvenes, maestros/as y otras instituciones como la Casa de Cultura y los medios de comunicación. Solo dos mencionan no haber tenido algún logro. De manera similar a la primera campaña esta tenía una connotación especial por ser el cierre de un proceso muy importante para todas ellas.

“...lamentablemente yo siento que no lo logré, porque lo hice en comunidad abierta y era donde que mucha gente que estaba ahí que si había oído del proyecto o había quizá..., o había ido a ver por curiosidad alguna de las actividades, pero de hecho sí, yo lo vi como que la gente, como que cuando vio el video y decía "mmm, ¿a poco esto hizo?", como que la gente no se creía lo que habíamos hecho, y yo en esa actividad no me sentí satisfecha,

pero ya cuando el director y la maestra del IEBO me invitaron a presentarlo en la institución, fue como decir " ¿y ahora si lo logro o no lo logro?" y era como decir "pero es que el video ya lo vieron sus alumnos y sus alumnas, ya no le vana poner interés” (...) y cuando vi, desde el momento que llegué todo mundo estaba poniéndome atención y yo me sentía como nerviosa, como intimidada (...) ese día era como la despedida, de decir "¿saben qué?, el proyecto llegó a su cierre, es la última cosa que voy a hacer con ustedes", y era como tanto la melancolía, la tristeza de decir (...) y de hecho esa vez si me apoyaron todos, los dos maestros y la maestra, estaban ahí atentos al video"

Cada una expresa retos diferentes, algunos sobre hacer por sí mismas la gestión y no confiar de las autoridades, lograr la aplicación de todas las encuestas a los/as participantes, vencer sus temores y atreverse a realizar las actividades. Como se menciona en los logros de esta campaña, cinco líderes no perciben dificultades y el resto menciona detalles como la falta de regalos por parte de la autoridad y la falta de apoyo por parte de sus aliados/as pues dos de ellas realizaron solas la campaña.

"que como era el cierre de mi campaña y el cierre de mi proyecto, igual, este, hice invitaciones, como fue un programa sociocultural, hice invitaciones en la escuela del IEBO y en la escuela secundaria y en la escuela primaria, y ahí me apoyaron (...), con los números, pero no, no se llenó tan bien como yo quería, fueron como 60 personas", 


\section{Pasos a seguir}

Todas reflejaron en sus respuestas las ganas de seguir adelante con el trabajo en estos temas u otros dirigidos a jóvenes, algunas afirman que continuarán con o sin Movil.com, otras le apostaron a que los proyectos que enviaron a alguna institución fueran seleccionados, otras más a prepararse más, concluir estudios de bachillerato o carreras profesionales para poder regresar a sus comunidades a seguir compartiendo lo aprendido. Otras más buscaron trabajo para posteriormente solventar estudios y apoyar a sus familias. Alguna mencionó la posibilidad de replicar su trabajo en otras comunidades bajo el proverbio de en "nadie es profeta en su tierra".

“... a mi si la verdad si me gustaría seguir trabajando con..., no sé si con este proyecto o también con otro proyecto, pero que igual fuera dedicado especialmente a las y los jóvenes, que el caminito que dejamos, ahora sí, el pequeño espacio que dejamos en mi comunidad, que nomas no se quede estancado ahí, sino a mi me gustaría darle continuidad, porque como yo siempre he mencionado una frase "que el poquito camino que he avanzado quiero que un día pues se convierta en igualdad de oportunidades en todos los ámbitos entre hombres y mujeres"

"yo tengo la esperanza de que este proyecto salga seleccionado, por lo mismo, de que yo quiero seguir trabajando con los chavos, con las chavas de mi comunidad, porque yo sí, ahora si afortunadamente si he visto el cambio en mi comunidad, mas en los chavos y en las chavas, y eso quiero, que esa información que yo les impartí no nomas se quede como "ah sí, fue una bonita experiencia" y que después todo mundo se vaya olvidando de eso, sino quiero que siga adelante, que sigan creyendo que si se puede" 

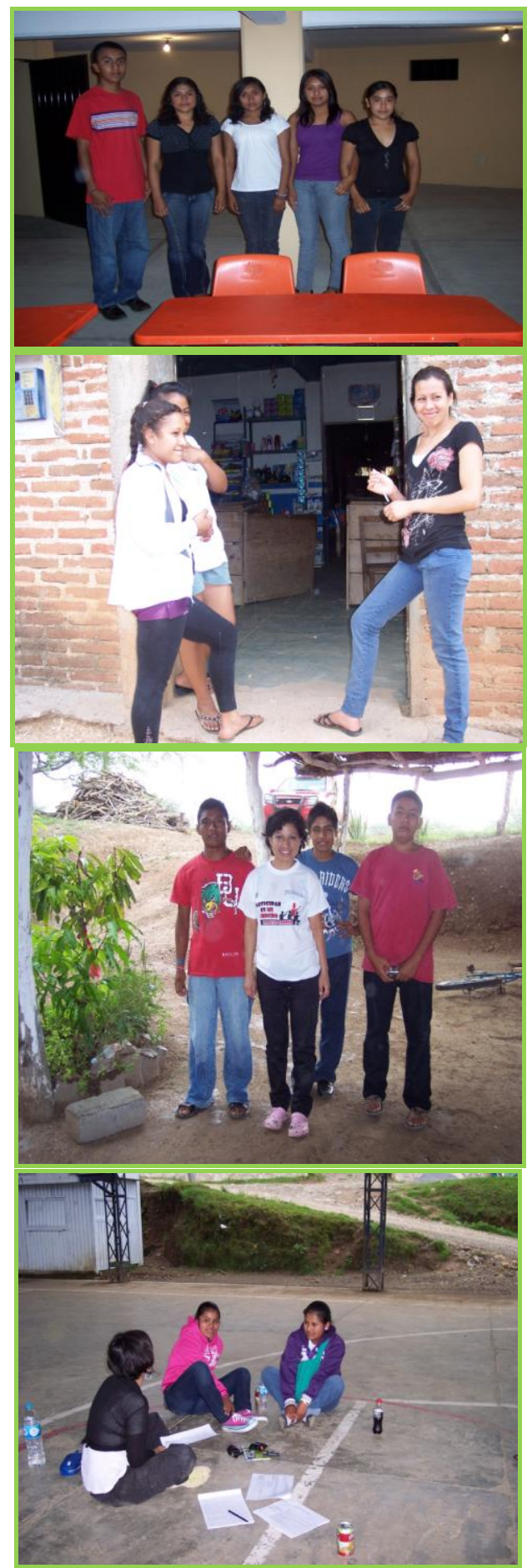


\section{Recolección de datos}

\section{Datos socio-demográficos}

Una vez concluida la última campaña las líderes, convocaron a sus aliados, para que el equipo de trabajo de campo del Population Council pudiera realizar los grupos focales y aplicar una encuesta a cada participante. En el Cuadro 11, hemos resumido las características socio-demográficas de los 17 aliados de siete comunidades distintas.

\section{Cuadro 11: Datos socio-demográficos y} experiencia en liderazgo (aliados)

- Promedio de edad: 15

- $70 \%$ mujeres, $30 \%$ hombres.

- Educación terminada: 7 secundaria, 8 bachillerato, 2 licenciatura.

- 11 han hecho alguna presentación en público.

La encuesta levantada se enfocó en los temas nucleares de Movil.com. Los grupos focales, cuyos resultados ofrecemos a continuación, exploraron su opinión acerca del trabajo realizado, sus expectativas, logros, retos, lecciones aprendidas, cambios en su percepción y conocimientos.

El grupo de aliados se conformó de 15 mujeres y 7 hombres de nueve comunidades (ver Cuadro 12), sin embargo en la etapa final solo se entrevistaron y encuestaron a seis grupos de las comunidades de Santa Ana Tlapacoyan, Guadalupe la Pe, San Sebastián Coatlán, Nejapa de Madero, Santa María Quiegolani, San Felipe Pueblo Viejo Yucuhiti y a una aliada/becaria de Santa María Apazco. No se recabó la información de San Juan Guelavía porque la líder nunca convocó a su grupo de aliados, probable porque estaba trabajando fuera de su comunidad (Ciudad de Oaxaca) aunque seguía viviendo en ella ${ }^{4}$, lo cual implicó una pérdida significativa en el número total de aliados. En lo que respecta a Santo Tomás Ocotepec, no fue posible entrevistar ni encuestar a la aliada-becaria porque estaba en preparativos de clausura de IEBO.

\begin{tabular}{|c|c|c|c|c|}
\hline Cuadro 12: Número o & aliados p & $\operatorname{sexoyc}$ & nunidad & \\
\hline & $1^{\circ} \mathrm{Campa}$ & & $4^{\circ} \mathrm{Campa}$ & \\
\hline Comunidad & Hombres & Mujeres & Hombres & Mujeres \\
\hline Guadalupe la Pe & 0 & 6 & 0 & 2 \\
\hline San Sebastián Coatlán & 2 & 6 & 0 & $2 *$ \\
\hline Santa Ana Tlapacoyan & 0 & 6 & 1 & 3 \\
\hline Santa María Apazco & 0 & 3 & 0 & 1 \\
\hline Santa María Quiegolani & 3 & 3 & 1 & 1 \\
\hline Nejapa de Madero & 2 & 3 & 3 & 0 \\
\hline Santa María Yucuhiti & 2 & 5 & 0 & 3 \\
\hline San Juan Guelavía & 4 & 5 & 2 & 2 \\
\hline Santo Tomás Ocotepec & 0 & 0 & 0 & 1 \\
\hline Total & 13 & 37 & 7 & 15 \\
\hline $\begin{array}{l}\text { *En el caso de San Seb } \\
\text { completo desde princip } \\
\text { entrevistaron y encuest } \\
\text { programa, pero ya no lo } \\
\text { en los resultados de las }\end{array}$ & $\begin{array}{l}\text { Coatlán, } \\
2011, \text { si } \\
\text { dos chic } \\
\text { más. La } \\
\text { lestas que }\end{array}$ & $\begin{array}{l}\text { el grupo } \\
\text { embarg } \\
\text { s que fu } \\
\text { piniónd } \\
\text { e analiz }\end{array}$ & $\begin{array}{l}\text { bía dist } \\
\text { nte la } 1 \\
\text { liadas a } \\
\text { as se v }\end{array}$ & $\begin{array}{l}\text { por } \\
\text { final se } \\
\text { icio del } \\
\text { reflejada }\end{array}$ \\
\hline
\end{tabular}

\footnotetext{
${ }^{4}$ Sin embargo no fue posible descartar que sea desinterés de su parte o conflictos al interior del grupo, ya que nunca dio explicaciones claras sino simplemente iba posponiendo la cita y finalmente ya no contestaba a nuestras llamadas. Cabe resaltar que unos meses antes fue agredida públicamente, con pintas en el mural de Movil en donde hablaban de su vida sexual.
} 
De las nueve líderes, una terminó el proyecto con cinco aliados, otra con cuatro, dos con tres, dos con dos, dos con una becaria del Fondo de becas "Guadalupe Mussalem" de Gesmujer y una realizó sola las actividades del programa en el último año (San Sebastián Coatlán). La propuesta del proyecto era que los grupos de aliados fueran mixtos con mayoría de mujeres. Solo dos grupos (Santa Ana Tlapacoyan y San Juan Guelavía) trabajaron bajo ésta lógica, del resto uno tenía un hombre y una mujer, cuatro solo mujeres y uno exclusivamente hombres (Nejapa de Madero); al respecto de éste último grupo cabe resaltar que fue uno de los que más se consolidaron.

\section{Grupo focal, entrevistas y encuestas $(\mathrm{n}=17)$}

Los resultados que presentamos se basan en la respuesta de 17 aliados (12 mujeres y cinco hombres). Al finalizar el proyecto cinco grupos, aunque habían sufrido deserciones contaban con algunos de los integrantes originales. Se realizaron una entrevista personal, tres entrevistas en pares y tres grupos focales, ya que el número de aliados variaba entre uno y cuatro integrantes. Todos se mostraron participativos y críticos sobre el desarrollo del proyecto. En general mostraron una actitud entusiasta al compartir sus experiencias haciendo evidente una gran satisfacción por lo que han aprendido. Expresaron de manera abierta sus deseos por aprender más y poner en práctica sus conocimientos. Los grupos focales y las encuestas se llevaron a cabo en lugares muy diversos: dos en el IEBO, uno en el espacio seguro, tres en casa de la líder y uno en la cancha. Si bien el número de mujeres duplicaba al de hombres, uno estaba conformado exclusivamente por varones y otro tenía la misma cantidad de muchachas y muchachos (ver Cuadro 12)

\footnotetext{
“Este proyecto nos ayudó mucho tanto como... personalmente a cada uno, porque a cada uno como que lo... le afectó de manera diferente, o sea, todos nos sentimos mal porque el proyecto termina y también aprendimos aquí a tratar a las demás personas, este aprendimos pues información, más información que no conocíamos, aprendimos a ... a dar esa información que nosotros sabíamos, a comunicarnos como, como... grupo, antes que nada a ver este que nuestro grupo funcionara”
}

Unos grupos fueron más comprometidos que otros, sin embargo hasta donde pudieron todos dieron acompañamiento a su líder, reconociendo y respetando su trabajo y viendo posibilidades de crecimiento en ellas. Al término de las entrevistas expresaron tristeza porque el programa se termina ya que además de todo lo aprendido, les permitió reforzar amistades y los hizo sentirse importantes y reconocidos por la comunidad ya que la gente decía en algunos lugares "ya vienen los de Móvil". Además los mantenía ocupados y representaba una buena excusa para reunirse y salir de sus casas, lo cual en la cotidianidad no hacían antes de formar parte del grupo al programa.

\section{Cambios significativos a raíz de su participación en Movil.com}

\section{Impacto personal y familiar}

La mayoría considera que Móvil.com logró un cambio en sus vidas y familias: piensan diferente, expresan sus ideas y dos grupos agregan que aprendieron a respetarse a sí mismos. Todos mencionan haber adquirido información nueva de temas antes vistos en la escuela, además dos grupos agregaron que se sienten más experimentados y con facilidad de comunicarse con los demás. 
“...bueno a mí me sirve de mucho, por eso decidi seguir para saber más”

"Pues a mí me pareció muy bonito porque, aprendo, aprendí cosas que antes no sabia"

"Porque tal vez antes nosotros, nosotros teníamos una manera diferente de pensar y con, cuando entramos en el proyecto, bueno, nuestras ideas fueron cambiando"

Opina que los temas son importantes y que la comunidad puede cambiar si se siguen hablando, un grupo ha notado que las mujeres participan más en las asambleas y que ya se habla de igualdad entre hombres y mujeres. Por último dicen que el proyecto les permitió descubrir habilidades que no tenían y por primera vez hacer algo en su comunidad $(n=1)$.

"Para mí si fue logro eso de, de poder, ahora si juntar a todos los maestros de la, de las instituciones, ¿no? Porque muchas de las veces no podemos a tener una plática o por lo menos convivir, ¿no?, aunque les decían muchos, pus nosotros eh, somos profesores, ¿no?, como, ¿porqué no nos juntamos una vez por lo menos a platicar? Yo digo que es un logro porque en una de

las actividades que hicimos, ya ni me acuerdo cómo se llama, cómo se llamó ese proyecto, donde nosotros dibujamos, hicimos dibujos y todo eso, que ganaran algunos chavos y todo, pero y ya todos los maestros si vinieron pues, como juez, ellos fueron como ser el, que ellos fueron los jueces de califica qué onda y que esto y si, pues hasta se reunieron"

Cuatro grupos consideran que el proyecto les permitió fomentar un lazo amistoso, aprender a trabajar en equipo, informarse, y principalmente planear y organizarse.

\footnotetext{
"Pues, a mí me, bueno a mí en mi opinión, personal, me sirvió de mucho porque pues a lo mejor, convivía con otras personas, y sé cómo se trabaja en equipo y todo"
}

\section{Relaciones interpersonales (confianza y autoestima)}

Si bien las respuestas (ver Cuadro 13) no pueden medirse en relación a la línea base si reflejan mejoría en la auto percepción, ya que 13 se sienten más capaces de hacer nuevos amigos, 12 en valorarse, 11 en expresar su opinión antes su pareja, 10 en convencer a los demás de su punto de vista y expresar su opinión ante sus padres, maestros y/o adultos. Resulta intrigante que sólo seis se sientan más capaces y uno menos que antes al expresar su opinión ante pares y que uno se sienta menos capaz en expresar su opinión ante sus padres, pareja, maestros y adultos. La mayoría reconoce tener igual número de amigas y amigos jóvenes y adultos, de los que tenía antes de empezar el programa. 


\begin{tabular}{|l|r|r|r|r|}
\hline Cuadro 13: Confianza y autoestima (aliados) & $n=17$ \\
\hline ¿Cómo se sienten en...? & Más capaces & \multicolumn{1}{l|}{ Igual } & Menos capaces & NC \\
\hline Hacer nuevos amigos & 13 & 3 & 0 & 1 \\
\hline Expresar su opinión ante sus padres & 10 & 5 & 1 & 1 \\
\hline Expresar su opinión ante sus pares & 6 & 3 & 1 & 7 \\
\hline Expresar su opinión ante su pareja & 11 & 0 & 1 & 5 \\
\hline Expresar su opinión ante maestros o adultos & 10 & 5 & 1 & 1 \\
\hline Convencer a los demás de su punto de vista & 10 & 6 & 0 & 1 \\
\hline Valorarse, tener confianza, quererse, evaluarse & 12 & 4 & 0 & 1 \\
\hline
\end{tabular}

\section{Percepción del liderazgo}

La mayoría de observa que su líder generó cambios positivos en la comunidad y que los jóvenes las reconocen como líderes.

\footnotetext{
“... la mayor parte de los (...) jóvenes... pues ya la ubican, ¿no?, pus ella, la de los talleres (...), la de los derechos, la de las playeras..."

"Pues, pues mejor, mejor que antes, pues porque las dos no teníamos tanta influencia aquí en la comunidad, así, pero ahora pues si”"
}

También consideran que fueron entusiastas, motivadas, comprometidas y que demostraron mayor capacidad y claridad para organizarles. La totalidad habló del liderazgo demostrado además en su capacidad de generar un efectivo trabajo en equipo.

\section{"No pero al principio tenía así como una etapa (...) pero pues ahora que ya nos conoce, pues ya se desenvuelve entre el conocer y el saber, nuestras funciones a cada uno, y aprender, ella aprender a manejar el grupo, este pues ya le da más confianza, y como que con el paso del tiempo pues ya se da esta misma confianza"}

De manera general también reconocen los avances en conocimientos adquiridos a lo largo del programa, que se expresaban en la forma en que podía explicarles los temas que trataban y/o exponerlos ante los jóvenes o la comunidad. En este mismo sentido reconocen que adquirieron habilidades para hablar ante autoridades, comunales, de salud y de educación.

$$
\begin{gathered}
\text { "que ella se fue superando porque... porque tal vez al principio, bueno, } \\
\text { ella tenía pocas ideas ¿no? Pero ya con el paso del tiempo, a en cuanto se } \\
\text { integró, bueno, pues sus ideas fueron más claras, yo creo" } \\
\text { "Pues... la veo diferente, como que más activa... más activa, más decidida } \\
\text { en lo que hace”" }
\end{gathered}
$$

También percibieron en su mayoría la habilidad desarrollada por sus líderes para negocias con autoridades (comunales, educativas y de salud) así como con la comunidad en general, lo cual en la mayoría de los casos representó cambios radicales en la forma de dirigirse y desenvolverse al interior de la comunidad. 
"Yo creo que sí, porque bueno, eh, hablando de todo lo que ella hacía pues ahorita ahí, yo la veo como que un poco más comprometida con lo que ella

hace y un poco más atrevida para poder ir hablar con las personas, dirigirse a las personas, algo qui' antes pus eh, no hacia, pus como le digo, nosotros estamos en otros proyectos y le decían, "Sabes qué te toca ir a visitar a una señora", ahora dice, "No, pero es que ya esto y que lo otro, ponía pretextos, pues, como para que otra persona la acompañara. $Y$ ahorita, pus ya ella ya va solita, ya hace esto, ya. Ya ese es el cambio que yo le he notado, como que más decisión, pues, de poder llevar a cabo una cosa eh, si, bien"

\section{Relación con el Grupo}

En cuanto al acompañamiento por parte de Gesmujer, tres grupos mencionan la presencia de una de las coordinadoras en una campaña, la Lic. Angélica.

\footnotetext{
"P: ¿Alguna vez vinieron a hablar con ustedes directamente, o les mandaban información, o ustedes fueron allá (a la Casa)? Rl.- Si, si nos, vino la licenciada, si nos abrió Móvil.com cuando inauguramos lo de... eh, la pared... R2.- ¡Ah!, si, si, si... mural R1.- mural. Vino ella, estuvo con nosotros este, en el momento de la campaña, ¿no? R2.- Ese día yo no estaba. R2.- Ah, ah bueno. Si, si vino, ella. R2.- Es la única vez"

"Fue cuando creo que la licenciada fue cuando, cuando vino a supervisar lo que hacemos. Sí, sí varias veces vinieron a ver lo que hacía, pero algunas veces nosotras no pudimos estar con ella porque como le decía estamos en la escuela"
}

Dos no mencionaron acercamiento alguno, mostrándose incluso extrañados ante la pregunta

$$
\begin{aligned}
& \text { "P: ¿Tuvieron una relación con la Casa de la Mujer?R: Umm;, no" } \\
& \text { "P: ¿Tuvieron algún vinculo directo con la Casa de la Mujer? R: No" }
\end{aligned}
$$

Al respecto en por lo menos tres grupos sugirieron que sería de gran ayuda para el programa que el personal del Grupo acudiera periódicamente a sus comunidades.

\section{Vínculo con autoridades}

Si bien los grupos aseguran haber apoyado a sus respectivas líderes a lo largo del programa, la totalidad reconocen que ellas siempre estuvieron al frente en las gestiones con autoridades, en algunos casos iban solas y en otras acompañadas y respaldadas por el grupo.

"Pues, como a veces yo tenía clases aquí, o sea principalmente cuando era de autoridades iba ella y cuando era de escuela yo iba" 


\section{"P: ¿Ustedes fueron a hablar con las autoridades? R3.- Fuimos con ell Con la líder). P.- ¿Siempre fueron? R3.- Sí”}

\section{Apoyo de autoridades comunitarias}

La mayoría reconoce que hubo reconocimiento y apoyo de las autoridades comunales. Solo un grupo de aliados y su líder recibieron apoyo continuo a lo largo de todo el programa, en el resto de las comunidades varío en cada cabildo, dependiendo del interés de la autoridad en turno. Sin embargo todas en algún momento del programa pudieron gozar del apoyo del presidente municipal o de miembros de su cabildo, lo cual favoreció la realización de algunas actividades más que de otras. El apoyo consistió en prestar un "espacio seguro" para que se reunieran, ya fuera de forma permanente o intermitente, en prestar sillas, mesas, aparato de sonido, etc; en otorgar premios para los eventos deportivos y/o en asistir a las reuniones a los que fueron convocados.

\section{"Y el otro logro fue también poder eh... involucrar a los de la autoridad, eh y ellos también estuvieron con nosotros en este proyecto eh, bueno el presidente no estuvo pues, pero sí estuvieron como los regidores"}

También, encontramos algunas referencias de autoridades que no apoyaron o francamente entorpecieron el programa. Esta situación se dio al inicio, a la mitad y al final del programa indistintamente en algunas comunidades. Las causas referidas por aliados era que estaban ocupados en otros asuntos, que no los tomaban en cuenta, o que, como en el caso de Apazco que consideraban que los temas tratados por el programa no eran de interés a la comunidad.

"Pues antes, no, pero, tiene poquitito que apenas tuvimos una actividad, aquí, la de la última campaña, porque tuvimos un malentendido con la autoridad y lo único que hicimos fue decirles que como ahí lo que nos dijo, entonces como de ahí, ellos empezaron a hablar mal de nosotros, que somos unas viejas que andamos hablando cosas que ni siquiera a la comunidad le interesa"

“'́bamos ahí a la agencia, a uno a ver el aparato de sonido pero a la mera hora que, bueno, se les solicitaba a las personas se negaban, entonces eso fue un problema para nosotros"

\section{Apoyo autoridades de salud y educativas}

La gran mayoría reconocen de manera general el apoyo de las autoridades educativas. Sin embargo en algunos grupos mencionaron que pese a los acuerdos previos de las autoridades educativas, no habían recibido apoyo en las actividades.

"Hubo una ocasión en que el director le dijo a ella que en tal fecha iban a estar los alumnos en el auditorio para darles el taller y no llegaron. (...) no llegó nadie, incluso se hizo como en horario de, de clases, pues, y, y se le pidió al director que nos diera y si quedó bien, pues, así todo y nosotros dijimos "pues ya la hicimos", ¿no? Y ya también aquí como que este, buscamos un horario, decir, saben qué, pus tal hora nos dijeron los, los cuates de allá, entonces tal hora, nosotros (bachillerato) perdemos una hora de clase y hacemos esto, pues, para hacerlo con más gente. Incluso los 
Lo mismo sucedió con las autoridades de salud, ya que muchos comentan que no lograron involucrarlos permanentemente en las actividades de Movil.

"P: ¿Lograron vincular a autoridades como de salud, doctores, enfermeras? R2.- Eh... no P.- No R2.- Pos, no R1.-No... R2.- Pues casi no, no estuvieron con nosotros... R1.- Si se les informaba... R2.-...pus siempre les informamos R1.-...tal día va ser este taller, pero ellos no... no estaban aquí R2.- Si, incluso el, eh... fuimos con el doctor este que está ahorita a decirle sobre esto ¿no?, y decirle, no pus como él, él es ya una persona preparada específicamente, parte de ésta área, pus le decimos, no pus eh... si, si, vamos a dar un taller, tal, tal, y tal, aquí tenemos la información y todo, tal día lo vamos a ver, no sé si usted pudiera venir a reforzar lo que nosotros eh, damos, eh, para ver si tuviera un resultado mucho mejor, ¿no?,

pero a la mera hora, pus, no, no, no se involucró con nosotros"

\section{Trabajo realizado durante el programa}

\section{Participación y permanencia en Movil.com}

Al preguntarles por qué continuaron en el proyecto, expresan en su mayoría $(n=4)$ que les interesaron los temas y realizar actividades en las que nunca habían participado, por su parte uno de los grupos indicó que permanecieron pese a la falta de apoyo para dar a conocer los contenidos, en particular los derechos de los jóvenes, uno más aseguró que su además de Movil.com están involucrados en todos los grupos comunitarios que trabajan a favor de los jóvenes y del rescate de la cultura. El resto $(n=3)$ no hicieron comentarios específicos.

"Para demostrar que con el apoyo o sin el apoyo de las personas, sí nosotros íbamos a poder lograr cambiar, eh, para que los jóvenes sepan los derechos que tienen"

"Entonces, todo este rollo pus, siempre, siempre estamos involucrados en, en proyectos de aquí de la comunidad, entonces el proyecto de ella no podía ser la excepción, ¿no? entonces, estábamos ahí apoyando todo el tiempo y como decíamos, ¿no?, este, no teníamos eh... a veces, estábamos saturados, ¿no?, de trabajos, de actividades de aquí de la escuela o de otros proyectos $y$, pero nos dábamos chance de planear todo con ella, de que todo saliera bien y a la mera hora tal vez uno no podía estar pero los que sí, pus ahí estábamos aquí en..."

Los grupos en general opinaron que algunos aliados desertaron al proyecto por falta de interés, "no le echaron ganas", por falta de tiempo o por no tener eco en la comunidad.

"Yo creo que faltó, faltaron las ganas de ellas, porque, porque, bueno, al menos ella y yo, eh, si, veníamos con ganas, y con mucho entusiasmo, y pues como con ganas todo se puede" 


\section{"Pero casi después ya no iba (...) Por lo mismo, por tarea, tenía, teníamos muy poco tiempo para, este, apoyarala" \\ "Por ejemplo no teníamos el apoyo de las personas y eso nos ocasionaba que nuestra autoestima se nos cayera hasta en los suelos, porque no teníamos apoyo de las personas"}

Todos dicen haber sido convocados por su líder para asistir a las reuniones, las cuales se establecían de acuerdo a sus posibilidades: dos grupos se reunían de dos a tres veces por semana, uno una vez a la semana, uno cada quince días, otro cada mes o antes de cada campaña y los dos restantes no hicieron comentarios.

Las reuniones consistían para la mayoría en planear actividades, en menos casos para compartir información, leer libros y cinco grupos mencionaron para ver videos. Respecto a la planeación cuatro comentan que sus líderes fueron "democráticas", ya que escuchaban y tomaban en cuenta sus opiniones.

\footnotetext{
"Yo pienso que fue... un buen líder para nosotros porque tanto ella como nos decía qué hacer como que nos... también quería nuestra opinión, o sea nos, nos de, nos dejaba cuestionarnos sobre qué nos parecía esa campaña, qué nos gustaba de los, de los proyectos, qué hacer y nos pedía nuestras opiniones"
}

Las respuestas reflejan que el número de reuniones entre aliados y líderes fueron muy variadas (112), al igual que los lugares en donde se llevaban a cabo (casa de la líder, espacios públicos, cancha deportiva y espacio seguro)
“R2: Bueno, yo fui como a tres, tres reuniones, así que fuimos...R1.- Sí...
$R 2$.... con ella $R 1$. -... es que nos reuníamos una semana antes de la campaña. R2.- Mjmjm P.- Aja R1.- Nos decía, pus tal mes eh, tal, este en tal mes este va ser la próxima campaña y le decíamos, ah, pus tal día nos vamos a juntar, (...) Nos juntábamos un miércoles, planeábamos todos y lo sacábamos (...)Pero sí, es lo que nosotros hacíamos, nos reuníamos unos días antes como para hacer, ya sea la campaña o, ol taller que se iba a dar, pues (...)R1.- Y a veces, planeábamos reunirnos una vez a la semana o dos veces a la semana pero nunca se daba"
"Pues nunca le preguntábamos a ella, qué cuándo iba a ser la reunión o asî para ponernos de acuerdo y ella no, nos decía cuándo, y ya veníamos"

En el (ver Cuadro 14) podemos observar que la totalidad de aliados afirma ser más eficaz al apoyar y respaldar a su líder. Lo cual contrapone la respuesta de las líderes, $(n=15)$ se dicen más eficaces en ponerse de acuerdo sobre las funciones de equipo, $(n=14)$ en asistir a reuniones y resolver malentendidos con sus compañeros, $(\mathrm{n}=12)$ en comunicar mensajes claves de Movil.com, reclutar y motivar a jóvenes en lo cotidiano y motivarse a realizar alguna actividad, $(n=11)$ también se consideran más eficaces en planear en conjunto actividades para las campañas, tomar decisiones en grupo y representar a Movil.com en la comunidad, $(n=10)$ lo afirman en reclutar y motivar jóvenes en lo cotidiano y siete se perciben más eficaces que antes al distribuir tareas al resto del equipo. 
Comparando las respuestas de líderes y aliados encontramos algunas importantes contradicciones, por ejemplo todos afirman ser más eficaces en apoyarlas mientras que sólo seis líderes se sentían siempre o casi siempre respaldadas. La mayoría $(n=14)$ se piensan más eficaces en asistir a reuniones y ponerse de acuerdo sobre las funciones de equipo en tanto que menos de la mitad $(n=4)$ de las líderes lo consideraron así. En igual número $(\mathrm{n}=14)$ los aliados se perciben más capaces en resolver malentendidos con sus compañeros y sólo un poquito más de la mitad de las líderes lo percibe de esa forma.

\begin{tabular}{|l|c|c|c|c|}
\hline Cuadro 14: Desempeño del trabajo realizado como aliado \\
\hline $\begin{array}{l}\text { Comparado con la línea base } \\
\text { ¿Qué tan eficaces son en?: }\end{array}$ & $\begin{array}{l}\text { Más } \\
\text { eficaces }\end{array}$ & $\begin{array}{l}\text { Igual } \\
\text { eficaces }\end{array}$ & $\begin{array}{l}\text { Nunca } \\
\text { eficaces }\end{array}$ & $\begin{array}{l}\text { NS } \\
\text { NC }\end{array}$ \\
\hline ¿Comunicar entre ustedes el trabajo a realizar? & 12 & 5 & 0 & 0 \\
\hline ¿Asistir a las reuniones? & 14 & 2 & 1 & 0 \\
\hline ¿Ponerse de acuerdo sobre funciones de equipo? & 15 & 2 & 0 & 0 \\
\hline ¿Planear en conjunto actividades para campaña? & 11 & 6 & 0 & 0 \\
\hline ¿Distribuir tareas al resto del equipo? & 7 & 10 & 0 & 0 \\
\hline ¿Tomar decisiones en grupo? & 11 & 5 & 1 & 0 \\
\hline ¿Resolver malentendidos con compañeros? & 14 & 2 & 0 & 1 \\
\hline ¿Motivarse a realizar una actividad? & 12 & 5 & 0 & 0 \\
\hline ¿Reclutar a jóvenes en lo cotidiano? & 12 & 5 & 0 & 0 \\
\hline ¿Reclutar y motivar a jóvenes en las campañas? & 10 & 5 & 2 & 0 \\
\hline ¿Comunicar mensajes claves de Movil.com? & 12 & 5 & 0 & 0 \\
\hline ¿Representar a Movil.com en la comunidad? & 11 & 4 & 2 & 0 \\
\hline ¿Apoyar y respaldar a tu líder? & 17 & 0 & 0 & 0 \\
\hline
\end{tabular}

\section{Campañas}

Durante el desarrollo del proyecto Movil.com, las líderes y sus aliados realizaron cuatro campañas importantes (un paquete de actividades que incluye funciones de teatro, eventos deportivos, socioculturales, murales, juegos, etc.); todas relacionadas con los ejes temáticos del proyecto. En general los aliados perciben un buen trabajo en la realización de las actividades, dos grupos mencionan que todas fueron exitosas ya que hubo participación de jóvenes, maestros, autoridades y la comunidad en general. Tres grupos coinciden en que las campañas de mayor impacto comunitario fueron las de equidad de género y violencia en el noviazgo, además de ser las que más gustaron a los jóvenes por divertidas y participativas. Algunas campañas se presentaron en explanadas o espacios comunitarios y otras en las escuelas.

“¿Por qué?, porque los dos tenemos los mismos derechos, hombres, los hombres valemos igual que las mujeres"

"Este, tú me amas, yo te amo, nos respetamos. Porque es donde podría ser como, en un noviazgo, que donde el hombre se cree mucho, y ya desde entonces ya empiezan los celos y, todo, y es donde, este nosotros nos damos cuenta que tanto el hombre como la mujer se tienen que respetar, y no debe haber, algo más que... noviazgo"

\section{Ejes temáticos}

\section{Equidad de género}

Cuatro grupos de siete enfatizaron que no fue fácil hablar de equidad y violencia de género en sus familias y en la comunidad. Sin embargo, tres grupos mencionan que abordar dichos temas les permitió, al igual que a los jóvenes de la comunidad, aprender y comprender que los hombres y mujeres merecen igualdad y respeto. Solo uno de los grupos comentó que en su comunidad las 
mujeres pueden participar y desempeñar cargos políticos. Los tres grupos restantes no aportaron nada al respecto.

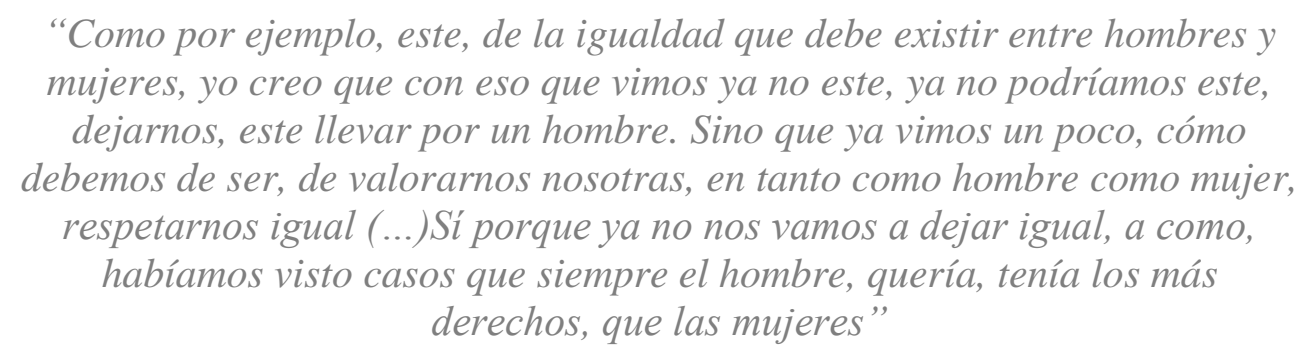

En relación a la línea base encontramos similitudes en la percepción de los aliados de que la escuela y la vida religiosa es el lugar donde hombres y mujeres reciben trato más igualitario. Las respuestas positivas en estos sentidos reflejan un incremento del 19\% relacionado a la escuela (del 81 al 100 por ciento) y del $12 \%$ a los servicios religiosos (de 70 a 82 por ciento). En menor medida las respuestas también denotan incremento de la percepción de trato igualitario en la casa 14\% (del 51 al 65 por ciento), en la vida cotidiana 26\% (del 39 al 65 por ciento) y en el trabajo 6\% (del 29 al 35 por ciento). En torno al sistema político el $30 \%$ sigue pensando que el trato no es igualitario. Es importante resaltar que todas estas percepciones distan de las respuestas de las líderes. (ver página 30)

Las razones que se citaron a propósito de la desigualdad en las comunidades fueron casi idénticas a las mencionadas en la línea base, a saber, la prevalencia de roles de género, "el machismo" ya que los hombre tiene más libertades y preferencias y la violencia de género.

\section{Cuadro 15: Opiniones sobre equidad de género (aliados) $n=17$}

\begin{tabular}{|c|c|c|c|}
\hline En su opinión: & Acuerdo & Igual & Desacuerdo \\
\hline La mujer puede escoger a sus amistades aunque al esposo /pareja no le gusten & 14 & 0 & 3 \\
\hline El hombre debe administrar el dinero de la casa & 1 & 0 & 16 \\
\hline La mujer casada puede escoger su plan de vida & 11 & 3 & 2 \\
\hline La mujer soltera puede escoger su plan de vida & 15 & 1 & 1 \\
\hline La mujer debe responsabilizarse del cuidado de los hijos & 5 & 1 & 11 \\
\hline La mujer debe tener relaciones sexuales con su pareja aunque no quiera & 1 & 0 & 16 \\
\hline La mujer u hombre puede expresar libremente su preferencia sexual & 12 & 1 & 4 \\
\hline
\end{tabular}

Al igual que durante la línea base la mayoría expresó valores sociales abiertos y equitativos (ver Cuadro 15) casi el $90 \%$ estaban de acuerdo en que las mujeres solteras elijan su plan de vida, el $82 \%$ a favor de que eligiera sus amistades ( $84 \%$ en línea base). En menor proporción se incrementó la opinión favorable sobre la elección de plan de vida de las mujeres casadas de un 50 a un 65 por ciento. La gran mayoría (94\%) se manifestaron en desacuerdo en que el hombre debe administrar el dinero del hogar y en que la mujer tenga relaciones sexuales forzadas. El 65\% también mostró su desacuerdo en que la mujer se responsabilice del cuidado de los hijos. El 70\% está de acuerdo en que hombres y mujeres expresen libremente su preferencia sexual. En su mayoría las opiniones de aliados coinciden con las expresadas por las líderes. 


\begin{tabular}{|c|c|c|c|c|c|c|c|c|c|c|c|c|}
\hline \multicolumn{13}{|c|}{ Cuadro 16: Experiencia de equidad de género (aliados) $n=17$} \\
\hline \multirow{2}{*}{ En tu experiencia: } & \multicolumn{3}{|c|}{ Tu pareja } & \multicolumn{3}{|c|}{ Tu padre } & \multicolumn{3}{|c|}{ Tu madre } & \multicolumn{3}{|c|}{ Tú } \\
\hline & $\mathrm{Si}$ & No & $\mathrm{NC}$ & $\mathrm{Si}$ & No & $\mathrm{NC}$ & $\mathrm{Si}$ & No & $\mathrm{NC}$ & $\mathrm{Si}$ & No & $\mathrm{NC}$ \\
\hline Puedes escoger a tus amistades aunque no le gusten & 4 & 1 & 12 & 14 & 1 & 2 & 16 & 1 & 0 & & & \\
\hline Puedes salir con tus amistades sin pedir permiso a: & 5 & 0 & 12 & 3 & 12 & 2 & 4 & 13 & 0 & & & \\
\hline Quién se responsabiliza de todos los gastos de la famili & 0 & 3 & 14 & 11 & 4 & 2 & 14 & 3 & 0 & 2 & 6 & 9 \\
\hline Quién administran el dinero de tu casa & 0 & 3 & 14 & 8 & 5 & 4 & 16 & 1 & 0 & 2 & 0 & 9 \\
\hline Quién toman las decisiones importantes de tu familia & 0 & 3 & 14 & 13 & 2 & 2 & 15 & 1 & 1 & 6 & 2 & 9 \\
\hline Quién se responsabiliza del cuidado de hijos/hermanos & 0 & 2 & 15 & 10 & 2 & 5 & 15 & 1 & 1 & 5 & 2 & 10 \\
\hline
\end{tabular}

En contraste con los altos porcentajes a favor de la elección de planes de vida, así como de elección de amistades, resulta ilustrativo resaltar que en su experiencia personal (ver Cuadro 16) entre el 70 y 76 por ciento no pueden salir con amigos sin la autorización de su padre y madre respectivamente. Por otra parte, contrario a lo que podríamos esperar, es importante resaltar que el $82 \%$ de las madres se responsabilizan de los gastos de la familia y el $94 \%$ administran el dinero de la casa, contra el $65 \%$ y $48 \%$ de los padres que asumen dichas responsabilidades. No nos extraña encontrar que el $88 \%$ de las madres se responsabilizan del cuidado de los hijos y de las decisiones importantes de la familia, contra el 76 y 59\% de los padres que asumen dichas tareas. Estas respuestas reflejan un leve contraste con las obtenidas durante la línea base en dónde la mayoría mencionó que madres y padres jugaban los roles tradicionales; sus papás se responsabilizaban por el dinero para los gastos (60\%) y las madres se ocupaban del cuidado de los hijos (68\%). No obstante, 84 por ciento argumentó que ellos mismos eran libres para definir sus planes de vida.

\section{Violencia basada en género}

El tema lo desarrollaron desde la perspectiva de violencia en el noviazgo. Al respecto dos grupos consideran que la juventud logró identificarla. Uno hablo del abuso sexual, tema que generó interés por parte de los jóvenes y otro comenta que desarrollaron el tema por medio de pláticas con mujeres adultas (grupo INEA), lo cual ha incidido en que ya no permitan que sus parejas/esposos las golpeen e insulten. El resto de los grupos no aportaron más información.

\footnotetext{
"Pues a mi... porque aquí, aunque digan mis compañeros "claro que no" (risas) se ve que si hay violencia, mmm, a veces vemos así, las que tienen novio, luego los novios son bien chantajistas, que también las chavas no se diga, son muy chantajistas, más que eso, hasta dicen, o dicen, "me voy a suicidar si me dejas" o así, cosas así o... (...) Bueno yo principalmente lo he visto, que eso es lo que hacen o las jalonean, o más eso," hacen lo que yo quiero" es más hombres hacia mujeres, o que el hombre baile con dos, tres y que la mujer esté ahí, es más eso. A mí me gustó mucho ese tema para darlo"
}

Resulta interesante escuchar que algunos consideran que hablar del tema generó cambios visibles en jóvenes y mujeres adultas de la comunidad en tanto concientizarse de la violencia que ejercen o de la que sufren.

\section{"P: ¿Cómo creen que Móvil este influyendo o haya influido en eso? R1.- Porque en las pláticas que ya, que las mujeres iban, ya ahora le dicen a sus maridos que todas esas pláticas les sirvieron de mucho}




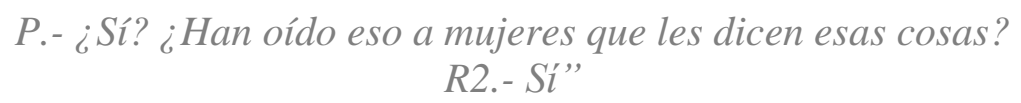

En similares porcentajes a la línea base (45\%), el $41 \%$ durante la final consideró que la violencia basada en género es un problema muy frecuente, o más o menos frecuente, en su comunidad. Solo el $29.4 \%$ señaló haber sido testigo de VBG (física o sexual) hacia alguna mujer/niña contra el 59\% de la línea base.

\begin{tabular}{|c|c|c|c|c|c|c|c|c|c|}
\hline \multicolumn{10}{|l|}{ Cuadro 17: Experiencia en violencia (aliados) $n=17$} \\
\hline \multirow[b]{2}{*}{ Alguna vez: } & \multicolumn{3}{|c|}{ Tú Pareja } & \multicolumn{3}{|c|}{ En tú casa } & \multicolumn{3}{|c|}{ En la calle } \\
\hline & Si & No & NC & $\mathbf{S i}$ & No & NC & $\mathbf{S i}$ & No & NC \\
\hline ¿Te ha hecho sentir menos por ser mujer/hombre joven? & 1 & 11 & 5 & 2 & 15 & 0 & 3 & 14 & 0 \\
\hline ¿Te ha hecho sentir incomodo con chiflidos, palabras y abures? & 3 & 10 & 4 & 2 & 15 & 0 & 12 & 5 & 0 \\
\hline ¿Te ha hecho amenazas de abuso físico? & 0 & 13 & 4 & 2 & 15 & 0 & 2 & 15 & 0 \\
\hline ¿Te ha hecho amenazas de abuso sexual? & 0 & 13 & 4 & 0 & 17 & 0 & 1 & 16 & 0 \\
\hline ¿Te ha agredido físicamente? & 0 & 13 & 4 & 7 & 10 & 0 & 3 & 14 & 0 \\
\hline ¿Te ha agredido sexualmente? & 0 & 13 & 4 & 0 & 16 & 10 & 1 & 16 & 0 \\
\hline ¿Has tenido relaciones sexuales aunque no quieras? & 0 & 11 & 6 & 0 & 11 & 6 & 0 & 10 & 7 \\
\hline
\end{tabular}

Ningún aliado manifestó haber tenido relaciones sexuales sin su consentimiento. Sin embargo una recibió amenaza de abuso sexual en la calle y otra fue agredida sexualmente en la calle. A siete las habían agredido físicamente en casa y a tres en la calle. A 12 las habían hecho sentir mal en la calle con chiflidos y albures y a seis las habían hecho sentir menos por ser mujeres: una su pareja, dos en casa y tres en la calle. (ver Cuadro 17)

\section{Salud sexual y reproductiva/prevención de VIH/ITS}

Sobre el tema comentan en general que fueron temas "incómodos", principalmente para los adultos, ya que son vistos como algo del "otro mundo". Dos grupos reconocen tener más conocimientos e información sobre qué hacer, cómo cuidarse y protegerse en una relación sexual, además consideran necesario seguir promoviendo el uso del condón. Otro grupo considera que los mensajes lograron ser transmitidos a la juventud, lo cual se reflejó en algunas actividades como la pinta del mural.

\footnotetext{
“Ajá, bueno, ese tema lo tratamos en la escuela, (...) Y nosotras lo que hicimos fue hacer actividades para los estudiantes y así que ellos conozcan ¿no? Porque para algunos ¿no? Es un poco difícil que hablen sobre eso, tal vez porque en su casa no platiquen sobre eso o no conozcan y por eso nosotras hacemos actividades para que así no tengan pena de poder expresar lo que sienten"
}

\section{Educación y métodos para prevenir embarazos, ITS y VIH}

La totalidad de aliados han recibido educación sexual, lo cual indica un incremento del $5 \%$ en relación a la línea base. Los lugares mencionados donde la recibieron fueron la escuela y el centro o clínica de salud. Sólo uno mencionó la casa y nadie en Movil.com. Los temas fueron: prevención de embarazos e infecciones de transmisión sexual (ITS), anticonceptivos y sexualidad. En casi todos los grupos mencionaron los talleres de IMSS oportunidades, a los que acuden los jóvenes regularmente a recibir información sobre el tema. Sin embargo algunos grupos cuestionan las formas en que dichos talleres son impartidos y por ende el impacto que tienen en la comunidad. 


\begin{abstract}
"Porque en varias comunidades hay esta modalidad que para recibir el apoyo los jóvenes acuden a talleres y que siempre en los talleres hablan sobre este tema. R1.- Aqui en esta escuela... R2.- Una vez, creo que... R1....una vez R2.-...nada más vino el doctor aquí a decir algo de eso y ya, pus creo que nada más vino una vez y ya les firmo todos los temas. ¡Sí!, en los tarjetones que dan para, para reporte pus si vienen como seis temas, creo que se trata de la sexualidad, de las enfermedades de transmisión sexual y todo eso. Pero pues eh, creo que en un, en un taller que, bueno, alguna vez que vino este, este doctor dijo todo, se tardó como una hora"
\end{abstract}

El cuadro posterior (ver Cuadro 18) refleja que la totalidad conocía cuando menos un método anticonceptivo para prevenir embarazos e ITS/VIH, lo que representa un incremento de $10 \%$ en relación a la línea base; la mayoría reconocieron abstinencia y condón masculino como los métodos más efectivos para prevenir ambos. Las respuestas obtenidas son idénticas a las de las líderes.

\begin{tabular}{|c|c|c|c|c|c|c|c|c|}
\hline \multicolumn{9}{|c|}{ Cuadro 18: Conocimiento sobre la efectividad de los métodos (aliados) $n=17$} \\
\hline \multirow{2}{*}{$\begin{array}{l}\text { ¿Cuál es la efectividad de los } \\
\text { siguientes métodos para prevenir: } \\
\text { Embarazo, ITS y VIH? }\end{array}$} & \multicolumn{2}{|c|}{ Muy efectivo } & \multicolumn{2}{|c|}{$\begin{array}{l}\text { Más o menos } \\
\text { efectivo }\end{array}$} & \multicolumn{2}{|c|}{ No efectivo } & \multicolumn{2}{|c|}{ NC/NS } \\
\hline & Embarazo & $\begin{array}{l}\text { ITS } \\
\text { VIH }\end{array}$ & Embarazo & $\begin{array}{l}\text { ITS } \\
\text { VIH }\end{array}$ & Embarazo & \begin{tabular}{|l} 
ITS \\
VIH
\end{tabular} & Embarazo & $\begin{array}{l}\text { ITS } \\
\text { VIH } \\
\end{array}$ \\
\hline No tener relaciones sexuales & 13 & 11 & 3 & 3 & 1 & 3 & 0 & 0 \\
\hline Condón masculino & 13 & 15 & 4 & 2 & 0 & 0 & 0 & 0 \\
\hline Condón femenino & 9 & 12 & 8 & 3 & 0 & 2 & 0 & 0 \\
\hline Hormonales & 3 & 0 & 13 & 8 & 1 & 7 & 0 & 2 \\
\hline DIU & 8 & 2 & 6 & 6 & 2 & 7 & 1 & 1 \\
\hline PAE & 8 & 2 & 7 & 3 & 2 & 11 & 0 & 1 \\
\hline Ritmo & 1 & 1 & 8 & 1 & 4 & 10 & 4 & 5 \\
\hline Coito interrumpido & 1 & 2 & 6 & 3 & 4 & 8 & 6 & 4 \\
\hline No tener más de una pareja a la vez & 8 & 7 & 3 & 5 & 6 & 4 & 0 & 1 \\
\hline $\begin{array}{l}\text { Tomar medicamento después de } \\
\text { tener sexo no protegido }\end{array}$ & 2 & 4 & 3 & 5 & 10 & 8 & 2 & 0 \\
\hline $\begin{array}{l}\text { Bañarse después tener } \\
\text { sexo no protegido }\end{array}$ & 5 & 3 & 1 & 1 & 10 & 10 & 1 & 3 \\
\hline Tomar té o infusión & 1 & 0 & 5 & 3 & 9 & 11 & 2 & 3 \\
\hline $\begin{array}{l}\text { Lavado vaginal con infusión de } \\
\text { hierbas }\end{array}$ & 2 & 3 & 2 & 1 & 9 & 9 & 4 & 4 \\
\hline $\begin{array}{l}\text { Otros para embarazo (salpingo, } \\
\text { vasectomía, implante dérmico) para } \\
\text { ITS/VIH noespecifican }\end{array}$ & 1 & 0 & 0 & 0 & 0 & 2 & 16 & 15 \\
\hline
\end{tabular}

En torno a los métodos para prevenir embarazos encontramos una diferencia entre línea base y final de casi un $10 \%$ menos reconocimiento del preservativo como método muy efectivo del $(85 \%, \mathrm{n}=53)$ en la línea base a $(76 \%, \mathrm{n}=13)$ en la final, el $(53 \%, \mathrm{n}=9)$ reconocieron al condón femenino como muy efectivo a diferencia de la línea final $(81 \%, \mathrm{n}=50)$ que lo había reconocido durante la línea base. De manera casi idéntica a lo ocurrido durante la línea base, más de la mitad reconocieron correctamente los métodos no efectivos, como bañarse después de una relación sexual no protegida $(60 \%, \mathrm{n}=10)$ y tomar o hacerse lavados vaginales con tés o infusiones de hierbas $(53 \%, \mathrm{n}=9)$. Sin embargo sorprende encontrar que casi la mitad $(48 \%, \mathrm{n}=8)$ cree que es igual de efectivo no tener 
más de una pareja y usar PAE mientras que el $(30 \%, \mathrm{n}=5)$ considera muy efectivo bañarse después de haber tenido sexo sin protección. Un aliado (6\%) sigue creyendo que el ritmo es muy efectivo mientras el $23 \%(n=4)$ no supo o no contestó y el resto $(48 \%, n=8)$ lo consideran más o menos efectivo. Algo similar ocurre con el coito interrumpido ya que en igual porcentaje (35\%) en la línea base $(n=21)$ y en la final $(n=6)$ lo considera más o menos efectivo o no saben y no contestaron, mientras el $(6 \% \mathrm{n}=1)$ lo sigue considerando muy efectivo.

Las métodos que consideraban muy efectivos para prevenir la trasmisión de ITS y VIH/SIDA (ver Cuadro 20) fueron el condón masculino $(88 \%, \mathrm{n}=14)$ contra el $(82 \%, \mathrm{n}=51)$ de la línea base, la abstinencia $(65 \%, \mathrm{n}=11)$, el condón femenino $(71 \%, \mathrm{n}=12)$ contra el $(81 \%, \mathrm{n}=50)$ de la línea base y la monogamia $(41 \%, n=7)$ a diferencia del $(61 \%, n=38)$ que lo consideraba muy efectivo en la línea base. En cuanto a respuestas erróneas encontramos que en la línea base $(30 \%, n=19)$ pensaron que el DIU eran efectivas para prevenir el VIH/ITS y el $(40 \%, \mathrm{n}=25)$ lo creían con respecto a las pastillas anticonceptivas (PAE) y las hormonas. Estas creencias/conocimientos aumentaron ligeramente en la línea final, en donde el $(48 \%, \mathrm{n}=8)$ considera a los hormonales como más o menos efectivos y el $(35 \%, n=6)$ al DIU. Además el $(29 \%, n=5)$ cree que es más o menos efectivo no tener más de una pareja y tomar algún medicamento después de tener sexo no protegido.

\section{Problemas en torno a la salud sexual y reproductiva}

En opinión generalizada, el principal problema que los jóvenes enfrentan es el embarazo adolescente, seguido de la falta de información e ITS y en menor medida mencionaron la violencia en el noviazgo y pena a solicitar anticonceptivos en los centros de salud. A diferencia de la línea base en donde el $(76 \% \mathrm{n}=47)$ dijo que los jóvenes pueden acceder a anticonceptivos modernos en clínicas o farmacias, durante la línea final sólo el $(30 \%, n=5)$ dijo en farmacias y el $(88 \%, n=15)$ en clínicas o centros de salud. Un aliado dijo que en su comunidad no hay lugares donde los jóvenes puedan encontrar métodos anticonceptivos.

\section{Aborto}

Las respuestas son muy controversiales ya que siete dijeron que el aborto debe estar prohibido en todos los casos, siete que debe ser permitido en algunas circunstancias y dos que debe ser permitido cuando la mujer lo decida. Lo anterior representa un incremento del 14\% a favor de la prohibición total del $(27 \%, \mathrm{n}=17)$ en la línea base al $(41 \%, \mathrm{n}=7)$ en la final y una reducción de más de la mitad de los que creen que debe ser permitido cuando la mujer lo decida, del $(24 \%, n=15)$ en la base al $(11 \%, n=2)$ en la final. Sin embargo, también refleja un aumento del $10 \%$ de los que consideran debe ser permitido en algunos casos (violación, salud, accidente o no deseado) del $(31 \%, \mathrm{n}=19)$ en la línea base al $(41 \%, \mathrm{n}=7)$ en la final.

Por otra parte siete no supieron responder a donde acuden las mujeres que necesitan abortar en sus comunidades, dos aseguraron que en sus comunidades no hay a dónde ir y cuatro mencionaron unidades de salud (hospital, clínica o centro de salud). Ninguno había oído hablar de Cytotec.

\section{Vida sexual}

Mientras que en la línea base nueve aliados (15\%) dijeron haber tenido relaciones sexuales, en la final solo tres (17\%) lo afirman. A diferencia de la primera vez donde el $(71 \% \mathrm{n}=6)$ señaló que la primera vez no fue planeada y tampoco usando protección, en ésta ocasión todos $(100 \%, \mathrm{n}=3)$ afirman que usaron protección y aseguran que la decisión se tomó en pareja. Dos usan anticonceptivos de vez en cuando por decisión de pareja, el otro no contestó o no usa. De manera general se sienten más cómodos que antes en buscar servicios, comprar anticonceptivos y solicitar a 
sus parejas que los usen. Dos se sienten igual de cómodos en solicitar pruebas ginecológicas y uno más que antes. En cuanto a solicitar pruebas de prevención de ITS y VIH en los servicios de salud los tres dicen sentirse más cómodos que antes y sin embargo sólo dos mencionan que se sienten más cómodos al solicitarlas pruebas a sus parejas. Todos estos cambios deben entenderse bajo la reducción significativa del número de aliados entre ambas líneas.

El $(65 \%, \mathrm{n}=11)$ aseguran no estar listos para tener relaciones sexuales, uno (6\%) porque no han tenido oportunidad, creen que el sexo es malo, tienen miedo al embarazo o a ser contagiados de VIH/SIDA o alguna otra ITS. A diferencia de la línea base en donde la razón de la mayoría era miedo al embarazo o infección de VIH (88\%); seguida de no estar listo (82\%); no tener la oportunidad (26\%) y porque el sexo antes del matrimonio era malo (27\%).

\section{Valores acerca de Salud Sexual y Reproductiva}

\section{Percepciones sobre los valores comunitarios acerca de SSR}

Las respuestas más conservadoras (ver Cuadro 19) se pueden observar en las proporciones inversas sobre la importancia de la virginidad ya que al parecer siete comunidades están de acuerdo en que las mujeres lleguen vírgenes al matrimonio y en siete en desacuerdo en que los hombres lo hagan. A diferencia de la respuesta de las líderes, los aliados consideran que sus comunidades son más abiertas en que las mujeres solteras tengan hijos, ya que en cinco están de acuerdo y a cinco les da lo mismo. Algo similar sucede con el hecho de que las parejas vivan juntas antes de casarse ya que sólo tres comunidades están en desacuerdo. En similitud con las respuestas ofrecidas por las líderes, los aliados consideran que las comunidades aceptan que las mujeres decidan el número de hijos y el tiempo entre cada embarazo (ocho están de acuerdo y a tres les da igual) y también lo están en que elija el método anticonceptivo que quiera (siete están de acuerdo y a cinco les da igual)

\begin{tabular}{|c|c|c|c|c|c|c|c|c|}
\hline \multicolumn{9}{|c|}{ Cuadro 19: Percepción de los valores comunitarios y valores personales en SSR (aliados) } \\
\hline \multirow{2}{*}{$\begin{array}{c}\text { Valores sobre } \\
\text { SSR: }\end{array}$} & \multicolumn{2}{|c|}{ Acuerdo } & \multicolumn{2}{|c|}{ Igual } & \multicolumn{2}{|c|}{ Desacuerdo } & \multicolumn{2}{|c|}{ NS/NR } \\
\hline & Comunidad & Líder & Comunidad & Líder & Comunidad & Líder & Comunidad & Líder \\
\hline $\begin{array}{l}\text { Los hombres } \\
\text { deben ser vírgenes } \\
\text { hasta el } \\
\text { matrimonio }\end{array}$ & 4 & 5 & 5 & 3 & 7 & 9 & 1 & 0 \\
\hline $\begin{array}{l}\text { Las mujeres deben } \\
\text { ser vírgenes hasta } \\
\text { el matrimonio }\end{array}$ & 7 & 6 & 5 & 2 & 4 & 8 & 1 & 1 \\
\hline $\begin{array}{l}\text { Las mujeres } \\
\text { solteras pueden } \\
\text { tener hijos }\end{array}$ & 5 & 7 & 6 & 6 & 6 & 4 & 0 & 0 \\
\hline $\begin{array}{l}\text { Las parejas pueden } \\
\text { vivir juntas antes } \\
\text { del matrimonio }\end{array}$ & 5 & 7 & 9 & 6 & 3 & 4 & 0 & 0 \\
\hline $\begin{array}{l}\text { La mujer puede } \\
\text { decidir el número } \\
\text { de hijos y el } \\
\text { periodo entre cada } \\
\text { embarazo }\end{array}$ & 8 & 11 & 3 & 3 & 5 & 3 & 1 & 0 \\
\hline $\begin{array}{l}\text { La mujer pueda } \\
\text { usar el método } \\
\text { anticonceptivo } \\
\text { que quiera }\end{array}$ & 7 & 15 & 5 & 1 & 4 & 1 & 1 & 0 \\
\hline
\end{tabular}




\section{Valores personales acerca Salud Sexual y Reproductiva}

De manera general los valores personales (ver Cuadro anterior) reflejan similitud con sus percepciones sobre los valores comunitarios y con la opinión expresada por las líderes. La mayoría (65\%) está de acuerdo (en igual proporción que en la línea base) que las mujeres decidan el número de hijos y el periodo entre cada embarazo. La gran mayoría (88\%) se manifestaron favorablemente para que la mujer use el método anticonceptivo que desee, lo cual también sucedió en la línea base pero en menor porcentaje $(67 \%)$.

En torno al tema de la virginidad encontramos importantes diferencia entre los valores personales y los comunitarios, ya que mientras ocho están en desacuerdo en que las mujeres lleguen vírgenes al matrimonio, la mitad (cuatro) consideran que sus comunidades están de acuerdo. En torno de la virginidad de los hombres encontramos además diferencias entre ambas líneas, ya que en la base el $31 \%$ estaba de acuerdo con que los hombres se conservaran vírgenes hasta el matrimonio y en la final el 53\% está en desacuerdo. Sin embargo con la virginidad de las mujeres no hubo cambio perceptible de opinión entre la línea base y la final, y tampoco en las opiniones a favor de que las mujeres solteras tuvieran hijos.

A diferencia de la línea base en donde el $46 \%$ consideraba apropiado que las parejas vivieran juntas antes de casarse, las respuestas de la línea final apuntan sólo un 29\% de acuerdo y a un $53 \%$ a los que les da igual.

\section{Derechos Sexuales y Reproductivos}

Todos coinciden que los jóvenes ya identifican sus derechos sexuales y reproductivos, entienden que tienen la libertad de decidir cuándo y con quién tener relaciones sexuales y el derecho a recibir anticonceptivos y servicios en salud sexual y reproductiva. Cuatro grupos aseguran que informaron, aclararon dudas al respecto y perciben a los jóvenes más conscientes.

Solo el $12 \%$ contra el $36 \%$ de la línea base consideraba que en sus comunidades los derechos humanos pueden dar origen a problemas con los usos y costumbres de sus comunidades, y se incrementó un $20 \%$ lo que no lo creen (de 51 a 71 por ciento).

De las mujeres aliadas, 25 por ciento se ha sentido discriminada por el hecho de ser mujer, indígena, joven; 68 por ciento no estuvo en ese caso, y 8 por ciento no supo.

Ochenta y cinco por ciento dijo saber algo alusivo al tema de los derechos humanos en general, así como sobre los derechos a la libertad y la igualdad (66\%), la vida (58\%), el pensamiento (57\%), la salud (51\%), la no discriminación (50\%). Fueron menos los que conocían acerca de los DSR: 40 por ciento nombró el derecho a casarse y a decidir el número de hijos de desea; pero nadie mencionó específicamente el derecho a acceder a métodos de planificación familiar. Sobre los derechos humanos, la mayoría (90\%) mencionó que "se aplican mayormente a todas las personas", y "a jóvenes y niños.” Más de la mitad citó alguna institución o ley cuya obligación es proteger los derechos humanos (v.g. el Centro Nacional de Derechos Humanos, "las ONG’s", "la ley").

En virtud de que el tamaño de la muestra de la encuesta a aliados fue relativamente pequeño, no pudimos hacer pruebas estadísticas para explorar las diferencias entre comunidades. Pero analizamos las respuestas por género, encontrando diferencias interesantes entre las y los jóvenes. En cuanto a habilidades de liderazgo, un número significativamente mayor de las muchachas aliadas (93\%), en comparación con los varones $(57 \%)$ se creía capaces de organizar un grupo de pares para conducir una actividad. Más muchachos (43\%) que muchachas (37\%) sentían que en la vida cotidiana las 
mujeres y los hombres recibían un trato similar en sus comunidades; sin embargo, en el resto de las preguntas relativas a equidad de género no se manifestaron diferencias significativas según el género. En cuanto a la VBG, un número significativamente mayor de mujeres (67\%) que hombres (35\%) informó haber sido testigo de violencia sexual o física contra una mujer o una niña alguna vez en su vida.

Para el resto de las asociaciones - como conocimiento de anticonceptivos, percepción del embarazo adolescente, roles y responsabilidades de hombres y mujeres, y conocimiento de los derechos humanos -, no constatamos diferencias significativas entre las y los aliados.

\section{Impacto comunitario}

En cuanto al impacto comunitario, la gama de opiniones fue amplia, desde los que opinaron que no había tenido ningún impacto, o muy poco básicamente por falta de interés, hasta los que consideran que generó cambios muy importantes sobre todo entre jóvenes y mujeres.

En cuanto a aquellos que consideran que Movil.com efectivamente generó cambios positivos en la comunidad, observan que sirvió para que en jóvenes y mujeres conocieran y empezaran a exigir sus derechos.

$$
\begin{aligned}
& \text { “P: En tu familia, hubo cambios a raíz de tu participación en Movil.com? } \\
& \text { Rl: Esto es a partir de que yo estoy participando en este programa. Ummm, } \\
& \text { no P.- No, ¿y en la comunidad cómo ven, creen que tuvo alguna, un } \\
& \text { impacto, Rl.- Un poco P.- Un poco ¿por qué un poco? Rl.- Porque, bueno } \\
& \text { yo he escuchado que, cuando hacen reuniones el presidente, eeeh a veces } \\
& \text { como que las mujeres, no hablaban mucho, no, opinaban, y ya ahora sí, } \\
& \text { porque nosotros este, decíamos este que, tienen derecho a decir, sus } \\
& \text { opiniones y todo eso, yo creo que sí P.- ¿Y tú crees que eso tiene que ver } \\
& \text { directamente con lo que ustedes le dijeron a las mujeres? Rl.- Sí porque } \\
& \text { básicamente pues nosotros les decíamos que, o sea le poníamos un ejemplo, } \\
& \text { en las reuniones ¿no? y les decíamos que tienen que opinar, que no sólo los } \\
& \text { hombres pueden, desempeñar cargos, esos de presidente, también pueden } \\
& \text { las mujeres P.- Y a raíz esto, ustedes ven que las mujeres están participando } \\
& \text { más Rl.- Sí” } \\
& \text { “El impacto(a partir de Movil)... que pudo más la libertad de expresar (...) } \\
& \text { Sí, yo digo que sí, que si tienen más la libertad y la confianza de decir no } \\
& \text { quiero, sí quiero. Pues en especial es también eso de ir con tu novio en la } \\
& \text { calle, hablar con tus papás, acerca de esos temas, también lo de expresar tus } \\
& \text { ideas... más en eso”" }
\end{aligned}
$$

Si bien las respuestas en torno al impacto fueron opuestas, en lo que todos los grupos coincidieron es que la comunidad los llegó a identificar como parte de un movimiento de jóvenes, gracias a las campañas y en particular a las actividades recreativas, socioculturales y deportivas. Logrando asociarlos por lo menos a uno de los temas que trataron a lo largo de dos años. 


\section{Recomendaciones para mejorar el proyecto}

Durante el proceso identificaron algunas necesidades, las cuales pueden fortalecer al proyecto, por ejemplo dos mencionan buscar información actualizada de los temas, nuevos conocimientos, materiales didácticos y audiovisuales que les permitan conocer a profundidad los temas para poder hablar de ellos; uno considera importante integrar a más jóvenes (hombres y mujeres), realizar más actividades (socioculturales y deportivas) en las campañas y salir a las comunidades de los alrededores a dar talleres y otro propone un trabajo de seguimiento más personal, de "casa en casa"; uno más expresa que deben tener una capacitación más profunda, conocer mejor el proyecto, tener más acompañamiento por parte de las organizaciones y representantes de Móvil.com. Uno más cree importante intercambiar con otras grupos de aliados las experiencias del cómo resuelven y realizan sus actividades para conocer nuevas estrategias de trabajo (reunión entre aliados). Tres grupos expresan abiertamente poder continuar con el proyecto siempre y cuando tengan apoyo de la comunidad y de una líder. Otros más pensaban que tendría que haber más actividades a lo largo del programa para que lograran una presencia más notoria en la comunidad. 


\section{Jóvenes de la Comunidad}




\section{Recolección de datos: Cuarta Encuesta Rápida}

Ofrecemos ahora los resultados de la cuarta "encuesta rápida", que midió la línea final de CAP sobre los temas de Movil.com entre la juventud que participó en la última campaña. La encuesta recogió datos socio-demográficos básicos, qué tan familiar les era Movil.com, e información sobre conocimientos y actitudes en torno a los cuatro temas nucleares del proyecto, que se expresaron de manera similar a las encuestas de la línea final para las líderes y sus aliados. Tal y como se ha descrito previamente, las líderes y los equipos de aliados llevaron a cabo la encuesta justo antes de la campaña. Las coordinadoras del proyecto capacitaron a las líderes en técnicas de encuestas y manejo de equipos de aliados a lo largo de todo el programa para levantar encuestas rápidas en cada una de las campañas (exceptuando una). En ésta ocasión, pretendía alcanzar la meta de involucrar en cada sitio a 50 participantes jóvenes de 15 a 25 años de edad. Las líderes/equipos de aliados llevaron a cabo la encuesta durante el mes de mayo de 2011.

\section{Datos socio-demográficos}

El total de encuestas completas y devueltas fue de 374, con información de nueve comunidades. En promedio, 41 jóvenes (14-60 por comunidad) completaron las encuestas en cada sitio (ver el Cuadro 20). A grandes rasgos, los jóvenes participantes abarcaban un número similar de varones y muchachas, que estaban en el rango de edad del grupo meta (17). En términos generales, los perfiles socio-demográficos de esos jóvenes eran similares a los de las líderes y sus aliados de Movil.com, lo cual sugiere que mediante las campañas comunitarias el proyecto está llegando a la audiencia meta.

\author{
Cuadro 20: Perfil socio-demográfico \\ y conocimiento de Movil.com de los \\ jóvenes participantes $(n=270)$ \\ - $\quad 55 \%$ de mujeres jóvenes, $45 \%$ de \\ hombres jóvenes. \\ - $\quad$ Promedio de edad: 17 (de 7 a 25 años). \\ - $52 \%$ habla una lengua indígena, \\ mayoritariamente mixteco 35\% \\ - $78 \%$ tiene estudios de preparatoria o \\ bachillerato, $19 \%$ de secundaria, $1.3 \%$ \\ de primaria y $.3 \%$ ninguna. \\ - $\quad 79 \%$ (96) ha oído hablar de Móvil.com
}

\section{Conocimiento de Movil.com}

Casi el 80\% señaló haber oído hablar de Movil.com. La mitad conocía el nombre de la líder, el 30\% la forma en que el proyecto se organizaba, un $23 \%$ la organización que lo dirigía (El Grupo/Casa) y el $38.5 \%$ aseguró conocer los objetivos del proyecto mencionando: equidad de género, apoyo a mujeres y jóvenes, promoción de sus derechos así como los SSR; realizar actividades recreativas fue uno de los "objetivos" más mencionados.

Casi el 60\% había participado en más de una actividad de Movil.com de los cuáles el 51\% participó en la campaña de EG el $28 \%$ en la de Salud y DSR, el $60 \%$ en la de Violencia en el Noviazgo. En cuanto al tipo de evento en el que habían participado el 44\% asistió a talleres o pláticas, el 32\% a eventos deportivos, el $48 \%$ a proyección de películas, el 13\% apoyó en la planeación de eventos y el $12 \%$ en la planeación, organización y realización de campañas.

En los comentarios expresados sobre lo que más les gustó de Movil.com, en primer lugar mencionaron los "eventos" en el que destacan los deportivos y la proyección de películas; en menor medida hablaron de las actividades lúdico-artísticas y muy pocos mencionaron las campañas (equidad y de violencia). En segundo lugar mencionaron los temas abordados en el siguiente orden: equidad de género, derechos (hombres, mujeres, jóvenes y DSR) y violencia. En tercer lugar 
mencionaron las pláticas y los talleres. Es importante marcar que en cuarto lugar se mencionó la organización del proyecto. En menor medida les gustó que promueva la participación y apoya a mujeres y jóvenes. Solo tres mencionaron que lo que más le gusto fue lo que ofrecían en sus actividades y dos que no les gustó nada.

\section{Ejes temáticos}

\section{Equidad de Género}

En relación a la igualdad de género, el 55 por ciento refirió que en su comunidad no se valora igual a las mujeres que a los hombres. Pese al alto porcentaje podemos considerar una mejoría respecto a la línea base en donde el 69\% contestó en ese sentido. Al igual que en la línea base, el 91\% señaló que no creía que los hombres merecen mayor respeto que las mujeres.

\section{Violencia basada en género}

En torno a la violencia física o sexual contra niñas y mujeres el 55\% la considera un problema en su comunidad y el $44 \%$ ha sido testigo de actos violentos. En lo que respecta a violencia durante el noviazgo el $40 \%$ considera que los celos, empujones, pellizcos y golpes denotan violencia y sólo el $7 \%$ creen que el control en la forma de vestir y el dejar de hablarse sean actos violentos.

De manera similar a lo que las líderes y sus aliados reportaron en la encuesta de línea base, la mayoría (52\%) de los participantes jóvenes consideran que la VBG es un problema en sus comunidades; mientras tanto, 40 por ciento no lo creía así, y 8 por ciento no sabía. Asimismo, 30 por ciento dijo saber de alguna mujer o niña que había sido víctima de abuso físico o sexual (lo que se definió como golpeada, abofeteada, pateada o forzada a tener relaciones sexuales), mientras $68 \%$ dijo no saber (2\% no sabía).

\section{Sexualidad y salud sexual y reproductiva (SSR)}

\begin{tabular}{|l|c|c|c|c|}
\hline Cuadro 21: Conocimiento de métodos para prevenir embarazo no deseado (jóvenes n=270) \\
\hline Línea & \multicolumn{2}{|c|}{ Base } & \multicolumn{3}{c|}{ Final } \\
\hline Métodos para prevenir: & Embarazo & ITS/VIH & Embarazo & ITS/VIH \\
\hline Condón masculino & $66 \%$ & $80 \%$ & $76 \%$ & $87 \%$ \\
\hline Condón femenino & $0 \%$ & $17 \%$ & $29 \%$ & $31 \%$ \\
\hline Implantes & $0 \%$ & $0 \%$ & $15 \%$ & $1 \%$ \\
\hline Pastillas & $19 \%$ & $5 \%$ & $34 \%$ & $2 \%$ \\
\hline DIU & $9 \%$ & $5 \%$ & $24 \%$ & $3 \%$ \\
\hline Otros & $0 \%$ & $0 \%$ & $10 \%$ & $3 \%$ \\
\hline
\end{tabular}

Los resultados (ver Cuadro 21) reflejan un aumento en el conocimiento de los método para prevenir embarazos no deseados, en relación con los métodos mencionados durante la línea base el número de jóvenes que mencionaron el condón masculino se incrementó en un 10\%, el del pastillas y DIU en un 15\%. Además mencionaron condón femenino, implantes, inyecciones, parches, salpingoclasia, vasectomía, píldora del día siguiente (PAE), ritmo y abstinencia. A diferencia de la línea base en donde el $12 \%$ no supo de ninguno, en ésta ocasión sólo el .8\% no supo o no contestó. En cuanto a uso correcto 
de la PAE el $83 \%$ respondió que debe utilizarse inmediatamente después de una relación sexual no protegida.

De manera más contundente (ver Cuadro 21) el $87 \%$ mencionó el condón masculino como método efectivo para prevenir el VIH/ITS, con un incremento del 7\% en relación a la línea base, el condón femenino aumentó en un 14\%. De manera incorrecta se mencionaron los implantes, el DIU y las píldoras, éstos últimos disminuyeron en un $2 \%$ y $3 \%$ respectivamente con respecto a la línea base. Un 3\% mencionó la abstinencia, los parches, no tener relaciones con muchas personas y tener relaciones con una sola pareja. Sólo el $1.3 \%$ no sabía o no contestó.

\section{Derechos Sexuales y Reproductivos}

Sorprende que una mayoría (77\%) manifestara haber escuchado sobre los derechos sexuales y reproductivos, y que 86 por ciento haya dicho que sabe que toda la juventud tiene derecho a demandar acceso a la atención en SSR. El 71\% respondieron que el hombre tiene el derecho de exigir el uso de anticonceptivos a su pareja y el $84 \%$ respondió que la mujer tiene el derecho. Las respuestas fueron ligeramente más altas en la línea base, $77 \%$ los hombres y $89 \%$ las mujeres. Sin embargo la gran mayoría coincide, en ambos momentos, en que las decisiones deben tomarse en pareja, $94 \%$ en la línea base y $98 \%$ en la final. En lo que respecta a la decisión sobre el número de hijos y cuando tenerlos el $72.5 \%$ respondió la mujer a diferencia de $8.3 \%$ de la línea base; mientras que solo el $25 \%$ dijo que debe ser una decisión en pareja contra la respuesta basal (88\%) de la gran mayoría.

\section{Derecho de los jóvenes}

En torno a la toma de decisiones de la comunidad el $75 \%$ considera que hombres y mujeres mayores de 18 tienen el derecho de participar, mientras el 11\% considera que sólo es un derecho de hombres. El $51 \%$ considera que las autoridades no toman en cuenta las necesidades y puntos de vista del los jóvenes, a diferencia del $68 \%$ que pensaba lo mismo en la línea base. Sin embargo, alrededor del 90\% durante ambas líneas (base y final) creen que éste grupo puede lograr cambios políticos, culturales y sociales en sus comunidades.

\section{Logros y limitaciones de la aplicación de la encuesta}

Como se ha comentado anteriormente, este método e instrumento tiene diversas limitaciones ajenas a nuestro control (v.g. una tasa de participación baja por eventos que competían con él, los participantes varían entre sitios y en el tiempo; variaciones en las habilidades de las líderes/aliados para administrar la encuesta, carencia de datos de jóvenes que no fueron encuestados y otros). Dejando de lado tales limitaciones, las encuestas rápidas nos ofrecieron una agradable instantánea sobre los conocimientos y opiniones relevantes del tercer grupo de jóvenes a lo largo de las campañas. Representaron además una oportunidad importante para desarrollar las habilidades de las líderes/aliados en relación con la planeación de actividades, el manejo del tiempo y la recolección de datos de calidad. Las líderes sobrepasaron nuestras expectativas en cuanto a la calidad de las encuestas que completaron, sin embargo en la mayoría de los casos la cuota de encuestas solicitadas no se cubrió por diversas razones: 1) Sobre carga de trabajo de algunas líderes ya que realizaban actividades y levantaban la encuesta, en vez de que sus aliados lo hicieran; 2) Una baja participación en las actividades por parte del grupo de edad meta; 3) Negativa de la audiencia a responder. 
Autoridades
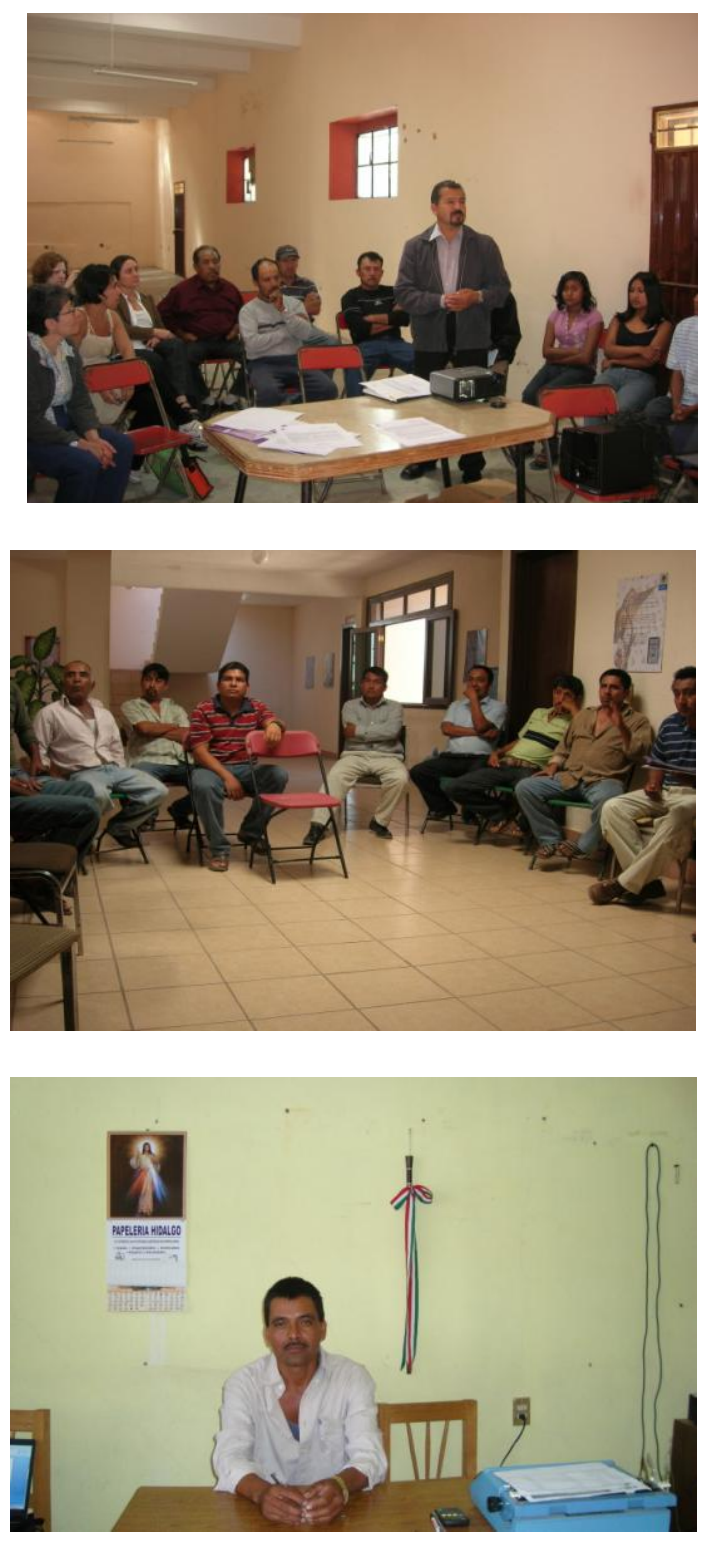


\section{Entrevistas con autoridades comunitarias}

Una de las partes integrales del monitoreo y evaluación durante la línea final consistió en entrevistar a autoridades comunitaria (v.g el presidente municipal o miembros de su cabildo) por ser los "representantes" de la comunidad, además que su aval y apoyo fueron críticos para el éxito del proyecto.

Cabe anotar que las entrevistas (ver Anexo A) se basaron en el instrumento utilizado durante la línea base, simplificando las preguntas y el lenguaje utilizado para hacerlo más accesible. La línea base reflejó en general desconocimiento de los conceptos centrales y la necesidad de adaptar el lenguaje a autoridades con niveles educativos elementales (primaria y/o secundaria) o incluso analfabetas.

A continuación presentamos los hallazgos más relevantes basados en las opiniones de las autoridades de ocho comunidades en torno a los aspectos generales sobre las comunidades, los procesos de toma de decisiones, los cambios más significativos en usos y costumbres que atañen particularmente a jóvenes y mujeres, así como su apreciación sobre los ejes temáticos del programa (equidad de género, salud sexual y reproductiva, derechos humanos y violencia contra mujeres). Así como los servicios recursos y políticas públicas para promoverlos al interior de cada comunidad. De manera particular se abordaron las experiencias Movil.com en cada caso, sondeando además las posibilidades de continuidad y apropiación del proyecto.

\section{Perfil de entrevistados}

Se entrevistaron a autoridades de ocho comunidades, habiéndose logrado la participación de 22 miembros de los cabildos: presidentes y agentes municipales, síndicos, regidores y secretarios. A diferencia de la línea base en donde miembros del cabildo asistían a la entrevista pero no decían nada, en ésta ocasión la mayoría expuso sus puntos de vista sobre los temas a tratar y se mostraron más atentos, receptivos y participativos. Lo cual en términos generales podría indicar conocimiento del programa y reflejar interés en la implementación de programas como éste.

\section{Contexto político-religioso y sistema de cargos}

Inicialmente, es importante tener presente que todas las comunidades se rigen por el sistema de usos y costumbres; que su máxima autoridad es la asamblea del pueblo y que el representante de ésta es el cabildo. En todas ellas la asamblea elige al presidente municipal y en la mayoría a la totalidad del cabildo (regidores, síndico, tesorero y secretario). En pocos casos, es el presidente municipal quien elige a miembros del cabildo, en particular al secretario y al tesorero. Asimismo, es importante tener presente que el sistema de cargos políticos está vinculado al de los cargos religiosos, que se asumen sin recibir paga, y que todo ciudadano puede y debe brindar a la comunidad si esta así lo decide.

Algunas de las particularidades del sistema de cargos que refirieron las autoridades son: la totalidad refiere haber sido elegido por voto directo en asamblea. La duración de los cargos políticos varía entre uno $(n=3)$ y tres años $(n=5)$. Si bien no fue posible entrevistar a la autoridad de Apazco sabemos que en su caso hubo serios problemas internos porque por primera vez entró el sistema de partidos políticos y los cargos, hasta entonces gratuitos, iban a ser remunerados. Además, hasta el momento de la entrevista (finales de junio) la autoridad no utilizaba el palacio municipal por falta de la aceptación total de la comunidad. 


\section{Impacto de los usos y costumbres en Movil.com}

\section{Cambio de autoridades}

El principal impacto que los cambios de autoridad representaron para Movil.com fue la falta de continuidad en la relación autoridades - líderes, recibir apoyo durante las campañas y actividades comunitarias, así como para tener y conservar el espacio seguro. Además las líderes tuvieron que renegociar, en cada cambio de cabildo, los acuerdos establecidos con las anteriores autoridades. Lo cual además estaba atravesado por relaciones de parentesco o de representatividad de intereses de los distintos grupos al interior de la comunidad, lo cual favoreció o desfavoreció el trabajo de las líderes según el grupo al que se le consideraba más allá del reconocimiento del programa Movil.com

En algunos casos, en aquellas comunidades donde las autoridades se eligen anualmente, las líderes tuvieron que negociar con tres cabildos distintos. Lo cual significó indistintamente que las relaciones líder-autoridades mejoraran o empeoraran, y por ende que hubiera una buena o mala disposición en apoyar a Movil.com. Ejemplos de ello falta de apoyo lo encontramos en comunidades donde se les negó un espacio seguro, en otra donde se les quitó, en unas hubo resistencia para colaborar en las campañas, prestar infraestructura, otorgar premios en los eventos deportivos o simplemente no asistir a los eventos realizados por la líder y sus aliados.

En por lo que hace al levantamiento de la línea final del (M\&E), la implicación general fue la imposibilidad de entrevistar a las autoridades entrevistadas en la línea base y el desconocimiento total del trabajo que desarrollamos durante el primer año. Exceptuando Santa Ana Tlapacoyan y Nejapa de Madero en donde, gracias a la entregada de los resultados del Censo de SSyR, en enero 2011, el resto de las comunidades desconocían por completo la función evaluadora del Population Council. Sin embargo afortunadamente las líderes expusieron acertadamente la importancia de la entrevista y lograron obtener en todas las comunidades una cita para levantar la entrevista.

Al parecer el cambio de autoridades también influyó en el desconocimiento casi absoluto de Gesmujer, ya que sólo una de las autoridades entrevistadas habló de una reunión a la que asistieron en la Casa y el resto no hizo ninguna alusión de conocer al Grupo.

\section{Principales problemas de los jóvenes}

La mayoría coincide en que el principal problema que afecta a los jóvenes actualmente es el alcoholismo y en ciertas comunidades el uso de drogas, así como la falta de espacios recreativos o de convivencia "sana".

\footnotetext{
"Pues nosotros aquí como cabildo pues hemos tratado de prohibir venta de alcohol para jóvenes, ¿si? ahí en ese sentido queremos participar para que se puedan alejar de las cantinas, pues ¿no? evitando, pero la gente pues por el negocio pues no, no dejan eso ¿verdad? siempre siguen vendiendo, pero hay que insistir, pero ni modo, a ver hasta dónde podemos llegar (...) Y ya

luego meterlos, eso es lo principal, y tener a donde, por ejemplo, una unidad deportiva, pues ¿no? para evitar que ya vayan y se dedican y que les diga uno "aquí está la cancha”, dedíquense a eso" o aquí esta X (nombre de la líder) a que da su grupo o otras personas. Por ejemplo, aquí también
} 
veo para las jovencitas también ella pues le está echando ganas darles

cursos así de tejido, de muchas cosas, de pintura, pero bueno, eso es lo que queremos"

Incluso es importante ejemplificar en voz de una de las líderes, que las algunas fueron convocadas por autoridades educativas y/o comunitarias a impartir talleres o "platicas" sobre dichos temas:

\footnotetext{
"sino muchas veces como que te invitan a que vayas a impartir o lo otro, pero muchas veces no se puede por lo mismo de que son temas que quizás nosotras no lo hemos tocado (...) la otra vez me dijeron que era de drogadicción, creo, y del alcoholismo, son de adicciones, y yo pues dije pues obviamente que no podemos dar esos talleres porque no tenemos la información, pero en otros temas de los mismos que trabajamos de hecho si ha habido invitación" (líder)
}

También mencionaron la deserción escolar por falta de recursos económicos de los padres para seguir apoyando, la falta de oportunidades laborales y de estudios profesionales o técnicos, lo cual incide directamente en la migración hacia las ciudades de Oaxaca, México, estados del norte del país y finalmente Estados Unidos. Las únicas opciones de vida dentro de la comunidad se reducen al trabajo poco remunerado en el campo o a la siembra de autoconsumo y cría de animales de traspatio.

"Son muy pocos los que siguen estudiando, es una parte de jóvenes que
siguen 'ora si el estudio, pues la mayoría se emigra, se va a la ciudady
busca trabajo, este, para 'ora sí que, tener una ganancia económica para
su familia (...) se van a diferentes, este, lugares como es al Distrito Federal
o, este, a algunos estados del norte (...) No, este de todo de todo hay un
poco de que se vayan a la cabecera municipal, Oaxaca, pero 'ora sí que es
algo disperso pues, en diferentes estados de la república (...) pero la
mayoría se emigra (...) Si, son muy pocos los que se quedan para siempre”

En general las autoridades perciben que las mujeres ya desean otra forma de vida y buscan continuar sus estudios, sin embargo para muchas mujeres la única opción sigue siendo el matrimonio que por lo general se da entre los 18 y los 20 años. En algunas comunidades de "fácil acceso", las mujeres salen a las ciudades más cercanas para buscar trabajo y apoyar la economía familiar. Cada vez es más frecuente la migración de mujeres en busca de trabajo.

En cuanto al tema de embarazo adolescente solo dos autoridades lo mencionaron espontáneamente como un problema entre las jóvenes y solo en una entrevista se mencionó la falta de información sobre sexualidad.

\footnotetext{
"Yo creo que ya las cosas ya no son pecado ... porque ya no se dejan ya, la respetan E: Fíjate que a mí se me hace muy raro, un problema muy claro que ves a una jovencita que saliera embarazada, se me hace muy raro eh porque ya tienen todo la, la ... tienen toda la ... conocimiento, tienen todo para... no caer en ese, error y a lo mejor quedar embarazada, no se fijan, ese sería el problema"
} 


\section{Cambios significativos de usos y costumbres}

\section{Comunidad}

En general consideran que ha habido muchos cambios en los usos y costumbres de sus comunidades entre los que resaltan la baja participación voluntaria en trabajos comunitarios (tequio) ya que por parte de los comuneros ha disminuido debido a diferentes factores entre los que destacan que por ley (constitucionalmente) ya no puede ser un ejercicio obligatorio como lo era antes, además han proliferado otras religiones que no respetan los usos y costumbres y finalmente porque la migración, mayoritariamente de hombres, ha incidido directamente en el número de comuneros que pueden aportar sus servicios y por ende en la economía de las familias.

\section{Participación política}

La mayoría comentó que ha aumentado la participación política de las mujeres. Incluso en una comunidad este año fue el primero en el que votaron para elegir autoridades, y en otra el primero en el que aparecieron nombres de "señoritas" en las ternas para ser electas en el cabildo.

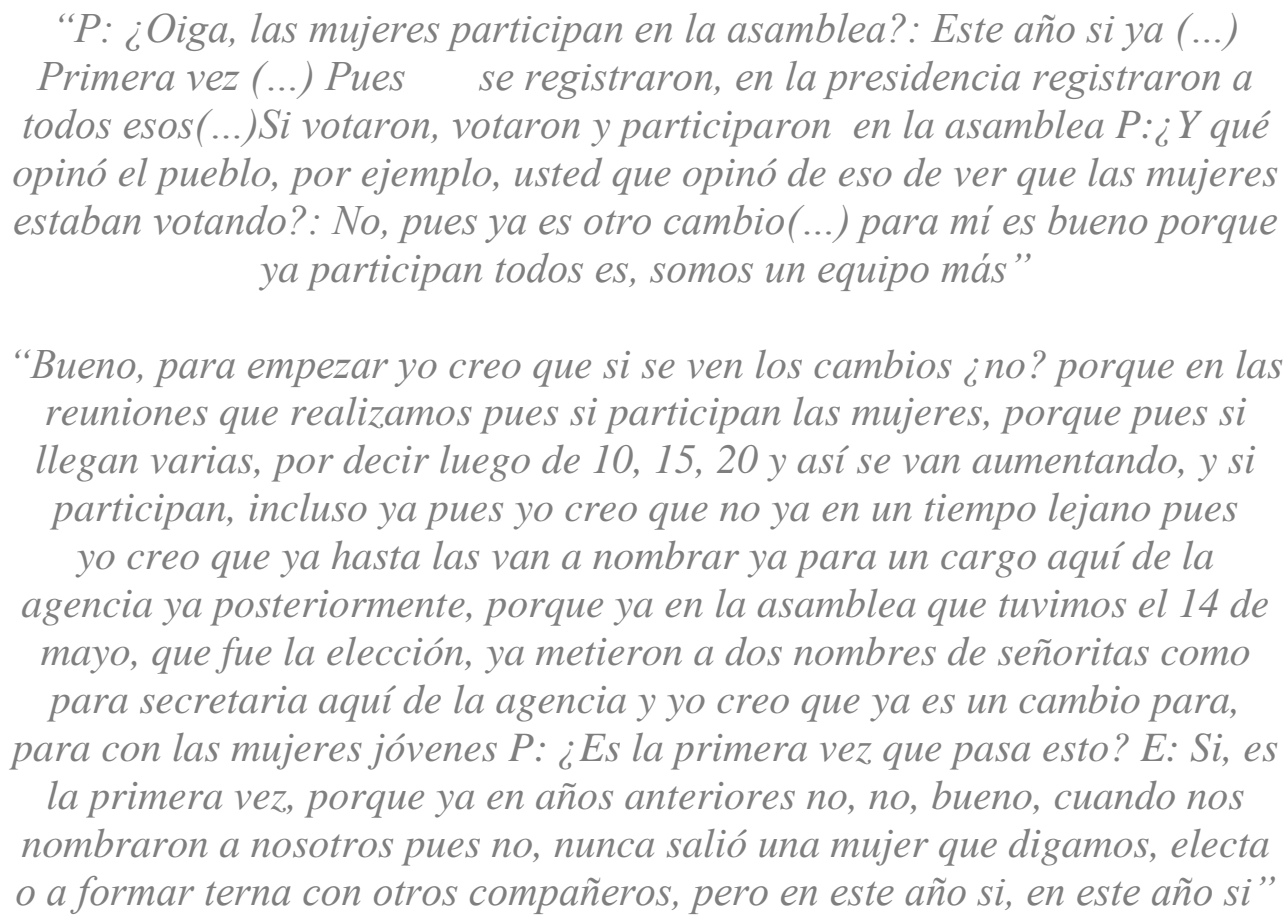

En la mayoría hay mayor asistencia a las asambleas, en algunas opinan públicamente y participan en la toma de decisiones y en contados casos ya han sido parte del cabildo.

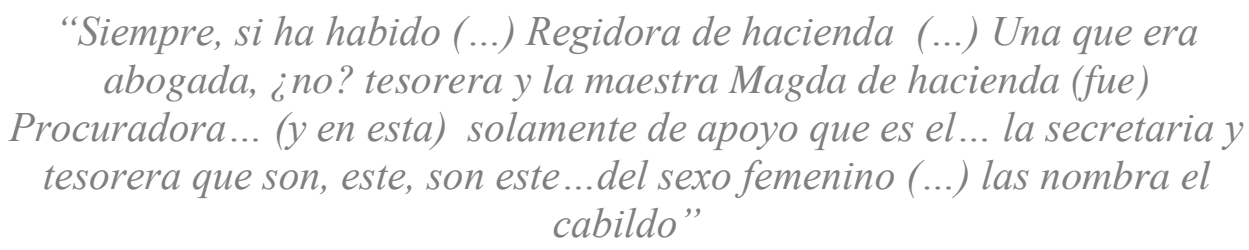

Este cambio, para la mayoría refleja mejoría e incluso hablan de la posibilidad de que próximamente asuman cargos en la presidencia o agencia municipal; sin embargo, resalta la opinión de una 
autoridad en particular que considera el incremento de la participación femenina como una desventaja para la comunidad.

“... aqui desafortunadamente aqui en (comunidad) casi las que opinan más son las mujeres que los hombres (...) Pues porque veo que a veces por falta de madurez, falta de valor, pues no sé, porque en ese sentido a veces los hombres no comentan así o comentan pero muy breve, entonces son las mujeres más, pero lo que más me extraña es que las mujeres participan más pero en las cosas malas. Por ejemplo cuando quieren desautorizar $\operatorname{algo..."}$

"P: ¿Y cómo se sentirían ustedes trabajando con una mujer en su equipo? E1: Hijole, pues no sé, a lo mejor y bien ¿no? porque pues una dama pues yo creo que no toma tanto como los hombres y son más responsables. E2: Si, tienen más responsabilidad. Más respeto. E3: No, si estuviéramos con una dama en el cabildo seria más mejor porque nosotros como compañeros y a sabemos porque ya ve como somos nosotros pero con una dama entre... entre caballeros E2: en el cabildo pues necesita uno ser más respetuoso, este, más confianza"

La mayoría comentó que los jóvenes asisten poco o no asisten a las asambleas lo que implica que no participen de la toma de decisiones de sus comunidades.

"P: ¿Y participan los jóvenes que den su opinión, que hablen? E: Pues, desgraciadamente no, pues, no, puras, este... aquí desafortunadamente aquí en (comunidad) casi las que opinan mas son las mujeres que los hombres"

También es importante resaltar que en una comunidad, las autoridades mencionaron que por primera vez se solicitó el voto a los jóvenes, los cuales votaron por primera vez en la elección del cabildo.

\footnotetext{
"P: ¿Y participan, ustedes ven jóvenes que vayan? E: Claro que si, si P: ¿Hombres y mujeres? E: Si P: ¿Y opinan? E: Si, y ahorita ya (...) Ahorita ya... por esta vez han participado más ya los jóvenes y las señoritas. Si ya han participado (...) hubo eh... comisiones donde se requería de que los que iban a pasar a votar, este tuvieran su... ya tuvieran su credencial de elector, menos no los dejaban participar..., no los dejaban este... que voten

$P:$ ¿Y por qué preferían ahora que votara la juventud? E: Esta es una decisión que se tomo aqui, realmente no se todavía, pero...'
}

\section{Educación}

En general comentan que los jóvenes tienen mayor acceso a la educación de la que ellos

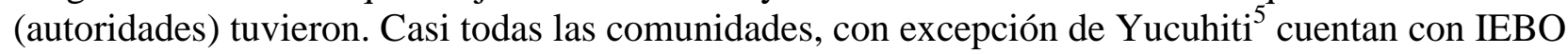
(bachillerato) y casi de manera general hombres y mujeres jóvenes concluyen sus estudios de bachillerato. Incluso un par de autoridades insistió en que actualmente la decisión de las mujeres para continuar sus estudios es más apoyada por las familias. En el caso de los hombres la deserción escolar está vinculada más a emigrar en busca de trabajo.

\footnotetext{
${ }^{5}$ Existe IEBO en la cabecera municipal a $1 \mathrm{hr}$ a pie.
} 


\section{"De unos... de unos años para acá ya cambio bastante. Ya cambio bastante esa mentalidad, ya no... ya no tienen esa mentalidad (las mujeres) de que... ya hasta acá llegue y espero al marido, espero formar un hogar, eso ya se acabo, ya tienen la mentalidad de superarse" \\ "Pues hay cambios, he visto, por ejemplo, en las escuelas con los jóvenes. Estudian más. Hombres y mujeres, hay más mujeres, porque los hombres casi salen a trabajar"}

El gran problema que enfrentan los jóvenes para continuar estudiando no son los usos y costumbres, sino los recursos económicos, en este sentido hacen hincapié en que abandonan la escuela porque la familia no puede pagar sus estudios más allá a los que tienen acceso en la comunidad y en algunos casos ni siquiera esos. En una de las comunidades mencionaron un programa de beca federal para apoyar los estudios universitarios de jóvenes y en otra que existen acuerdos a nivel estatal para que los niños no tengan que emigrar para cursar la secundaria, motivo por el cual han proliferado las telesecundarias.

\section{"Al principio del año (escolar a nivel secundaria) se anotan más, pero con el transcurso del año ya no van, dos tres por lo mismo del recurso económico del dinero"}

Un par de autoridades enfatizaron en que la educación en casa se ha descuidado ya que se deja la educación en manos exclusivamente de la escuela, eso en su opinión tiene graves implicaciones, como son la pérdida de valores comunitarios, entre los que destacan la pérdida de lengua materna, la pérdida de valores familiares, etc.

En dos comunidades las autoridades entrevistadas insistieron en la importancia de iniciar la educación en los temas tratados por Movil.com (equidad de género, violencia de género, educación sexual) desde la escuela primaria por dos motivos: uno porque los valores aprendidos de pequeños se reproducen de grandes y el otro porque los jóvenes que concluyen el IEBO generalmente emigran y lo que aprenden no tiene ningún impacto comunitario.

\footnotetext{
"Pues sí, pues sí, es bueno que se continúe. Bueno, digamos que como ya decía el comandante, es mejor que se aprenda a los de primaria para que estén más... para tengan más conocimiento pues, pues para mí que se continúe el programa..."
}

\section{La familia}

Algunas de las autoridades entrevistadas sugieren que ha habido cambios importantes en la actitud de los jóvenes, para algunas este es un cambio positivo que puede traer cambios importantes en sus familias y en la comunidad, sin embargo resalta la opinión de algunas autoridades que hicieron referencia directa a falta de respeto hacia los adultos, lo cual en su opinión se debe a que los jóvenes consideran que tener más estudios significa ser más que los adultos

\footnotetext{
"P: ¿Tiene que ver el problema con el nivel de estudio de los jóvenes? ¿Qué como estudian más se sienten más que un adulto quizá? R: Es que eso si más que una persona que a lo mejor no estudió y pues ya se quedó, digamos, más atrás que él, entonces no sé como toman eso que le pierden el respeto a esas personas"
} 
En su opinión las mujeres se casan aproximadamente entre los 18 y 20 años y los hombres entre los $20 \mathrm{y} \operatorname{los} 24$, en promedio tiene de tres o cuatro hijos.

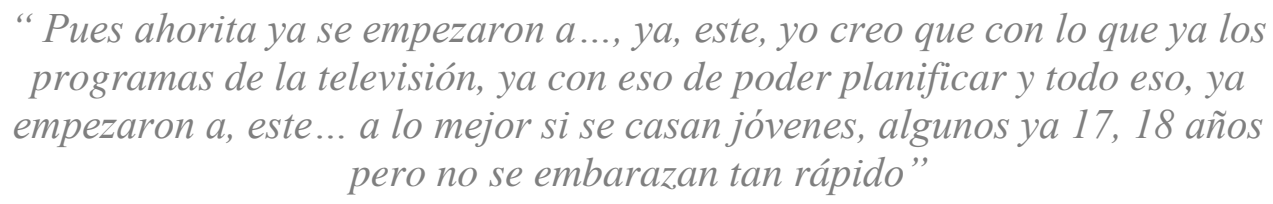

En este sentido se mencionó que existe mayor libertinaje, promovido en gran parte por la televisión, ya que los jóvenes empiezan a tener relaciones sexuales desde la secundaria. No obstante las respuestas anteriores, la mayoría piensa que a diferencia de antes ahora los hijos se planifican "ya no es como antes que cada año llegaba uno". Un par volvió a insistir en que el embarazo adolescente no es frecuente en sus comunidades, sin embargo uno de ellos recalcó que si existen madres solteras chiquitas. Otros opinaron que en sus comunidades ya no ven tan mal a las madres solteras.

“Le digo que pues, pues ya no, o sea, eso a lo mejor si sucedía... la verdad
es que en este pueblo pues casi, casi no han sido tan estricto en ese lado
(embarazo adolescente) porque si ha habido madres solteras, se les ha
apoyado, inclusive lo único que pasaba antes si era una madre soltera y no
tenía alguien que dar su servicio, por ejemplo, en la escuela de sus hijos, lo
tenía ella que dar ino? el servicio, eso era a lo mejor en parte que se
castigaba un poco a la mujer, pero también pues es parte de la
responsabilidad también de uno, pero así, verlos así de muy mal, en la
sociedad que muy mal visto, no, no sucede también”"

\section{Valores comunitarios sobre SSR}

Si bien fue un tema un poco difícil de tratar por la connotación sexual, las autoridades entrevistadas expresaron que los valores comunitarios en torno a la sexualidad han cambiado en varios sentidos, entre los que mencionaron que: aunque no de manera general, los padres ya platican con más "normalidad" de sexualidad con los hijos y que esta apertura se debe en gran medida a que en las escuelas se habla del tema. En cuanto al tema de la virginidad algunos consideran que sigue siendo importante para las mujeres y que nunca ha sido importante para los hombres, mientras otros creen que actualmente ninguno de los dos llega virgen al matrimonio.

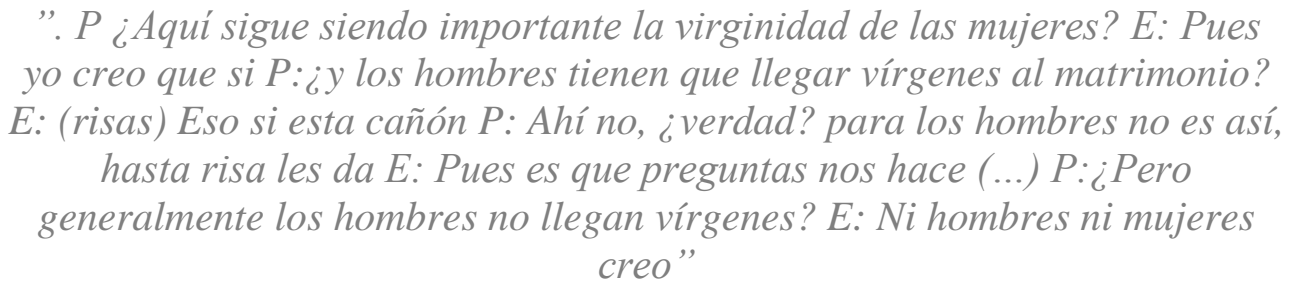

\section{Ejes temáticos}

\section{Equidad de Género}

Todos coincidieron en que en sus comunidades hay un fuerte peso de la costumbre y que los roles de género están muy arraigados. 
"Pues eso si es muy difícil, aquí, por ejemplo, aquí no trabajan las mujeres.

Se quedan en la casa (...) Si, cuidan los chicos, hacen los quehaceres de la casa, pero por ejemplo, las mujeres pueden ir al campo a trabajar, sobre todo cuando hay corte de café aquí en la zona de acá atrás, ahí si participan las mujeres, pero en otro pueblo"

Sin embargo también reconocen que los valores comunitarios al respecto han ido cambiando "hay menos machismo" y se empieza a entender que hombres y mujeres valen lo mismo y tienen los mismos derechos.

“Bueno, este, en la relación de, bueno, hablando de las personas, el cambio que se ha notado un poco es, este, que ya la gente ya no es muy, este, machista, se puede decir, ya se va quedando, pues, a un lado esa cuestión,

la gente ya entiende que la mujer tiene el mismo valor, pues, que el hombre"

Algunas autoridades reconocen que cada vez más hombres, sobre todo los más jóvenes colaboran en los quehaceres domésticos, lo cual sigue prestándose a que hablen mal de ellos, aunque la práctica empieza a normalizarse.

\footnotetext{
"Si, si, anteriormente, este, las mujeres se iban a trabajar al campo igual que un varón, este, ya ahorita ya, este, se ha cuidado mucho de ese lado la mujer, pues si se queda aquí o, este, si es exclusivamente para la casa, nada mas quehaceres de la casa, en algunos casos pues se ha notado ya también de que los varones pues participan también en la vida, en los quehaceres de la casa también'"
}

Otros comentan que cada vez más mujeres participan del gasto de la familia con pequeños trabajos remunerados, aunque la gran mayoría se desempeña en las labores de la casa y del campo. Todos coinciden en la importancia que se siga hablando del tema en sus comunidades para generar cambios en la opinión de los más jóvenes, insisten en trabajar el tema desde la escuela primaria.

\section{Violencia contra mujeres y niñas}

La opinión de las autoridades sobre el tema puede reflejarse en los tres comentarios a continuación: uno asegura que las mujeres "mandan" a diferencia de antes que le temían al marido, incluso hay quienes opinan que ellas son las que violentan a sus esposos.

"La mujer de antes que le tenía miedo al marido, ahora no, ahora al contrario somos nosotros los que les tenemos miedo, pero ya cambio. Las

mujeres mandan ahora (...) $P$ : ¿En sus casas quiénes mandan, por ejemplo? E: Este... las mujeres (...) Si, en nuestras casas, este... tenemos como maridos tenemos los mismos derechos que las mujeres"

Otro entrevistado comenta que en su comunidad se sabe que existe violencia de género pero que las mujeres no la denuncian.

\footnotetext{
"Bueno, que la gente se venga a quejar aquí, en particular las señoras en este caso, de que se vengan a quejar a la agencia casi no, pero de haberlas las hay, nosotros nos damos cuenta lo mismo con el tema de la pregunta
} 
anterior, pero eso si se da más sin querer es un tema más abierto, es un

problema más abierto, que a veces el vecino o la vecina están gritando, te

das cuenta de esa manera, de esa manera te das cuenta que ahí hay violencia intrafamiliar"

Un tercero narra la denuncia de una mujer que fue atendida por alcalde y síndico, quienes actúan como parte conciliadora.

\begin{abstract}
Sí, hay algunos que han aparecido acá sobre ese pleito matrimonial, si han aparecido acá, pero gracias a dios que pues a veces llegan para separarse pero nosotros como autoridad pues no tenemos derecho de separarlos, porque claro dice, pues, dios que lo que une él pues ningún hombre lo puede, entonces lo que tratamos aquí es darles una oportunidad de quince días y si de veras se quieren desapartar pues ya, pero luego hay unas que luego se reconcilian, pues, porque el pleito no mas es un rato y realmente es por el alcohol"
\end{abstract}

En general la violencia doméstica sigue sin denunciarse y cuando está asociada a alcoholismo algunas autoridades la minimizan, el castigo en este caso en particular es una multa y la solución que mencionaron es la conciliación de la pareja. Además es claro que las autoridades no tienen competencia para resolver o atacar la violencia de género, la única medida drástica ante un hecho de violencia es referir el caso al Ministerio Público correspondiente.

\footnotetext{
"Eh... durante el transcurso de este año un caso se ha presentado (...) Pues aquí este, dependiendo de la gravedad del asunto, en este caso pues le compete que si es alguien que haya caído en un delito pues le compete a los de la sindicatura y, este, aquí contamos también con un alcalde que es el juez, ahora sí que se puede decir que es el juez del pueblo, que en dado caso de esos problemas pues es el que media, pues, el asunto para resolverlos, y en caso del delito, ya le decía que es el síndico municipal y si está en sus manos si se puede resolver aquí y si no se manda al ministerio público."
}

\title{
Salud Sexual y Reproductiva
}

A excepción de una autoridad, todas comentaron que en sus comunidades, las clínicas o centros de salud dan pláticas/talleres sobre salud sexual para mujeres y adolescentes, además de tratar temas como alcoholismo, drogadicción entre otros. En tres comunidades se comentó que estos temas también se imparten a hombres adultos. Por lo general estas pláticas se imparten regularmente y son de carácter obligatorio ya que la asistencia condiciona el que se otorguen apoyos económicos que son de gran ayuda para la familia.

"Pues mas en las pláticas de las beneficiarias de Oportunidades y sus hijos, los que están beneficiados, mas, pero pues decimos que es un $80 \%$ de la población (...) Cuando hay cita de los hombres también acuden, no, a lo mejor no sucede en un $100 \%$, pero podemos decir un 70-80\% si sucede”

El principal problemas que enfrentan en cuanto a los servicios de salud es la falta de personal de salud o médicos pasantes, sumado en ocasiones a falta de medicamento. 
"No tenemos médico. Hay una persona que atiende alli (en el Centro de

Salud), pero yo pienso que necesita una capacitación más, más especial para que pueda ella determinar ciertos, manejar ciertos medicamentos para poder atender, por ejemplo, una mordida de animal, una quebradura, pero yo pienso que esas personas no tienen la capacidad para hacer ese tipo de

$$
\text { trabajo (...) Tenemos que salir afuera" }
$$

En casi todas las comunidades mencionaron la existencia de ambulancia para traslado de emergencias, sin embargo, no obstante en un par de comunidades mencionaron la falta de transporte adecuado (ambulancia) para traslados de emergencias, la cual se tiene que hacer en transporte del municipio o en carros particulares. Ninguno mencionó que en sus comunidades sea frecuente la muerte materna ${ }^{6}$.

$$
\begin{gathered}
\text { "P: ¿tienen ambulancia? R: No, no tenemos } P: ¿ \text { En qué trasladan a los } \\
\text { pacientes? R: En una patrulla que está al servicio de aquí" }
\end{gathered}
$$

Ante el tema de partería, algunos refirieron que desde que existen las casas y centros de salud o las clínicas, las mujeres se atienden en los servicios públicos, algunos mencionaron que es sus comunidades las parteras ya no ejercen la partería por orden de la Secretaría de Salud y en otra comentan que las parteras reciben capacitación por dicha Secretaría.

\section{Derechos humanos}

Solo tres autoridades mencionaron algo al respecto, dos en el sentido de que los usos y costumbres están muy arraigados en las comunidades y que no hay necesidad de promover los derechos humanos, la tercera comentó que en una ocasión se multó a una persona que no cumplió con sus obligaciones (tequio y asamblea) motivo por el cual éste se quejó ante el municipio. En cuanto al tema de DSyR no hubo ningún comentario.

\section{Opinión acerca de Movil.com}

En general las autoridades tenían un vago conocimiento del programa Movil.com, sin embargo la mayoría mencionaron explícitamente que el trabajo que desempeñaron favorecía al mejoramiento de la vida de los jóvenes.

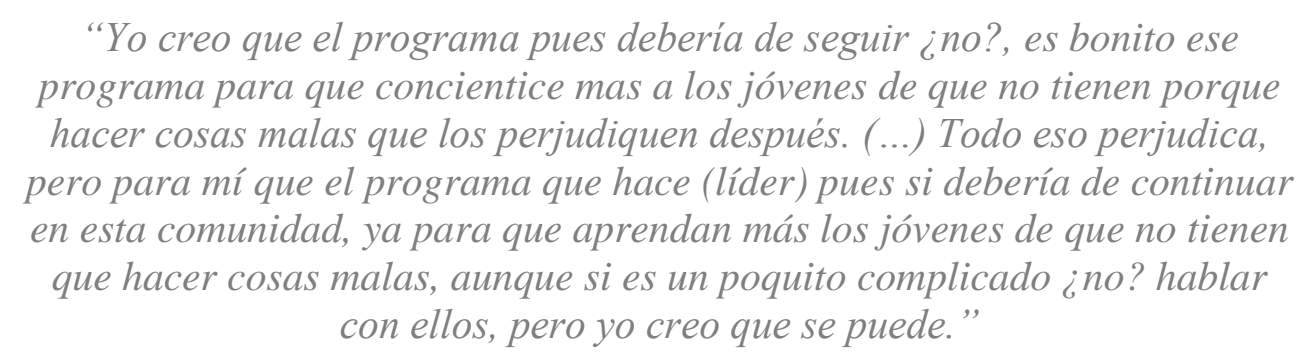

Los miembros del cabildo de una de las comunidades consideran incluso que en su comunidad nació una nueva mentalidad con el proyecto, ayudó a que los/as jóvenes a que vayan pensando más como adultos/as, que las mujeres no se embaracen a temprana edad.

\footnotetext{
${ }^{6} \mathrm{El}$ apoyo que reciben las familias se condiciona a la asistencia a platicas y revisiones periódicas, el control prenatal no es la excepción, las mujeres embarazadas están censadas y des ser posible obligadas a asistir a sus citas regularmente.
} 
En un par de comunidades también mencionaron que el programa mostró formas de convivencia" sana" y que también tuvo impacto positivo en los adultos.

"Yo creo que aquí la comunidad ya desde que empezó (líder) ya la ha apoyado porque al mandar a sus hijos ya es lo primero creo y luego como padres ven como ha trabajado (líder) ¿sabes qué hijo? ve de lo bueno y lo malo lo bueno, y de lo malo no hay que agarrar lo malo y si yo creo que la comunidad, pues como terminaron, como dijo (líder) cuando vino que iba a terminar con ese video que se hizo y no, si se llenó, se llenó bastante, casi media cancha, entonces ya ha avanzado algo"

"Pues "orita pues simplemente en este proyecto que trabajó la muchacha, pues si, gracias a dios muchos jóvenes, señores adultos, muchas personas si se acercaban al proyecto de la muchacha, según, este como del programa del punto como no sé cómo se llamaba esto, pero yo veía que si, ella cuando hacia las actividades invitaba al pueblo y si gracias a dios si venían bastantes personas a acompañarla porque eso es lo que necesita uno apoyar a la muchacha en ese proyecto pues"

Todos expresaron abiertamente el deseo de que iniciativas como esta continúen en sus comunidades y en seis casos mostraron gran interés de seguir apoyando a las líderes, ya sea con el local, con costear gastos aportar incentivos (premios) en algunas actividades, etc. Sin embargo todas coinciden en que no es posible mantener el proyecto sin ayuda exterior.

"Pues, este, nos gustaría ¿no? de que tal vez a través de jóvenes como ella se pudieran hacer eventos deportivos para nuestra juventud, pues para que ellos tengan un espacio de entretenimiento, porque si se necesita tener de jóvenes que tengan ese espíritu para que, ahora sí, que vayan ¿cómo le pudiera decir? jalando a los demás jóvenes a concentrarse a lo sano"

En un par de ocasiones las autoridades expresan abiertamente que para que el programa tenga un mayor impacto en la población debe utilizar mensajes más claros y sencillos y que las actividades que realicen tengan continuidad y no sean eventos aislados.

"Mire, nosotros aquí en la comunidad somos una comunidad de personas muy humildes con un nivel de estudios muy bajo. Yo, y a mi opinión, yo quisiera que cuando se dieran este tipo de, de este ¿cómo se dice? reuniones, sobre de ese tema, que se hablara un poco más con palabras más sencillas, mas entendibles, espero que me esté explicando, y que sean más consistente las reuniones, los eventos como le digo X: ¿Más seguidos? E: Más consistentes, más enriquecidos de palabras más comprendidas que haiga una información más amplia, que no nos reducimos, que no nos limitemos a un horario, a un tiempo de una hora que esa información para mí es muy vital, informarnos, porque usted sabe que entre más le buscamos al tema, al problema hay más información y más información se va dando,

yo es, yo quisiera, bueno, de manera particular, más personal que estos temas no se redujeran tanto a un espacio muy pequeño, que, este, yo eso pienso no, que se enriqueciera de este..., si de mas información y que sean más consistentes" 
Incluso en un par de comunidades se enfatizó que para que haya impacto comunitario sería necesario impartir los temas de Movil.com a nivel primaria

"Yo siento que desde, desde chiquitos, desde la primaria irles hablando porque el dicho muy conocido está de que pues "árbol torcido..." y si nosotros no damos atención desde cuando un niño está, está pequeño, pues así va a crecer ¿no? dependiendo, yo les decía hace rato, dependiendo en que situación esté en su casa. Si su papá es violento, pues a lo mejor de esa manera va a pensar y así piensa que son las cosas ¿no? Entonces meterle

esa idea desde niño es mucho más fácil que ir con los grandes ya en el IEBO, que a lo mejor son importantes, son temas diferentes pero, pero ya irlos... a lo mejor es aquí pues es hablar de una cosa y aquí hablar, pero pues a lo mejor serían también importantes las dos, pero yo si veo que con los más pequeños para que se vayan formando con esa idea"

En general podemos decir que en comparación a la línea base la mayoría de las autoridades estuvieron apoyando a la líder de su comunidad. Cuatro contaban con espacios seguros, uno de los cuáles era dentro del Palacio Municipal. Sin embargo es importante contrastar algunas de las opiniones de las líderes, quienes afirma que la autoridad no solo no apoyaron sino entorpecieron el programa. 


\section{Conclusiones y \\ Recomendaciones}
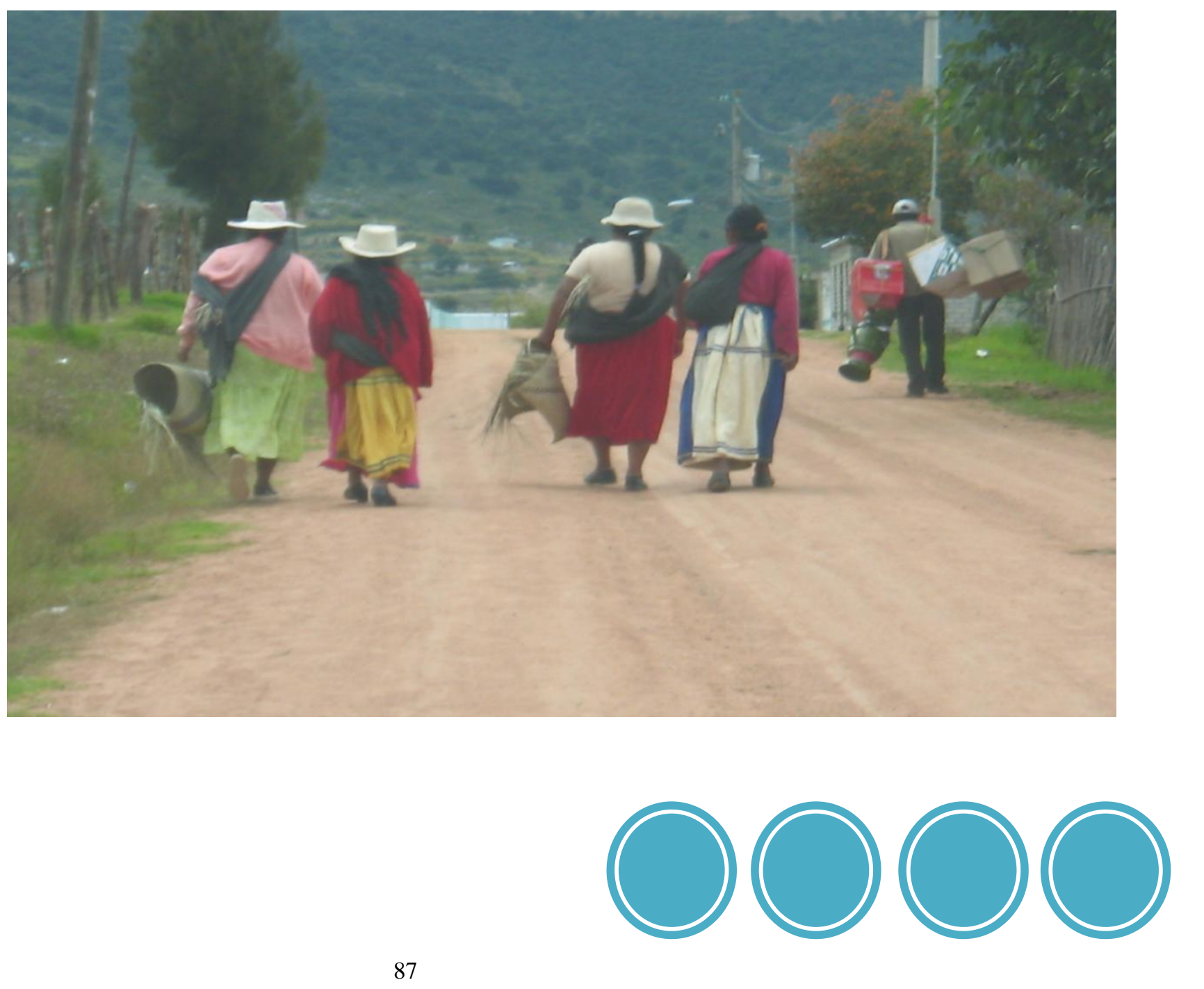


\section{Limitaciones en el diseño de la evaluación}

En un principio, nos inclinábamos por usar el diseño cuasi experimental en cuando menos tres comunidades comparativas (tal y como el Council lo hace en intervenciones de "espacios seguros"), para demostrar que los cambios positivos entre los participantes de Movil.com podían atribuirse al proyecto y no a factores externos. Este diseño es más riguroso que la comparación línea base/línea final dentro del grupo de estudio que aquí se presenta. Esta opción la discutimos extensamente con el Grupo y las colegas que coordinan el proyecto "Abriendo oportunidades" (que incluye también grupos comparativos). Sin embargo, diversas razones nos llevaron a pensar que para este proyecto no era factible incluir grupos de comparación si bien queríamos explorar esa opción en la fase a seguir.

En primer lugar, las comunidades indígenas no solamente son diversas -lo que haría de la comparación entre jóvenes un reto-; podría también dar origen a suspicacias entre personas ajenas al proyecto. El Grupo condujo un extenso proceso de tamizaje para seleccionar a las comunidades, ganarse la confianza de las autoridades y elegir a las líderes juveniles. De ahí que la aleatoriedad del proyecto Movil.com fuera logísticamente imposible y éticamente irracional. Una selección no aleatoria de comunidades a comparar plantea incluso el reto de convencer a las autoridades y a los miembros de la comunidad para que acuerden participar en algo que no les representa beneficios tangibles. Lo que es más, el Council carecía de la capacidad para ir a las comunidades donde el Grupo no tiene presencia. Este hecho nos dejó con una sola comunidad que no es Movil.com para considerar; y una comparación uno a 12 carecía de sentido.

Por otro lado, habíamos considerado el diseño de una intervención alternada que reuniera en un primer momento a seis líderes, mientras las seis restantes se convertían en grupo de comparación hasta el segundo momento, cuando se incorporarían al proyecto, tal y como se ha hecho en "Abriendo oportunidades". Sin embargo, la estructura y los recursos de proyecto impidieron acudir a esta opción. El Grupo realizó en su propia sede los seminarios mensuales de liderazgo para las 12 líderes, y no en las comunidades, por ese motivo, si la intervención se alternaba, representaba un doble trabajo para los capacitadores y también la espera durante seis meses de las otras seis líderes reclutadas y comprometidas, con una deserción que era inevitable. Otro factor era la cercanía de algunas de las comunidades entre sí, que podía dar cabida a una "contaminación" entre los lugares de intervención y los de comparación. Finalmente, acordamos que el diseño de la evaluación no contemplaría a un grupo de comparación, a pesar de lo cual incluiría medidas para una rigurosa línea base y final.

En el indicador de campañas realizadas, no ha sido posible poner el porcentaje de los aliados que lo cubrieron, debido a la gran movilidad en este grupo, ya que solo algunos de los que fueron entrevistados en la línea base permanecieron hasta la final, las respuestas cualitativas nos indican que una gran mayoría participó de las campañas pero no es posible poner un valor específico.

En lo que respecta al grupo de jóvenes es importante resaltar dos aspectos fundamentales más allá de los vacios de indicadores (ver el Cuadro 22), lo primero es que se preguntó a población abierta y anónima lo cual nos impide tener un porcentaje de los cambios en conocimientos actitudes y prácticas (CAP) de los jóvenes que respondieron y sin embargo nos proporciona una foto algo desenfocada de los CAP. No obstante resaltan el incremento del 8 al $72 \%$ de los que respondieron que una mujer pueda decidir el número de hijos y el espaciamiento entre ellos, y del 66 al $99 \%$ de los que conocen por lo menos un método para prevenir embarazos y VIH/ITS, aunque ambos valores no pueden adjudicarse de manera exclusiva al programa Movil.com. 
El plan de M\&E, siguió puntualmente el plan para medir los indicadores propuestos desde el inicio, como era de esperarse, a lo largo de la evaluación se realizaron ajustes y modificaciones en los instrumentos de recolección. Lo cual implicó en el caso de los datos cuantitativos, que no se pudieran comparar algunos indicadores de la línea base a la final, dichos valores (ver Cuadro 22) aparecen como ( $\mathrm{NP}=$ No se preguntó). En su mayoría las preguntas que no realizadas durante la línea base eran temas sensibles que pudieron abordarse en algunos casos durante la línea final, o que se abordaron desde un enfoque distinto como es el caso de "Piensan que ambos deben decidir sobre relaciones sexuales, métodos y $n^{\circ}$ de hijos" o "Piensan que no es obligatorio tener relaciones sexuales si su pareja no quiere" o "Están de acuerdo en la promoción de DH en sus comunidades".

Además después de levantar la línea base se hizo evidente la necesidad de simplificar los instrumentos para hacerlos más accesibles a los cuatro grupos (líderes, aliad@s, jóvenes y autoridades), se tuvieron que incluir o descartar preguntas para poder evaluar mejor el programa. Cabe anotar que fueron instrumentos muy extensos, lo cual si bien representa una riqueza de datos también ha implicado forzosamente tener que elegir los hallazgos más significativos y dejar de lado en este informe una gran cantidad de ellos.

Hubiera sido importante incluir los resultados de conocimientos pre y post sobre las evaluaciones temáticas de las líderes, que por acuerdo con El Grupo quedaron a su cargo, es importante pues que se agreguen a este informe. 
Cuadro 22: Tabla de indicadores CAP líderes, aliad@s y jóvenes

\begin{tabular}{|c|c|c|c|c|c|c|c|c|}
\hline \multicolumn{3}{|c|}{ Líderes } & \multicolumn{3}{|c|}{ Aliados } & \multicolumn{3}{|c|}{ Jóvenes } \\
\hline & eas & & & & & & & \\
\hline $\begin{array}{l}\text { Base } \\
n=13\end{array}$ & $\begin{array}{c}\text { Final } \\
n=9\end{array}$ & $\begin{array}{l}\text { Avance } \\
\text { Esperado }\end{array}$ & $\begin{array}{l}\text { Base } \\
n=62\end{array}$ & $\begin{array}{l}\text { Final } \\
\mathrm{n}=17\end{array}$ & $\begin{array}{l}\text { Avance } \\
\text { Esperado }\end{array}$ & $\begin{array}{c}\text { Base } \\
\mathrm{n}=270\end{array}$ & $\begin{array}{c}\text { Final } \\
\mathrm{n}=270\end{array}$ & $\begin{array}{l}\text { Avance } \\
\text { Esperado }\end{array}$ \\
\hline
\end{tabular}

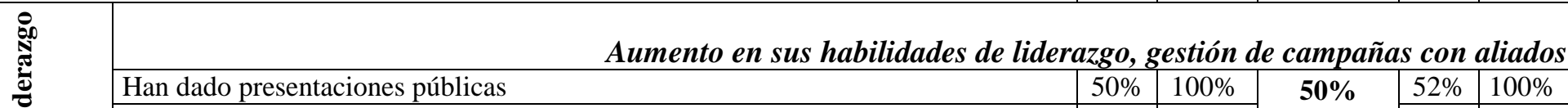

\begin{tabular}{|l|l|l|l|l|l|}
\hline Se sienten muy capaz a gestionar actividades en un grupo de pares & $30 \%$ & $100 \%$ & & $21 \%$ & $70 \%$ \\
\hline
\end{tabular}

Aumento en su conocimiento, actitudes favorables, y relaciones iguales

Piensan que hombres y mujeres deben ser tratados iguales

Piensan que una mujer tiene el derecho a decidir sobre su plan de vida

\begin{tabular}{|l|l|l|}
\hline Piensan que una mujer pueda decidir el número de hijos y el espaciamiento & $84 \%$ & $100 \%$ \\
\hline
\end{tabular}

\begin{tabular}{|l|l|}
\hline $90 \%$ & $100 \%$ \\
\hline $80 \%$ & $100 \%$ \\
\hline
\end{tabular}

Piensan que ambos deben decidir sobre relaciones sexuales, métodos $\mathrm{y}^{\circ}{ }^{\text {de hijos }}$

Han realizado una campaña sobre EG con su equipo

\begin{tabular}{|c|c|c|}
\multirow{4}{*}{$50 \%$} & $90 \%$ & NP \\
\cline { 2 - 3 } & NP & $90 \%$ \\
\cline { 2 - 3 } & $67 \%$ & $65 \%$ \\
\cline { 2 - 3 } & $75 \%$ & NP \\
\hline
\end{tabular}

$50 \%$

NA

Aumento en su conocimiento, actitudes favorables, y relaciones saludables

Conocen por lo menos un método para prevenir embarazos y VIH/ITS

Conocen la pastilla para el día siguiente

Saben dónde pueden conseguir métodos y servicios de SSR

Reportan que usan algún método "siempre o casi siempre"

Han realizado una campaña sobre SSR con su equipo

\begin{tabular}{|c|c|}
\hline $90 \%$ & $100 \%$ \\
\hline $30 \%$ & $100 \%$ \\
\hline $90 \%$ & $100 \%$ \\
\hline $1 / 1$ & $2 / 3$ \\
\hline 0 & $100 \%$ \\
\hline
\end{tabular}

\begin{tabular}{|c|c|c|}
\multirow{2}{*}{$50 \%$} & $85 \%$ & $100 \%$ \\
\cline { 2 - 3 } & $75 \%$ & $100 \%$ \\
\cline { 2 - 3 } & $76 \%$ & $100 \%$ \\
\cline { 2 - 3 } & $30 \%$ & $0 \%$ \\
\hline $\mathbf{1 0 0 \%}$ & $0 \%$ & NP
\end{tabular}

(1)

\begin{tabular}{|c|c|c|c|}
\hline \multirow{3}{*}{$30 \%$} & $91 \%$ & $91 \%$ & $\mathbf{1 0 \%}$ \\
\cline { 2 - 4 } & \multicolumn{3}{|c|}{ NA } \\
\cline { 2 - 3 } & $8 \%$ & $72 \%$ & \multirow{3}{*}{$10 \%$} \\
\cline { 2 - 3 } & $90 \%$ & NP & NA \\
\hline \multirow{2}{*}{$\mathbf{9 0 \%}$} & \multicolumn{3}{|c|}{} \\
\hline
\end{tabular}

\section{Aumento en su conocimiento, actitudes favorables para prevenir/denunciar}

Entienden el concepto y las raíces del problema

Han visto VBG en sus comunidades

Han experimentado VBG en noviazgo

\begin{tabular}{|c|c|}
\hline $70 \%$ & $100 \%$ \\
\hline $75 \%$ & $33 \% *$ \\
\hline $20 \%$ & $11 \%$ \\
\hline NP & $100 \%$ \\
\hline $80 \%$ & $100 \%$ \\
\hline $20 \%$ & $100 \%$ \\
\hline 0 & $100 \%$ \\
\hline
\end{tabular}

Piensan que no es obligatorio tener relac

Piensan que nunca es justificable

Saben dónde y cómo se puede denunciar

Que han realizado una campaña sobre VBG con su equipo

(1)

$\mathbf{5 0 \%}$

\begin{tabular}{|c|c|}
\hline $70 \%$ & $\mathrm{NP}$ \\
\hline $59 \%$ & $29 \% *$ \\
\hline $\mathrm{NP}$ & $\begin{array}{c}12 \% \\
\mathrm{n}=2\end{array}$ \\
\hline $97 \%$ & $\mathrm{NP}$ \\
\hline \multicolumn{2}{|c|}{$\mathrm{NP}$} \\
\hline $26 \%$ & $\mathrm{NP}$ \\
\hline 0 & $\mathrm{NP}$ \\
\hline
\end{tabular}

$20 \%$

\begin{tabular}{|c|c|c|}
\hline $66 \%$ & $99 \%$ & \multirow{3}{*}{$30 \%$} \\
\hline NP & $83 \%$ & \\
\hline \multicolumn{3}{|c|}{ NA } \\
\hline \multicolumn{3}{|c|}{ NA } \\
\hline
\end{tabular}

\begin{tabular}{|c|c|c|c|}
\hline \multirow{6}{*}{$30 \%$} & \multicolumn{3}{|c|}{ NA } \\
\hline & $\mathrm{P}$ & & \\
\hline & \multicolumn{3}{|c|}{ NA } \\
\hline & \multicolumn{3}{|c|}{ NA } \\
\hline & \multicolumn{2}{|c|}{ NP } & $20 \%$ \\
\hline & \multicolumn{2}{|c|}{ NP } & $20 \%$ \\
\hline $90 \%$ & \multicolumn{3}{|c|}{ NA } \\
\hline
\end{tabular}

Aumento en su conocimiento, actitudes favorables, y prácticas

Han escuchado del concepto

Saben a quién se aplican los DH/SR y porque

\begin{tabular}{|c|c|c|c|c|}
\hline $90 \%$ & $100 \%$ & \multirow{5}{*}{$50 \%$} & $85 \%$ & $85 \%$ \\
\hline $20 \%$ & $100 \%$ & & $40 \%$ & $90 \%$ \\
\hline $50 \%$ & $100 \%$ & & $50 \%$ & NP \\
\hline $20 \%$ & $100 \%$ & & $26 \%$ & $50 \%$ \\
\hline $\begin{array}{l}30 \% \\
\mathrm{n}=4\end{array}$ & $\begin{array}{l}44 \% \\
\mathrm{n}=4\end{array}$ & & $25 \%$ & $25 \%$ \\
\hline 0 & $100 \%$ & $100 \%$ & 0 & NP \\
\hline
\end{tabular}

\begin{tabular}{|c|c|c|}
\hline \multirow{5}{*}{$30 \%$} & \multicolumn{2}{|c|}{ NA } \\
\hline & \multicolumn{2}{|c|}{$\mathrm{NA}$} \\
\hline & \multicolumn{2}{|c|}{ NA } \\
\hline & NP & $20 \%$ \\
\hline & \multicolumn{2}{|c|}{ NA } \\
\hline $90 \%$ & \multicolumn{2}{|c|}{$\mathrm{NA}$} \\
\hline
\end{tabular}

Han realizado una campaña sobre DSR con su equipo

$100 \%$

0

$90 \%$ 


\section{Encuesta rápida de jóvenes que participan en las actividades de Movil.com}

En razón de los retos descritos previamente para reclutar y evaluar al tercer grupo de jóvenes, todavía queríamos encontrar la manera de recolectar mediciones básicas de CAP entre quienes participan en las actividades de Movil.com en todos los sitios del proyecto. Como estas actividades las organizan y desarrollan las líderes/equipos de aliados y no el Grupo, necesitábamos capacitar a las líderes para administrar las encuestas. Se trataba también de una oportunidad para construir habilidades en las líderes para levantar/ manejar encuestas. Investigamos varias opciones con el Grupo y acordamos que las líderes levantarían una encuesta breve con todos los participantes (15 preguntas sobre el tema de cada campaña y acerca de información socio-demográfica), justo antes del inicio de cada campaña. Si consideramos que los participantes fueron distintos en cada campaña, no podremos hacer comparaciones individuales pre/post en los temas centrales de Movil.com. Lo que ocurre más bien es que cada encuesta representa respuestas agregadas de los participantes en todos los sitios en relación con las actividades individuales. Como esta es la primera ocasión en que probamos el enfoque de manejo por parte de líderes, es posible que tengamos que revisarlo, o bien que adoptemos un mejor método si las actividades Movil.com se prolongan más allá del 2011.

Al reunir todos los hallazgos de los tres grupos primarios de Movil.com - líderes, sus aliados, los actores del ámbito comunitario (otros jóvenes y las autoridades) -, pudimos extraer varias conclusiones acerca de los conocimientos, opiniones y prácticas de la línea final. A continuación de cada una de las siguientes conclusiones, incluimos recomendaciones de carácter general, tanto para Movil.com como para el Grupo.

Al final de esta sección, analizaremos las limitaciones del diseño de evaluación y cómo podría mejorarse, ya que consideramos que dichas limitaciones han sido determinantes en las interpretaciones de nuestras conclusiones.

\section{Líderes}

En general, el programa Movil.com parece haber tenido un significativo impacto en las líderes desde su propia perspectiva. A pesar de algunos desafíos las líderes hablaron positivamente del programa y convinieron en que su participación tuvo un impacto positivo sobre sí mismas, sus familias y sus comunidades.

En particular, se perciben mejoras en sus conocimientos y habilidades en los temas claves de Movil.com: liderazgo, equidad de género, salud sexual y reproductiva, violencia basada en género, derechos humanos/derechos sexuales y reproductivos. En particular, hubo cambios importantes en la percepción de inequidad, violencia y violación de derechos sexuales y reproductivos. También consideraban que habían mejorado sus habilidades de liderazgo, en particular con respecto a la gestión de actividades y a la influencia ejercida sobre jóvenes y adultos de la comunidad. También hubo un fuerte impacto a nivel personal, cambios en sus planes para el futuro dirigidos básicamente, a retomar los estudios y en lo posible adquirir una profesión, trabajar y salir de la comunidad. No obstante la mayoría argumentó seguir colaborando en programas a favor de los jóvenes dentro o fuera de sus comunidades.

Dentro de la comunidad, muchas líderes desarrollaron exitosamente relaciones con las autoridades comunitarias y educativas. En este sentido consideramos que un apoyo más cercano desde El Grupo habría 
facilitado la construcción de estas relaciones y proporcionando credibilidad de una agencia externa que habría aclarado el propósito del proyecto y las intenciones de las líderes.

Las líderes desarrollaron la habilidad de comunicar los mensajes claves de algunos conceptos de los ejes temáticos, tales como equidad de género y derechos sexuales y reproductivos, pero no de todos, ya que mezclan conceptos básicos como equidad y violencia de género, así como derechos sexuales y reproductivos con salud sexual y reproductiva. Además persiste falta de claridad sobre la eficacia de algunos métodos para evitar embarazo, VIH e ITS.

Al final del programa, las líderes se convirtieron en "agentes" de cambio al interior de la comunidad, con muchos conocimientos sobre los distintos temas y con un liderazgo creciente, que debe aprovecharse, pero sobre todo acompañarse por parte de la organización. Es importante buscar formas de continuar el trabajo con ellas para aprovechar todo lo aprendido y por otra para no dejarlas solas en las comunidades donde ya son identificadas como "diferentes", lo cual en algunos casos ha llegado a estigmatizarlas.

Muchas retomaron estudios, la gran mayoría dejó su comunidad o estaba pensando dejarla. Lo cual se torna lógico aunque no deseable para el programa, en este sentido hay que pensar estrategias para asegurar la permanencia en la comunidad o la continuidad del programa a través de los aliados de ser posible.

Si bien no se consideró un plan de capacitación de carácter formal de las líderes hacia sus redes de aliados. La metodología se diseño de tal manera que las líderes desarrollaran sus capacidades de planeación y motivaran su creatividad a fin de generar condiciones para ir construyendo autonomía del grupo. Se propuso como estrategia que cada actividad creativa y cada "Campaña Comunitaria" fuera el resultado de un trabajo conjunto donde los aliados conocieran las temáticas a fin de hacer una planeación y ensayo previo y poder contar con los elementos necesarios para una adecuada realización de las tareas. Esta estrategia permitió que los aliados se involucraran en todo el proceso y no solo en los aspectos logísticos. Sin embargo las respuestas y opiniones de aliados y líderes, demostraron que pocas líderes compartían sus lecturas y la mayoría de aliados comentó que los capacitaban siguiendo criterios y metodologías muy diversos y dispares entre si. Por lo tanto consideramos que el no tener acceso de primera mano a dichas lecturas y documentos influyó en el aprendizaje de los temas claves del programa y que probablemente sea necesaria una planeación central sobre la forma de socializar los conocimientos. Al respecto cabe anotar confusiones importantes en los temas claves.

\section{Aliad@s}

En la línea final, el número de aliados se redujo significativamente. Se trata de un hallazgo muy importante para El Grupo en términos de la sostenibilidad del programa. Líderes y aliados sugieren que la deserción fue en gran parte debido a los compromisos de la escuela y el empleo, pero también a la falta de interés en los temas. Sería útil para El Grupo explorar a profundidad las razones de la deserción y posiblemente hacer ajustes pertinentes al programa para mantener un elevado número de aliados participando en el futuro.

Pese a lo anterior los aliados que permanecieron demostraron buena disposición para trabajar en equipo y continuar trabajando los temas por lo cual se sugiere pensar estrategias para evitar deserción, probablemente acercarlos más al proyecto hubiera permitido que por ejemplo en los casos donde las líderes desertaran alguno hubiera retomado el liderazgo.

Similares a los hallazgos con las líderes, los aliados que permanecieron en el programa creen que participar en Movil.com tuvo un impacto positivo sobre sí mismos, sus familias y comunidades. En particular, eran 
capaces de desarrollar habilidades en colaboración hacia un objetivo más amplio del proyecto. También desarrollaron habilidades en liderazgo, negociación y confianza para expresar su opinión personal. La percepción de los aliados sobre de las líderes fue totalmente positiva, las consideran modelos y convienen en que su trabajo tuvo una influencia positiva en la comunidad.

Las campañas que fueron los más exitosos desde la perspectiva de los aliados fueron las vinculadas a los temas de igualdad y violencia de género. Discutir estos temas en contextos donde se normaliza la desigualdad de violencia y sexo, en su opinión generó un impacto positivo en las percepciones de la comunidad. Dicho esto, cualquier impacto sostenible tendría que abordar las normas sociales de la comunidad y esto puede tomar más tiempo y más inversión trabajando directamente con los adultos y actores claves interesados.

Los aliados acordaron que algunos ajustes a sus formas de trabajo son necesarios para poder comunicarse adecuadamente los mensajes a sus compañeros y a la comunidad en general. Las líderes insisten en necesitar más herramientas metodológicas para poder abordar los temas ya que fue complicado transmitir los mensajes porque son temas difíciles de abordar en sus comunidades. Esto se refleja claramente en que algunos mensajes y temas claves no "bajaron", observando grandes huecos en conceptos centrales e información errónea en métodos de planificación.

Sería importante establecer un plan de trabajo específico que garantice el aprendizaje de conceptos e ideas claves, habilidades en trabajo de grupo y ciertas de liderazgo (negociar con autoridades, hablar en público, realizar intervenciones, etc.) Es decir establecer una metodología precisa para la formación de los grupos.

Faltó mayor cercanía del Grupo con los aliados y de los diferentes grupos de aliados entre si para compartir experiencias (se podrían establecer redes sociales, chats, etc. entre los aliados durante toda la formación para compartir experiencias, estrategias, etc.)

Resaltó la importancia de incluir en igualdad a hombres y mujeres a participar en el programa para resaltar la equidad en los grupos, favoreciendo la igualdad en conocimientos, habilidades y prácticas.

Un problema clave con el programa es sostenibilidad y abandono, tanto con respecto a los líderes y los aliados. Si el objetivo del proyecto es desarrollar un programa sostenible que tendrá repercusiones a largo plazo en estas comunidades, El Grupo debe seguir explorando las explicaciones de abandono del programa y estudiar mecanismos para garantizar la sostenibilidad y participación.

\section{Campañas y actividades comunitarias}

Resalta para un mejor impacto del programa, la necesidad de más eventos comunitarios, más continuos, apropiar el lenguaje al contexto comunitario, hacerlo más sencillo, abordar temas de interés para jóvenes como son alcoholismo y drogadicción, incluir a padres/madres, relacionarlos y compartirles la información sobre los temas, proporcionar la información desde nivel primaria. Ampliarlo necesariamente a toda la comunidad, ya que sucedió naturalmente la inclusión y participación desde pre-escolar hasta IEBO, hombres y mujeres, jóvenes y adultos.

Es fundamental tener presente el tipo de responsabilidades y obligaciones que adquieren las líderes en las comunidades (devolver favores) para poder apoyarlas desde la organización y tratar de evitar en la medida de lo posible que su participación en el programa sea una fuente de gasto o compromiso familiar. 
Retomar la cultura popular (música, bailes, deportes, etc.) ya que lo que tuvo mayor impacto fueron los eventos deportivos y los socioculturales

Establecer estrategias de convocatoria para los eventos y extremar cuidado en los materiales que se usan así como en la estrategia para difundir temas sensibles.

\section{Ejes temáticos}

\section{Salud sexual y reproductiva}

Fue sin duda alguna el tema más sensible a tratar en las comunidades debido a que no se habla en público y/o en privado. En este sentido y con base a los conocimientos y prácticas expresadas por líderes, aliados y jóvenes consideramos imprescindible seguirlo abordando, pensando estrategias para hacerlo accesible a hombres y mujeres de todas las edades. Tomando en consideración que debe abordarse con cautela para evitar que líderes y aliados sean señalizados o cuestionados por hablar del tema.

La mayoría habló de la educación (obligatoria) para jóvenes en temas de salud sexual y reproductiva por parte del programa de IMSS Oportunidades. Sin embargo persiste la falta de información, los problemas de acceso a servicios de salud reproductiva para jóvenes y por consecuencia las prácticas sexuales de riesgo. Al parecer el principal problema de la información que reciben es una deficiente estrategia de comunicación de los mensajes claves o del lenguaje utilizado.

Por otra parte, a partir de las percepciones de líderes y aliados sobre los valores comunitarios, al parecer las mujeres empiezan a tener un poco más el control sobre su reproducción y a decidir el número y espaciamiento de hijos.

\section{Equidad de Género}

En la línea base, las líderes tenían conocimientos limitados sobre equidad y violencia de género. La mayoría de los jóvenes en este programa identificaron relaciones no equitativas y violencia en casa y en sus comunidades.

En la línea final se describe una mayor participación de las mujeres en la vida política. Aunque se habla de mayor igualdad las respuestas refieren prevalencia de roles de género y desigualdad en el trato entre hombres y mujeres. No nos extraña encontrar que el $88 \%$ de las madres se responsabilizan del cuidado de los hijos y de las decisiones importantes de la familia, contra el 76 y $59 \%$ de los padres que asumen dichas tareas. Esto probablemente más que reflejo de crecimiento de autonomía o de igualdad una consecuencia de la migración, el abandono y/o puede reflejar el aumento de madres solteras.

En línea base la casi totalidad de las líderes consideraba que en la escuela existía trato equitativo entre hombres y mujeres, no obstante para la línea final solo un poco más de la mitad lo consideraba así, lo cual puede interpretarse como un ojo más crítico en el tema de igualdad de género y/o que la relación establecida a raíz de Movil.com con autoridades educativas y maestros fuera menos equitativa.

\section{Violencia Basada en Género}

No se reporta como un problema muy frecuente, tampoco hay instancias en las comunidades para atender a víctimas, no obstante se reconoce que persiste en sus comunidades, que generalmente no se denuncia y se resuelve en familia y rara vez por un Síndico y o Alcalde. La Violencia basada en género y el uso del alcohol están fuertemente ligados y se minimiza el agravio por alcoholismo. 
Resalta también que a lo largo de la formación líderes, de la línea base a la final refieren actos de violencia en su contra y al interior de su familia y resalta también que al inicio no la percibían como tal.

\section{Derechos Sexuales y Reproductivos}

Ninguna líder conocía estos derechos al inicio del programa, por lo referido con aliados y jóvenes de las comunidades el tema era completamente desconocido, por lo que consideramos de gran importancia continuar trabajando al respecto. 


\section{Anexos}




\section{Anexo A Instrumentos línea final: Guía para entrevista a líderes}

\section{Ficha de Identificación Personal}

No.de Líder Nombre

Fecha de entrevista Entrevistadora

Comunidad

Introducción: Hola estamos haciendo la línea final del monitoreo y evaluación del programa Movil.com queremos hablar contigo después de dos largos y exhaustivos años de trabajo, recuerda que esta entrevista no es un examen, sino un registro de tus conocimientos, percepciones, opiniones y experiencias durante este periodo. Tus respuestas sinceras y honestas, nos ayudarán a enriquecer nuestro entendimiento de tu proceso como líder, el de tus aliados y el impacto que el programa ha tenido en tu comunidad.

Muchas gracias

\section{Quién eres.}

A. Saber cómo se ven a sí mismas

B. Sondear si ha habido cambios en su auto percepción sobre el trabajo en Movil.com desde que levantamos la línea media (junio 2010)

- ¿Cómo te ves ahora qué participas en el programa?

- ¿Qué es lo que más te gusta de ti?

- ¿Qué es lo que te disgusta de ti?

- ¿Hay algo que te gustaría cambiar de ti?

- ¿Qué significa ser mujer/indígena?

\section{Liderazgo}

A. Conocer su percepción sobre su liderazgo y los cambios significativos en su rol de líder

B. Explorar necesidades en habilidades, conocimientos y recursos

- ¿Qué ha significado para ti ser líder (guía y apoyo)? ¿Ha cambiado el significado de ser líder desde que hablamos en junio 2010?

- ¿Cómo te perciben tus aliados en tu rol de líder?

- ¿Cómo te perciben tus padres/familiares desde que hablamos en junio 2010? ¿te ven más como líder que antes o igual?

- ¿Qué crees que te haya hecho falta aprender para gestionar tu grupo de Movil.com, para ser una líder ejemplar y realizar acciones efectivas?

$\bigcirc \quad$ ¿Qué habilidades?

○ ¿Qué conocimientos?:

○ ¿Qué recursos? (de tu comunidad, de tu familia y de Gesmujer)

\section{Participación en este programa}

A. Conocer la importancia del programa para la líder

B. Indagar acerca de logros, pendientes y metas desde junio 2010

- ¿Por qué seguiste como líder en Movil.com?

- ¿Cuáles eran tus metas al inicio del programa?

- ¿Cuáles (de ellas) lograste cumplir?

- ¿Cuáles quedan pendientes?

- ¿Piensas/quieres hacer algo para lograrlas, independientemente de que termina Movil.com?

\section{Plan de vida}

A. Conocer cambios en sus planes de vida desde el levantamiento de la línea media (junio 2010). Si menciona que no ha habido cambios pasar al punto VI

- ¿Cómo te imaginas en 5 años?

- ¿Cuáles son tus sueños (metas) profesionales y educativas? ¿En qué han cambiado?

- ¿Cuáles son tus metas familiares? ¿En qué han cambiado?

- ¿Ha cambiado tu decisión acerca de tener hijos o hijas? ¿Cuántos? ¿Por qué o por qué no?

- ¿Ha cambiado tu situación familiar? ¿Te casaste, vives en unión libre, estás embarazada? 
- ¿Han cambiado los obstáculos que observas para que tus planes de vida se realicen? Sí si ¿Cuáles son?

- ¿De qué manera crees que este programa te ha ayudado para que tus planes de vida se cumplan?

\section{Familia}

A. Conocer si la participación en Movil.com ha generado cambios en la relación líder/familia.

B. Conocer si se han generado cambios en el ejercicio de la toma de sus decisiones

- Desde el inicio del programa ¿Ha habido cambios en la forma en que te ve y trata tu familia?

- ¿Participas en la toma de decisiones importantes en tu familia?

- ¿Tomas tus decisiones? ( salir con tus amigos cuando quieras, seguir estudiando, tener novio, ...)

\section{Amigos y Pareja}

A. Conocer si la participación en Movil.com ha generado cambios en las relaciones de la líder con amigos y pareja.

B. Conocer si se ha generado cambios en el ejercicio de la toma de sus decisiones

- Cuéntame si además de Movil.com, desde junio 2010 ¿Participas en otro(s) grupo(s) comunitarios, deportivos, sociales, artísticos, recreativos, formativos, políticos, religiosos, etc.?

- Cuéntame ¿Cómo es la relación con tus amigos y amigas? ¿Si sigues viendo a tus viejos (as) amigos (as)? ¿Si tienes nuevos (as)? ¿Si tus amigos(as) colaboran en Movil.com y de qué manera?

- Cuéntame ¿cómo te perciben desde que eres integrante de Movil.com tus?

$\circ$ ¿Amigos?

¿ ¿Maestros?

- ¿Desde la última vez que hablamos tienes novio y/o pareja? Si no ¿Por qué?

○ Si sí ¿desde hace cuanto son novios?

$\circ$ ¿Qué hacen juntos?

○ ¿Tus padres están de acuerdo con su noviazgo?

○ ¿Cómo te ve, tu pareja, como líder en Movil.com?

- ¿A quién buscas cuando?:

$\circ$ ¿Necesitas dinero?

○ ¿En caso de una emergencia familiar?

- ¿En caso de una emergencia médica?

$\circ \quad$ ¿Con quién hablas sobre asuntos personales (sensibles)? 
VIII Movil.com

A. Conocer opinión y percepción de los distintos "aspectos" del programa: seminarios, aliados, campañas, espacio seguro, vínculos con la casa y M\&E

B. Ejemplificar con respuestas concretas sus experiencias (reseñas)

C. Conocer logros, dificultades y retos

1) Seminarios

- Piensa en los seminarios ¿Cuáles han sido?:

$\circ \quad ¿$ Tus logros?

○ ¿Tus retos?

- ¿Qué es lo que más te gustó? ¿Qué es lo que menos te gustó?

- ¿Cuál ha sido tu actividad favorita?

- ¿Tú tema favorito?

- Pensando en el trabajo durante los seminarios (formación, dinámicas, temas...) ¿Cuáles han sido?:

$\circ \quad$ ¿Tus logros?

¿ ¿Tus dificultades?

2) Aliados

¿ ¿Tus retos?

- Piensa en el grupo de aliados (formación, planeación de actividades, comunicación, participación, etc.) ¿Cuáles han sido?:

$\circ \quad ¿$ Tus logros?

$\circ$ ¿Tus retos?

3) Realizando actividades en tu comunidad a través de las campañas

- Piensa en el trabajo realizado durante las campañas por tu grupo de aliados. ¿Cuáles han sido?:

¿ ¿Tus logros?

$\circ \quad$ ¿Tus retos?

4) En cuanto las cuatro campañas (explorar cada una por separado)

- ¿Cuáles fueron los logros?

- ¿Cuáles fueron los retos?

- ¿Cuáles fueron las lecciones aprendidas?

- ¿Cuál es tu percepción general?

5) Espacio Seguro

- Cuéntame si a lo largo del proyecto ¿Lograste tener (mantener) un espacio seguro para trabajar con tus aliados?, Si sí

○ ¿Dónde está o estaba?

○ ¿Quién te lo asignó (prestó, donó, alquiló)?

○ ¿Qué utilidad le diste? ¿Cuántos días/hrs a la semana lo utilizan o utilizaron?

○ ¿Todavía lo tienes? Si sí, ¿qué vas a hacer con él?

\section{6) Relación Líder-Casa}

- Podrías contarme como fue la relación con La Casa de la Mujer (por ejemplo cuando tienes algún conflicto con las autoridades o con tus aliados, antes y/o durante el lanzamiento de campaña. ¿bajo cuales situaciones te pones en contacto con ellas? ¿Cuál ha sido su respuesta ante dichos problemas? ¿Ta han apoyado para solucionarlos? ¿De qué forma?

7) Monitoreo y Evaluación (M\&E)

- ¿Cómo fue tu experiencia en la evaluación que el Population Council hicimos a Movil.com?

- Entrevistas y cuestionarios personales

- Los grupos focales a tus aliados

- Las encuesta rápida después de cada campaña

- La entrevista con tus autoridades

IX. Tu Comunidad

A. Contextualizar Movil.com en el ámbito comunitario

- Conocer cambios importantes surgidos en la comunidad vinculados o no a Movil.com que puedan afectar directa $o$ indirectamente al programa 
- ¿Conoces algunos programas para jóvenes en tu comunidad (fuera de Movil.com)? ¿Cuáles son? ¿Cómo funcionan? por ejemplo: programas de otras ONG's, deportivos, culturales, artísticos, etc.)

- ¿Hay cambios en tu comunidad que afecten a Movil.com, como resistencia y/o apoyo de autoridades, comunidad, etc.? NUEVA

- ¿Cómo te ven a ti y a tus aliados? ¿les hacen caso? ¿los respetan?:

$\begin{array}{cl}\bigcirc & \text { Tú comunidad } \\ \bigcirc & \text { Las autoridades } \\ \bigcirc & \text { Los jóvenes } \\ \bigcirc & \text { Las jóvenes } \\ \bigcirc & \text { Las mujeres adultas } \\ \bigcirc & \text { Los hombres adultos }\end{array}$

\section{Igualdad de Hombres y Mujeres.}

A. Indagar sobre las modificaciones en percepción y opinión al respecto del tema

B. Explorar necesidades en conocimientos, habilidades, capacidades técnicas, conocimientos y recursos

C. Hablar sobre su experiencia personal

- ¿Con base en lo aprendido en Movil.com consideras que ha cambiado tu percepción sobre (EG) desde la última vez que platicamos? Si sí ¿Cómo?

- Basado en lo aprendido en Movil.com sobre EG ¿Podrías darnos ejemplos de desigualdad en tu comunidad que antes no percibías?

- En cuanto al manejo de estos temas en tu comunidad ¿cuáles fueron?:

- Tus retos

○ Tus logros

○ Las lecciones aprendidas

- Si tuvieras que seguir realizando actividades para promover la EG ¿Qué más necesitaría en cuanto conocimiento del tema y habilidades? ¿Qué te gustaría aprender?

- En tu experiencia personal

- Alguna vez te has sentído tratada de manera desigual a un hombre?

○ ¿Cómo fue?

XI. Violencia basada en género
A. Indagar sobre las modificaciones en percepción y opinión al respecto del tema
B. Explorar necesidades en conocimientos, habilidades, capacidades técnicas, conocimientos y recursos
C. Hablar sobre su experiencia personal

- ¿Con base en lo aprendido en Movil.com consideras que ha cambiado tu percepción sobre (VBG) desde la última vez que platicamos? Si sí ¿Cómo?

- Basado en lo aprendido en Movil.com sobre EG ¿Podrías darnos ejemplos de VBG en tu comunidad que antes no percibías?

- En cuanto al manejo de estos temas en tu comunidad ¿Cuáles fueron?:

○ Tus retos

- Tus logros

- Las lecciones aprendidas

- Si tuvieras que seguir realizando actividades para prevenir la VBG ¿Qué más necesitaría en cuanto conocimiento del tema y habilidades? ¿Qué te gustaría aprender?

- En tu experiencia personal

○ ¿Has visto o experimentado algún tipo de violencia?

¿ ¿Qué tipo de violencia has visto?

○ ¿Qué tipo de violencia has experimentado?

XII. Derechos Humanos/Derechos Sexuales y Reproductivas.

A. Indagar sobre las modificaciones en percepción y opinión al respecto del tema

B. Explorar necesidades en conocimientos y habilidades, capacidades técnicas, conocimientos y recursos

C. Hablar sobre su experiencia personal

- ¿Con base en lo aprendido en Movil.com consideras que ha cambiado tu percepción sobre DH y DSyR desde la última vez que platicamos? Si sí ¿Cómo? 
- Basado en lo aprendido en Movil.com sobre EG ¿Podrías darnos ejemplos de desigualdad en tu comunidad que antes no percibías?

- En cuanto al manejo de estos temas en tu comunidad ¿cuáles fueron?:

○ Tus retos

○ Tus logros

- Las lecciones aprendidas

- Si tuvieras que seguir realizando actividades para promover los DH y DSyR ¿Qué más necesitaría en cuanto conocimiento del tema y habilidades? ¿Qué te gustaría aprender?

- En tu experiencia personal

¿ ¿Has visto o conoces algún caso de violación de DH en tu comunidad?

$\circ \quad$ ¿Alguna vez han violado tus DH; DSyR y/o DJ?

- ¿Quieres contarme cómo fue?

\section{Sexualidad y Salud Sexual y Reproductiva}

A. Averiguar sobre los conocimientos adquiridos

B. Indagar sobre las modificaciones en percepción y opinión al respecto del tema

C. Explorar necesidades en conocimientos y habilidades, capacidades técnicas, conocimientos y recursos

D. Hablar sobre su experiencia personal

- ¿Con base en lo aprendido en Movil.com consideras que desde la última vez que platicamos ha cambiado tu percepción sobre?
○ Sexualidad
- Salud Sexual
- Salud Reproductiva

- Si sí ¿Cómo?

- Basado en lo aprendido en Movil.com sobre Sexualidad y SSyR ¿Podrías darnos ejemplos de los problemas relacionados a sexualidad y SSyR en tu comunidad que antes no percibías?

- En cuanto al manejo de estos temas en tu comunidad ¿Cuáles fueron?:

$\circ$ Tus retos

- Tus logros

- Las lecciones aprendidas

- Si tuvieras que seguir realizando actividades para promover la SSyR ¿Qué más necesitarías en cuanto conocimiento del tema y habilidades? ¿Qué te gustaría aprender?

- En tu experiencia personal

○ ¿Desde qué estás en Movil.com hablas con alguien sobre tu sexualidad y SSyR (uso de métodos, solicitud de pruebas ginecológicas, etc)

○ ¿Qué opinas sobre tú virginidad?

○ ¿Alguna vez te has sentido presionada a hacer algo con tu pareja que no querías? (tener relaciones sexuales, no usar anticonceptivo, etc.), ¿Por qué? y ¿Qué hiciste?

\section{Interculturalidad}
A. Averiguar sobre los conocimientos adquiridos
B. Indagar sobre las modificaciones en percepción y opinión al respecto del tema
C. Explorar necesidades en conocimientos y habilidades, capacidades técnicas, conocimientos y recursos
D. Hablar sobre su experiencia personal

- ¿Con base en lo aprendido en Movil.com consideras que desde la última vez que platicamos ha cambiado tu percepción sobre interculturalidad? Si sí ¿Cómo?

- Basado en lo aprendido en Movil.com sobre Interculturalidad ¿Podrías darnos ejemplos de los problemas relacionados a interculturalidad en tu comunidad que antes no percibías?

- En cuanto al manejo de estos temas en tu comunidad ¿Cuáles fueron?:

$\circ$ Tus retos

- Tus logros

- Las lecciones aprendidas

- $\quad$ Si tuvieras que seguir realizando actividades para promover la Interculturalidad ¿Qué más necesitarías en cuanto a conocimiento del tema y habilidades? ¿Qué te gustaría aprender? 


\section{Anexo A Instrumentos línea final: Guía para grupo focal de alid@s}

\section{Su experiencia en Movil.com}

- ¿Cuándo y cómo se integraron al grupo?

- ¿Por qué decidieron permanecer?

- ¿Cuáles fueron los retos y logros personales?

- ¿Qué les gustaría mejorar de su participación?

- ¿Qué van hacer ahora que el programa está terminado?

II. Organización como grupo aliados/líder

- ¿Con qué frecuencia se reunían?

- ¿Quién y cómo convocaba las reuniones?

- ¿Qué hacían durante las reuniones?

- ¿Cómo funcionó el trabajo aliados/líder?

- ¿Quién o quiénes tomaban las decisiones de qué, cómo, cuándo y con quién hacer las actividades?

- ¿Quién o quiénes diseñaban las actividades a realizar en la comunidad?

- ¿Quién o quiénes hablaban con las autoridades (municipales, maestros, médicos...)?

- ¿Cómo se repartían las tareas a realizar?

- ¿Cuáles fueron los retos y logros grupales?

- ¿Hubo conflictos entre ustedes? Si sí ¿Cómo los resolvieron?

- ¿Qué funcionó y qué no funcionó de la organización?

- ¿Qué y cómo podrían mejorar la organización?

III. Describan el liderazgo de XXX con relación a:

- El grupo de aliados

- Los temas a tratar en las actividades y en las campañas

- Enseñarles los temas aprendidos durante los seminarios

- Los cambios que observaron en ella.

- ¿La comunidad la reconoce como líder? Si, no. Por favor den ejemplos

- ¿Qué creen que se necesita para que la comunidad responda positivamente al su liderazgo?

IV. Cuál fue la dinámica/vínculo con Gesmujer

- Recibieron algún apoyo por parte del Grupo. Si sí ¿cuál?

V. Las cuatro campañas (EG; SSR; VBG y DH)

- ¿Qué actividades hicieron?

- ¿Quiénes y cuántos participaron?

- ¿Cuáles fueron los pros y los contras de cada una?

- ¿Cuáles fueron los retos y los logros de cada una?

- ¿Cuál fue su campaña favorita? ¿Por qué?

- ¿Cuál fue la más exitosa y cuál la menos exitosa? ¿Por qué?

- ¿Qué funcionó? y ¿Qué no funcionó?

- ¿Qué se necesitaría para lograr un mayor impacto de los temas de las campañas entre jóvenes?

- ¿Cómo fue su experiencia con las encuestas rápidas?

VI. Igualdad entre hombres y mujeres

- ¿Cómo abordaron el tema a través de Móvil.com? (ideas principales)

- Estas ideas/conocimientos les generaron cambios (actitudes, prácticas)a nivel: oPersonal ○Pareja oFamiliar

- ¿Han observado cambios a nivel comunitario en igualdad entre hombres y mujeres en el último año?

- ¿Creen que Movil.com contribuyó a generar dichos cambios? Si sí ¿Cuáles?

VII. Salud sexual y reproductiva

- ¿Cómo abordaron el tema a través de Móvil.com? (ideas principales)

- Estas ideas/conocimientos ¿Les generaron cambios (actitudes/prácticas) a nivel? 
- Personal

- Pareja

- Familiar

- ¿Han observado cambios a nivel comunitario en torno a la salud sexual y reproductiva en el último año?

- ¿Creen que Movil.com contribuyó a generar dichos cambios? Si sí ¿Cuáles?

- ¿Fue fácil o difícil abordar el tema en la comunidad?¿Por qué? Expliquen

VIII. Violencia basada en género

- ¿Cómo abordaron el tema a través de Móvil.com? (ideas principales)

- Estas ideas/conocimientos ¿Les generaron cambios (actitudes, prácticas) a nivel?

- Personal

- Pareja

- Familiar

- ¿Han observado cambios a nivel comunitario en torno a la violencia hacia mujeres y niñas en el último año?

- ¿Creen que Movil.com contribuyó a generar dichos cambios? ¿U otros? Si sí cuáles

- ¿Fue fácil/difícil abordar el tema en la comunidad? ¿Por qué? Expliquen

IX. DH/DSR

- ¿Cómo abordaron el tema a través de Móvil.com? (ideas principales)

- Estas ideas/conocimientos ¿Les generaron cambios (actitudes, prácticas) a nivel?

oPersonal

oPareja

oFamiliar

- ¿Han observado cambios a nivel comunitario en torno a los Derechos Humanos en general y a los DSyR en particular?

- ¿Creen que Movil.com contribuyó a generar dichos cambios? Si sí ¿Cuáles?

- ¿Fue fácil/difícil abordar el tema en la comunidad? ¿Por qué? Expliquen

X. Impacto Movil.com

- Su participación ¿Les cambio la relación con?

o Amigos

oFamiliares

○En la comunidad

○Con las autoridades

- Su participación comunitaria ¿Cambió?

o Asistencia a manifestaciones

o Asistencia y participación en Asamblea

o Participación en otros grupos a raíz de su participación Movil.com

- ¿Creen ahora que pueden hacer cambios positivos en su comunidad? (ejemplos)

- Si el programa continua ¿Cuáles son los retos a superar?

- ¿Qué necesitarían hacer las líderes y los aliados(as) (incluso con el apoyo de la casa) para seguir trabajando efectivamente? ¿Para mejorar el conocimiento y actitudes en la comunidad acerca de los temas abordados?

- Que debe mejorarse 


\section{Anexo A Instrumentos línea final: Guía para entrevista de autoridades}

I. Experiencia como autoridad en esta comunidad

- ¿Cuál es su formación?

- ¿Cuáles son los proyectos prioritarios mientras sea autoridad?

II. Proceso de tomar decisiones políticas en su comunidad

- Asamblea (elección de presidente municipal y cabildo)

- Sistema de cargos

- Actores claves

- Participación de mujeres

- Participación de jóvenes hombres/mujeres (mayores de 18años)

III. Usos y Costumbres de su comunidad

- ¿Cuáles son los cambios más visibles (ejemplos) en cuanto a la relación que se establece entre hombres y mujeres? (sondear EG)

- Los roles y participación de hombres y mujeres dentro de:

$\circ$ La familia

○La escuela

oLa comunidad

oLa asamblea

oLos cargos políticos (comunitario y municipal)

$\circ$ Las oportunidades laborales

○El trabajo comunitario (beneficios/compensación)

- La relación entre adultos (hombres y mujeres) y jóvenes (hombres y mujeres)

- Los líderes (hombres y mujeres) de la comunidad

- Hay jóvenes líderes ¿hombres/mujeres?

○Si sí, ¿Qué hacen?

$\circ$ ¿Cómo son vistos (as) por la comunidad?

$\circ$ ¿Como las tratan?

- Educación

$\circ$ ¿Los valoran, los respetan?

- El acceso a trabajo

- La migración

IV. Cambios significativos

- ¿Cuál es su opinión sobre esos los cambios?

V. Problemas y necesidades de salud entre hombres/mujeres (adultos, jóvenes y niños)?

- ¿Por qué?

- ¿Qué se hace para resolverlos?

- ¿Quién lo hace?

- ¿Ustedes como autoridad qué hacen para resolverlos?

VI. Servicios, recursos y políticas públicas para promover la salud sexual y reproductiva en la comunidad en general y en los jóvenes de su comunidad (Nota explicar con ejemplos de SSR porque el término no se entiende)

- ¿Cuáles han sido los avances?

- ¿Cuáles han sido las dificultades?

- ¿Qué cree que se necesita para mejorar la situación de salud sexual y reproductiva?

VII. Mortalidad materna

- ¿Con qué frecuencia ocurren casos de mortalidad materna en su comunidad?

- ¿Cuáles son las principales causas?

- ¿Qué hacen las autoridades frente a la mortalidad materna?

- ¿Qué hace la comunidad frente a la mortalidad materna?

- ¿A dónde refieren a una mujer embarazada con complicaciones? ¿tiempo, distancia? ¿forma de transporte?

VIII. Usos y Costumbres sobre salud sexual y reproductiva 
- Platíqueme un poco los Usos y Costumbres en su comunidad sobre algunos aspectos de salud sexual y reproductiva ¿Qué permanece? ¿Cuáles son los cambios más visibles? En cuanto: (

○ Virginidad de hombres y mujeres

- Inicio de vida sexual para hombres y mujeres,

- Planificación familiar y/o uso de anticonceptivos ¿quién decide cuándo y cuántos hijos tener? ¿quién decide el uso de anticonceptivos?

- Embarazo adolescente y embarazo fuera del matrimonio

- Uso de anticonceptivos y preservativos en jóvenes (hombres y mujeres)

IX. Violencia hacia mujeres y niñas

- ¿Queremos saber si en su comunidad existe violencia hacia mujeres y niñas? (Ejemplos)

- ¿Es una práctica común/frecuente? ¿Igual que antes o menos?

- ¿Cómo ve la comunidad la violencia hacia mujeres y niñas? ¿"normal” o no?

- ¿Qué hacen las mujeres que sufren violencia?

○ Denuncian

- Dejan a la pareja

- ¿Qué hace la autoridad ante una situación de violencia?

○ Denuncia ante instancias municipales/estatales

- Castiga/multa

- Lleva a cabo juntas de reconciliación a la pareja

- ¿Ha habido cambios en los últimos años? ¿Cuáles? (ejemplos)

X. Servicios, recursos y políticas públicas para promover derechos humanos para todos y para mujeres/niñas en particular.

- ¿Cuáles son los avances?

- ¿Cuáles son las dificultades?

- ¿Qué cree que se necesita para mejorar la situación de DH en cuánto políticas públicas? ¿servicios? ¿información?

XI Necesidades de los jóvenes en general y de las mujeres jóvenes

- Principales necesidades que usted percibe en cuanto:

- Educación,

- Trabajo

○ Oportunidades

XII. Ha oído hablar del programa Movil.com

- ¿Cuál es la relación que ha tenido con la Casa de la Mujer? (reuniones, llamadas, visitas)

- ¿Qué sabe? ¿Cómo ven las autoridades y la comunidad la propuesta Movil.com?

- ¿Conoce a los integrantes del programa? ¿Cuál es su opinión sobre ( la líder)?

- ¿Ha asistido a las campañas que han hecho?

○ ¿Qué opinión tiene de ellas?

○ ¿Cuál le gustó más/cuál menos? ¿por qué?

- ¿Qué le parece que hablen de:

- Equidad de Género

- Violencia Basada en Género

- Salud Sexual y Reproductiva

- Derechos Humanos

- ¿Qué opinión tiene sobre el programa?

○ Ventajas/desventajas,

- Pros/contras,

- Logros

- ¿Ha visto cambios en los jóvenes desde el arranque de Movil.com? (ejemplos)

- ¿Qué tan positivo/negativo ha sido el programa?

- ¿Qué necesita para que sea más efectivo?

- Están colaborando con el programa ¿De qué forma lo apoyan?

XIII. Continuidad de Movil.com

- ¿Les gustaría que Movil.com siga realizándose en su comunidad? ¿Por qué?

- En caso de que continuara ¿quieren seguir colaborando? Si, no ¿Por qué?

- Si sí ¿De qué manera podrían apoyarlos? (incluirlo en el gasto comunitario, municipal) 


\section{Anexo A Instrumentos línea final: $4^{\circ}$ Encuesta Rápida}

\section{Introducción:}

Hola, soy parte del equipo de movil.com. Hoy, vamos a empezar nuestra primera actividad para jóvenes como tú. Antes queremos saber un poco más acerca del conocimiento que los jóvenes entre 15 y 25 años de (Nombre de la comunidad) tienen sobre los temas que vamos a abordar.

¿Tienes 5 minutos para responder a unas preguntas? Tus respuestas son completamente anónimas y confidenciales. Gracias

NOTAS:

1) SI TIENE ENTRE 15 Y 25 AÑOS CONTINUAR, SI NO DAR LAS GRACIAS Y BUSCAR A OTRO PARTICIPANTE

2) NO LEER EN NINGUNA PREGUNTA LAS RESPUESTAS

\section{Datos del participante}

Hablante de lengua indígena: $\square \mathrm{Sí} \uparrow \square$ No $\uparrow$

Si sí, ¿Cuál?

Sexo: Mujer $\uparrow$ Hombre $\uparrow$

Edad: __ años

Ultimo nivel de escolaridad: $\square$ Ninguno $\square$ Primaria 4 Secundaria $\uparrow \square$ Preparatoria o bachillerato

\section{Conocimiento sobre Movil.com}

2.1 ¿Alguna vez, has oído algo de movil.com?

$\square$ Sí $\square$ No

2.2Si sí, ¿Qué es lo que sabes de este proyecto? (Indica todas las opciones que conoce y de ser necesario agrega otras)

$\uparrow \square$ Nombre de la líder

$\uparrow-$ Forma de organizarse

Organización que dirige movil.com

- Objetivos del proyecto

Otro (s)

\section{Es la primera vez que participas en una actividad de Movil.com?}

$\square$ Sí $\square$ No

4. Si no, ¿Cuáles han sido las otras? ¿Podrías mencionar los nombres de las campañas?

Ni más ni menos ¡hombres y mujeres valemos lo mismo! (equidad de género)

$\mathrm{X}$ ti $\mathrm{x}$ mi me informo y decido (salud y derechos SyR

Yo te amo, tú me amas, nos respetamos (Violencia en el noviazgo)

Otro tipo de actividad dirigida por Movil.com:

\section{De qué manera has participado}

Asistiendo a talleres/ pláticas

En eventos deportivos

Proyección de películas

Apoyando en la planeación de eventos

En la planeación, organización y realización de las Campañas Comunitarias

6. ¿Qué es lo que más te ha gustado del trabajo realizado por Movil.com? 


\section{Salud Sexual y Reproductiva}

7.1 ¿Me puedes nombrar por lo menos un método de planificación familiar para prevenir embarazos no deseados?

Condón masculino $\square$ Condón femenino $\square$ Implantes $\square$ Pastillas $\square$ DIU

Otro (s):

No sabe o no contestó

7.2 ¿Me puedes nombrar por lo menos un método para prevenir infecciones transmitidas sexualmente así como VIH/SIDA?

$\square$ Condón masculino $\square$ Condón femenino $\square$ Implantes $\square$ Pastillas $\square$ DIU
$\square \begin{aligned} & \text { Otro (s): } \\ & \text { No sabe o no contestó }\end{aligned}$

7.3 ¿En tu opinión, ¿Qué tan frecuentes son los embarazos en jóvenes en esta comunidad?

Muy frecuentes

Más o menos frecuentes

No frecuentes/casi nunca ocurren

No sabe o no contestó

7.4 La anticoncepción de emergencia (PAE) es un método que debe utilizarse

Inmediatamente después de una relación sexual no protegida

Cuando no llega el periodo menstrual

\section{Derechos Sexuales y Reproductivos}

8.1 ¿Alguna vez has oído hablar de derechos sexuales y reproductivos?

Sí $\square$ No

8.2 ¿Qué tan capaz te sientes para poder exigir que se cumplan tus derechos sexuales y reproductivos ante de las autoridades, medico/a?

$\square$ Muy capaz $\square$ Más o menos capaz $\uparrow \quad \square$ No muy capaz $\square$ Nada capaz

8.3 ¿El acceso a los anticonceptivos es un derecho de las y los jóvenes?

Sí $\square$ No

8.4 Es un derecho que a las y los jóvenes les proporcionen métodos anticonceptivos en las clínicas y centros de salud.

Siempre $\square$ Solo si están casados

8.5 En tu opinión ¿quién debe tomar la última decisión sobre cuántos hijos tener y cuándo?

Mujer $\square$ Hombre $\square$ En pareja (ambos) $\square$ Médico $\square$ Otro (s):

8.6 En tu opinión ¿quién debe tomar la decisión sobre cuándo debe empezar su vida sexual una mujer joven?

$\square$ Ella misma $\square$ Su pareja $\uparrow \square$ En pareja (ambos) $\square$ Sus padres $\square$ Otro (s):

8.7

a) En tu opinión el hombre tiene derecho a exigir el uso de un método anticonceptivo a su pareja

$\square \mathrm{Si} \square \mathrm{No}$

b) En tu opinión la mujer tiene derecho a exigir el uso de un método anticonceptivo a su pareja

$\square$ Si $\square$ No 


\section{Equidad de Género}

9.1 En tu opinión, ¿quién debe tomar las decisiones en la relación de pareja?

Hombre

Mujer $\square$ En pareja (ambos)

Otro (s):

9.2 En tu opinión, ¿los hombres merecen más respeto y reconocimiento que las mujeres?

$\square$ Sí $\square$ No $\square$ No sabe o no contestó

9.3 ¿En tu experiencia, se valoran igual a los hombres y las mujeres en tu comunidad?

$\square$ Sí $\square$ No $\square$ No sabe o no contestó

9.4 Participar en las decisiones de la comunidad es un derecho de las y los jóvenes

Solo si eres hombre y tienes más de 18

Mujeres y hombres mayores de 18

Hombres y mujeres casados sin importar la edad

10 Violencia Basada en Género

10.1 ¿En tu opinión, crees que la violencia (física o sexual) hacia mujeres y niñas es un problema en esta comunidad?

$\begin{array}{lll}\text { Sí } & \square \text { No } & \square \text { No sabe o no contestó }\end{array}$

10.2 ¿Alguna vez, has visto violencia física o sexual hacia una mujer o niña en esta comunidad?

$\square$ Sí $\square$ No $\square$ No sabe o no contestó

10.3 Durante el noviazgo, se dice que hay violencia si existen:

Celos, empujones, pellizcos, golpes

Control en la forma de vestir, te castiga dejándote de hablar

Todas las anteriores

\section{Liderazgo}

11.1 En tu opinión las autoridades y comunidad toman en cuenta las necesidades y puntos de vista de los jóvenes

$\uparrow$ Sí $\quad \uparrow$ No $\quad \uparrow \quad$ No sabe o no contestó

11.2En tu opinión ¿los jóvenes pueden lograr cambios políticos, culturales, sociales en esta comunidad?
$\uparrow$ Sí
$\uparrow \quad$ No
$\uparrow \quad$ No sabe o no contestó 


\section{Anexo A instrumentos línea final: Cuestionario (líderes y aliad@s)}

\section{Ficha de identificación personal}

Nombre

Escolaridad

Fecha de encuesta

Encuestadora

Buen día

éste cuestionario explora tus conocimientos, percepciones, opiniones, experiencias y cambios ocurridos desde junio 2010 (cuando lo respondiste por última vez) acerca de tu trabajo, el de tus aliados, el de la Casa de la Mujer y el del Population Council. Recuerda que no es un examen y que todas las respuestas son buenas. El objetivo de hacerte nuevamente éstas preguntas es poder evaluar y monitorear el desarrollo del programa Movil.com. Te recordamos que es un ejercicio personal para el cual te pedimos respuestas claras y sinceras, que no comentes las respuestas con tus compañeras y que te sientas con la libertad de expresar tus opiniones.

\begin{tabular}{|c|c|c|c|c|}
\hline Pregunta & Respuesta & & & \\
\hline \multicolumn{5}{|c|}{ I LIDERAZGO (AUTO EVALUACIÓN) } \\
\hline \multirow{9}{*}{$\begin{array}{l}\text { 1. En cuanto a las habilidades de } \\
\text { liderazgo adquiridas en Movil.com ¿Cómo } \\
\text { te evalúas ahora comparado con el inicio } \\
\text { del proyecto para?: } \\
\text { (una respuesta para cada habilidad) }\end{array}$} & & Más capaz & Igual & Menos capaz \\
\hline & Gestión de actividades con aliados & & & \\
\hline & Planeación de actividades con aliados & & & \\
\hline & Escribir informes & & & \\
\hline & Persuadir a jóvenes & & & \\
\hline & Persuadir a adultos & & & \\
\hline & Levantar una encuesta & & & \\
\hline & Hacer entrevistas y o encuestas con miembros de tu comunidad & & & \\
\hline & Otra(s) & & & \\
\hline
\end{tabular}




\begin{tabular}{|c|c|c|c|c|c|c|}
\hline \multirow{6}{*}{\begin{tabular}{|l} 
Pregunta \\
$2 . \quad$ ¿Cuántas presentaciones has \\
hecho desde junio 2010 en Movil.com? Si \\
sí has hecho presentaciones (escribe una \\
respuesta para una) y especifica los \\
temas tratados en cada una
\end{tabular}} & \multicolumn{6}{|l|}{ Respuesta } \\
\hline & & & Número & Tema de presentación & & \\
\hline & \multicolumn{6}{|c|}{ Durante el Seminario } \\
\hline & \multicolumn{6}{|c|}{\begin{tabular}{|l|} 
Con tu grupo de aliados \\
\end{tabular}} \\
\hline & \multicolumn{6}{|c|}{ En la campaña Movil.com } \\
\hline & \multicolumn{2}{|c|}{ Otro } & & & & \\
\hline \multirow[t]{2}{*}{$\begin{array}{l}\text { 3. ¿Has hecho otras presentaciones } \\
\text { públicas fuera del proyecto Movil.com } \\
\text { desde junio 2010? }\end{array}$} & $\mathrm{Si}$ & \multicolumn{5}{|c|}{$\begin{array}{l}\text { ¿Dónde? } \\
\text { ¿Con que propósito? }\end{array}$} \\
\hline & No & & & & & \\
\hline \multirow{9}{*}{$\begin{array}{l}4 . \quad \text { En cuanto a la lista de habilidades } \\
\text { en liderazgo ¿Cuáles son las que } \\
\text { quieres/necesitas desarrollar? } \\
\text { (una respuesta para cada habilidad) }\end{array}$} & & & & & Si desarrollar & No desarrollar \\
\hline & \multicolumn{4}{|c|}{ Gestión de actividades con aliados } & & \\
\hline & \multicolumn{4}{|c|}{ Planeación de actividades con aliados } & & \\
\hline & \multicolumn{4}{|c|}{ Escribir informes } & & \\
\hline & \multicolumn{4}{|c|}{ Convencer y motivar a jóvenes } & & \\
\hline & \multicolumn{4}{|c|}{ Convencer y motivar a adultos } & & \\
\hline & \multicolumn{4}{|c|}{ Levantar una encuesta } & & \\
\hline & \multicolumn{4}{|c|}{ Hacer entrevistas con miembros de la comunidad } & & \\
\hline & \multicolumn{4}{|c|}{ Otra(s) especifica } & & \\
\hline
\end{tabular}




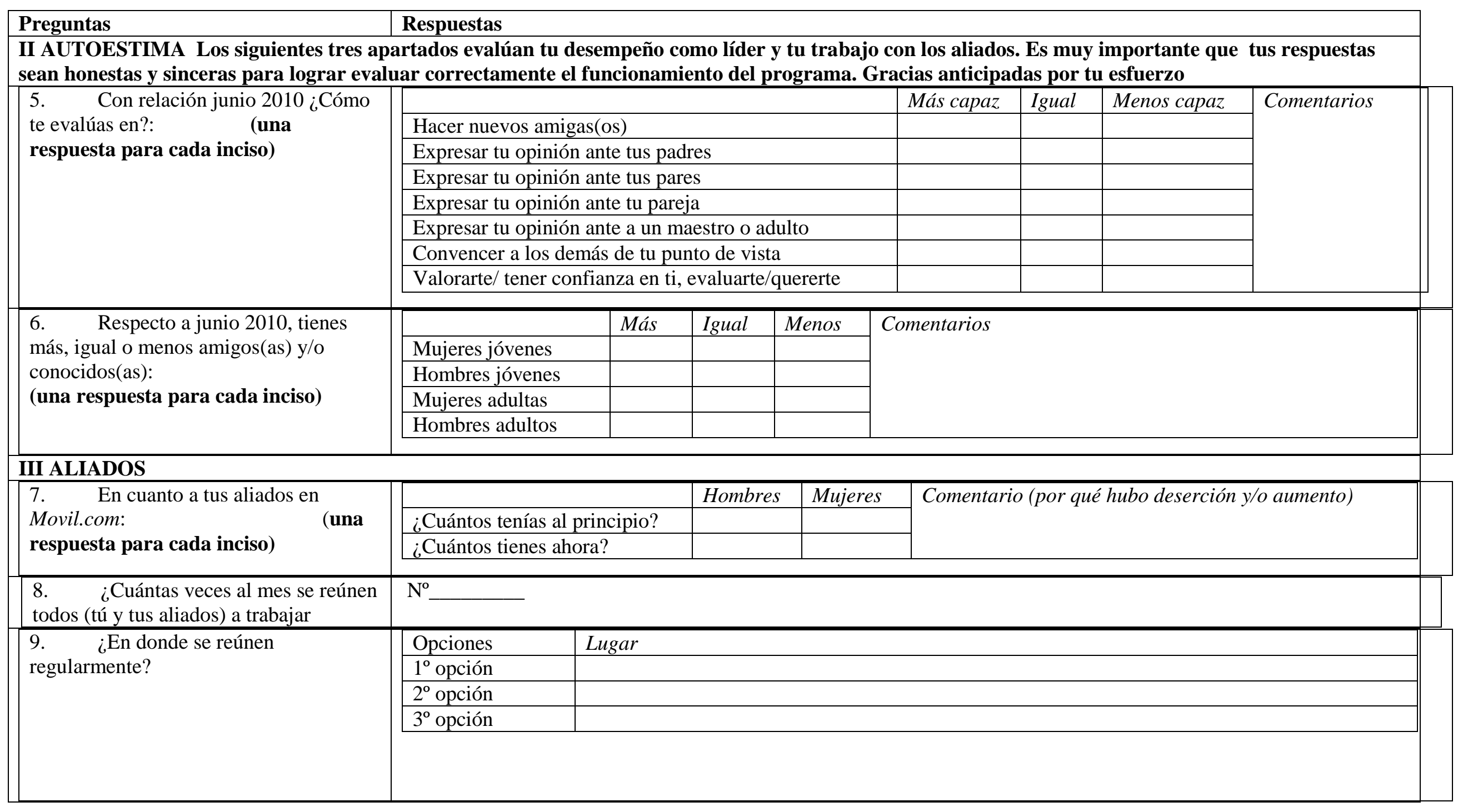




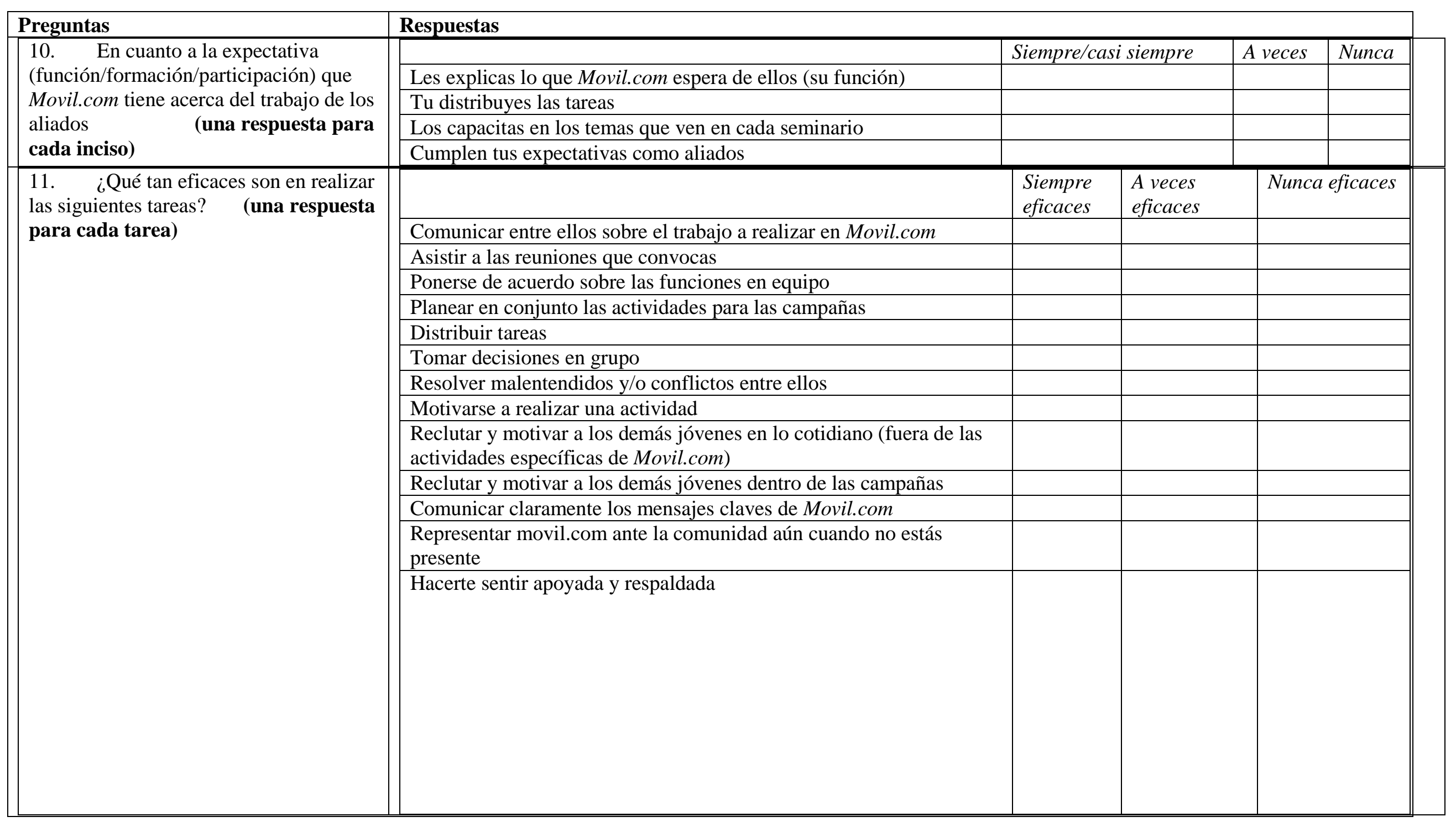




\begin{tabular}{|c|c|c|c|c|c|c|}
\hline Preguntas & Res & uestas & & & & \\
\hline 12. Si tienes hombres en tu equipo & & & No & $\mathrm{Si}$ & Comentarios & ¡cuáles? ¿Cómo? ¿Por qué? \\
\hline (una respuesta para cada inciso) & & $\begin{array}{l}\text { abres y mujeres } \\
\text { n tareas diferentes }\end{array}$ & & & & \\
\hline & & $\begin{array}{l}\text { eres y Hombres } \\
\text { onden igual a tu } \\
\text { cazgo }\end{array}$ & & & & \\
\hline IV ESPACIO SEGURO & & & & & & \\
\hline 13. En cuanto a espacio seguro (una & & & & & $\overline{S i}$ & No ¿Por qué?/¿Con quién? \\
\hline respuesta para cada inciso) & & $\begin{array}{l}\text { utoridad asignó espa } \\
\text { il.com }\end{array}$ & seg & Iro pa & & \\
\hline & & in lugar adecuado pa & sus a & tivid & des & \\
\hline & & xclusivo para Movil & & & & \\
\hline & & $\begin{array}{l}\text { spacio seguro ha can } \\
\text { ezó el programa }\end{array}$ & ado $c$ & esde & & \\
\hline $\begin{array}{l}\text { 14. Si tienen espacio seguro indica } \\
\text { ¿dónde se ubica? }\end{array}$ & & & & & & \\
\hline V .1 SALUD SEXUAL Y REPRODUCTIV & (SSI & & & & & \\
\hline $\begin{array}{l}\text { 15. En tu opinión, ¿Cuál crees que es el } \\
\text { principal problema de SR para los jóvenes en } \\
\text { tu comunidad? }\end{array}$ & & & & & & \\
\hline 16. En tu opinión, ¿qué tan frecuente es & & Frecuencia & & & Comentarios & \\
\hline el problema de embarazos en jóvenes en tu & 1 & Muy frecuente & & & & \\
\hline comunidad? (Una sola respuesta) & 2 & Más o menos frecu & & & & \\
\hline & 3 & No muy frecuente & & & & \\
\hline & 4 & No es un problema & ra na & & & \\
\hline & 5 & No se & & & & \\
\hline & 6 & No respondió & & & & \\
\hline
\end{tabular}




\begin{tabular}{|c|c|c|c|c|c|c|c|}
\hline \multirow{3}{*}{$\begin{array}{l}\text { Preguntas } \\
17 . \quad \text { ¿Desde que empezó Movil.com has } \\
\text { recibido educación sexual de algún otro lugar } \\
\text { y/o persona? } \\
\text { y si es sí especifica) }\end{array}$} & \multicolumn{7}{|c|}{ Respuestas } \\
\hline & 1 & $\mathrm{Si}$ & \multicolumn{5}{|l|}{$\begin{array}{l}\text { ¿Dónde? } \\
\text { ¿Quién te la dio? } \\
\text { ¿De qué te hablaron? }\end{array}$} \\
\hline & 2 & No & & & & & \\
\hline \multicolumn{8}{|l|}{$\begin{array}{l}\text { 18. ¿A dónde acuden mujeres y hombres } \\
\text { de tu comunidad para recibir información y } \\
\text { servicios sobre salud sexual y reproductiva }\end{array}$} \\
\hline \multirow{15}{*}{$\begin{array}{l}\text { 19. Podrías indicar si los métodos para } \\
\text { prevenir embarazos son muy efectivos, más o } \\
\text { menos efectivos, no efectivos: (también } \\
\text { puedes no contestar (NC) o no saber (NS) } \\
\text { (una respuesta para cada inciso) }\end{array}$} & \multicolumn{3}{|c|}{ Método } & Muy efectivo & $\begin{array}{l}\text { Más o menos } \\
\text { efectivo }\end{array}$ & No efectivo & $\mathrm{NC} / \mathrm{NS}$ \\
\hline & \multicolumn{3}{|c|}{ No tener relaciones sexuales } & & & & \\
\hline & \multicolumn{3}{|c|}{ Condón femenino } & & & & \\
\hline & \multicolumn{3}{|c|}{ Condón masculino } & & & & \\
\hline & \multicolumn{3}{|c|}{ Hormonales (pastillas, inyectables, parches) } & & & & \\
\hline & \multicolumn{3}{|c|}{ Diu } & & & & \\
\hline & \multicolumn{3}{|c|}{ Pastillas anticonceptivas de emergencia } & & & & \\
\hline & \multicolumn{3}{|c|}{ Ritmo } & & & & \\
\hline & \multicolumn{3}{|c|}{ Coito interrumpido } & & & & \\
\hline & \multicolumn{3}{|c|}{$\begin{array}{l}\text { Tomar un medicamento inmediatamente después } \\
\text { de tener sexo no protegido ¿cuál(es)? }\end{array}$} & & & & \\
\hline & \multicolumn{3}{|c|}{ No tener más de una pareja a la vez } & & & & \\
\hline & \multicolumn{3}{|c|}{$\begin{array}{l}\text { Bañarse inmediatamente después de haber tenido } \\
\text { sexo no protegido }\end{array}$} & & & & \\
\hline & \multicolumn{3}{|c|}{ Tomar té o infusión de hierbas } & & & & \\
\hline & \multicolumn{3}{|c|}{ Lavados vaginales con infusión de hierbas } & & & & \\
\hline & \multicolumn{3}{|c|}{ Otro(s) } & & & & \\
\hline
\end{tabular}




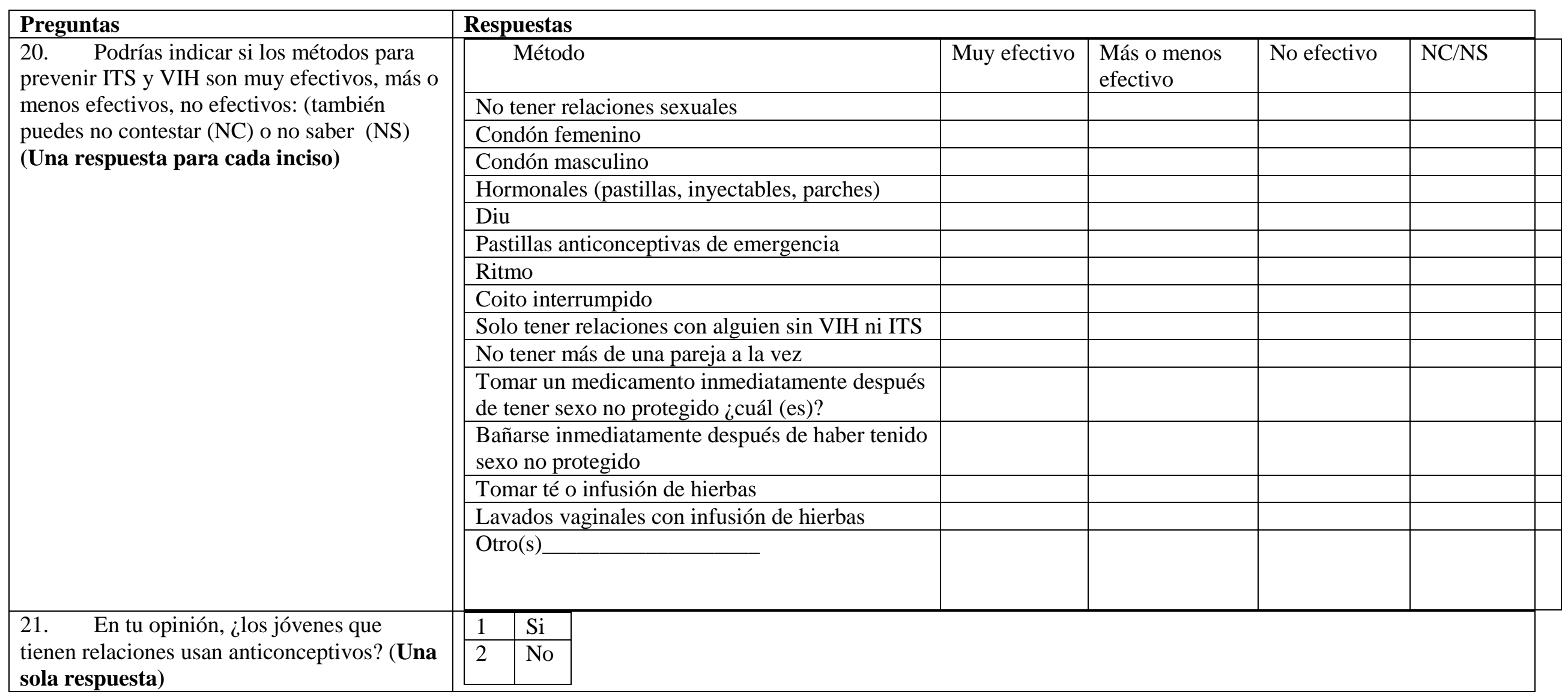




\begin{tabular}{|c|c|c|c|c|c|}
\hline Preguntas & & Respuestas & & & \\
\hline 22. ¿Con qué frecuencia los usan? (Una & & Métodos modernos & $\mathrm{Col}$ & itarios & \\
\hline sola respuesta) & 1 & Muy frecuente & & & \\
\hline & 2 & Más o menos frecuen & & & \\
\hline & 3 & No muy frecuente & & & \\
\hline & 4 & No es un problema pa & nada & & \\
\hline & 5 & No se & & & \\
\hline & 6 & No respondió & & & \\
\hline 23. ¿Dónde encuentran los jóvenes & & Lugares & & $\overline{\mathrm{Con}}$ & ntarios \\
\hline métodos anticonceptivos en tu comunidad? & 1 & Farmacias & & & \\
\hline (Puede haber más de una respuesta) & 2 & Clínicas/Centro de s & & & \\
\hline & 3 & Partera y/o médico t & dicional & & \\
\hline & 4 & Tiendas & & & \\
\hline & 5 & No hay & & & \\
\hline & 6 & Otro: & & & \\
\hline & 7 & Parteras y/o médicos & adicionales & & \\
\hline & 8 & No se & & & \\
\hline 24. Desde julio 2010 te has sentido & & & Más cómoda & Igual & Menos cómoda \\
\hline $\begin{array}{l}\text { (más/igual o menos cómoda) al buscar } \\
\text { información en tu comunidad sobre: } \\
\text { (Una respuesta para cada inciso) }\end{array}$ & & $\begin{array}{l}\text { vicios de SSR (ej. } \\
\text { iconceptivos, } \\
\text { firmación } \\
\text { barazo...) }\end{array}$ & & & \\
\hline & & $\begin{array}{l}\text { lebas ginecológicas } \\
\text { r ej. Papanicolao, } \\
\text { isiones) }\end{array}$ & & & \\
\hline & & $\begin{array}{l}\text { y VIH (pruebas de } \\
\text { vención) }\end{array}$ & & & \\
\hline
\end{tabular}




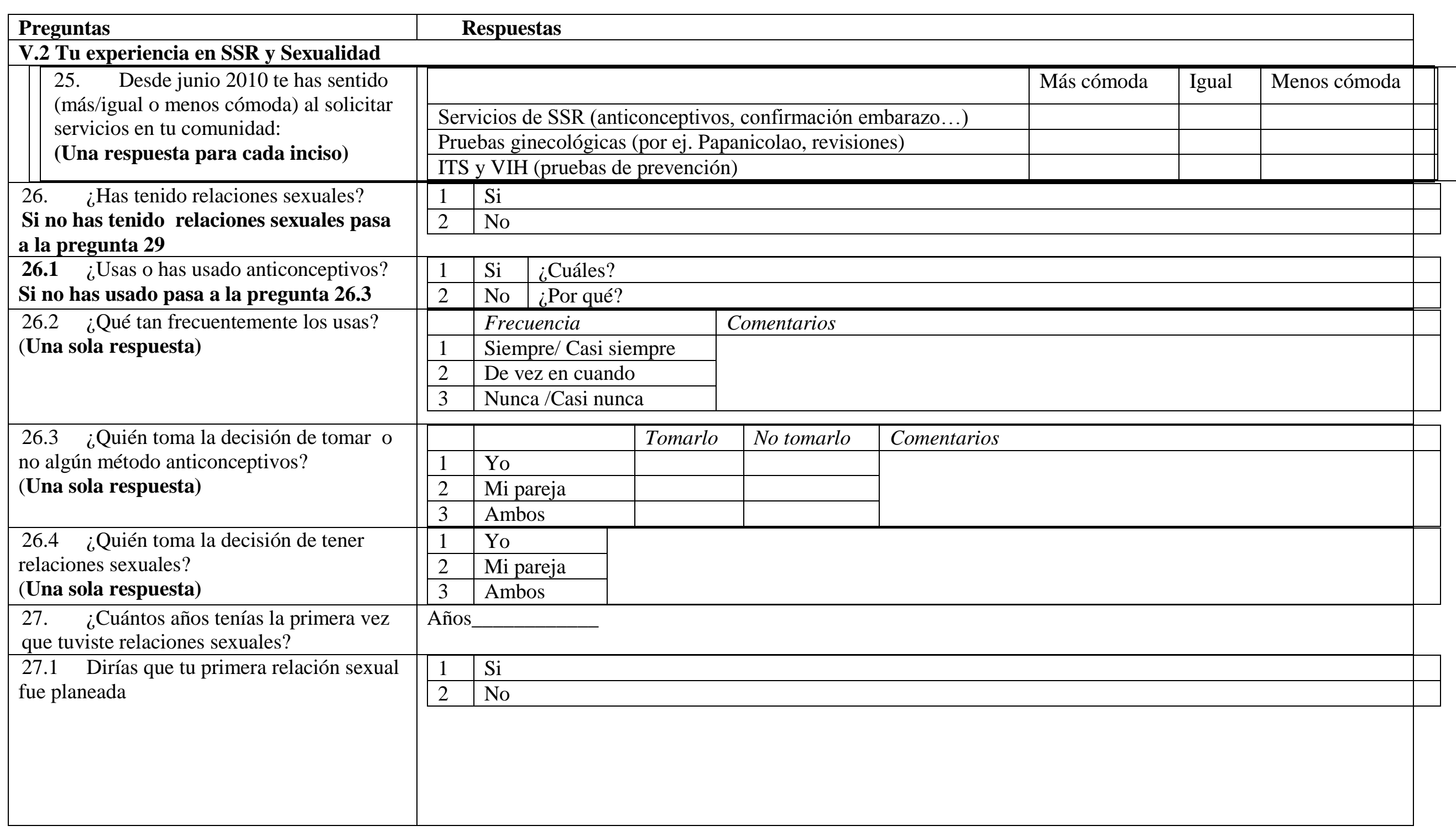




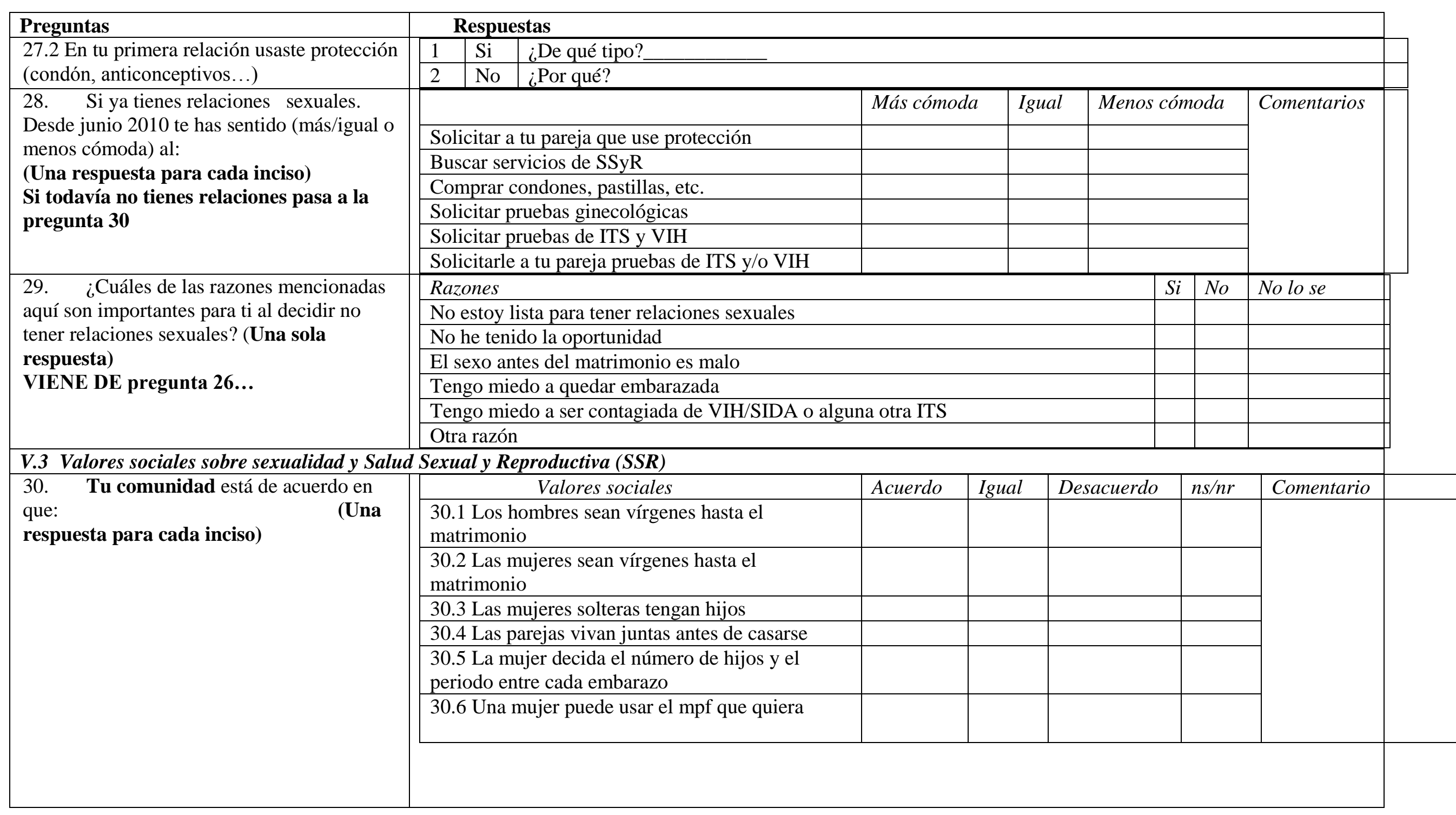




\begin{tabular}{|c|c|c|c|c|c|c|c|c|}
\hline \multirow{2}{*}{\multicolumn{2}{|c|}{\begin{tabular}{|l|l} 
Preguntas & \\
V.4 Valores personales sobre sexualidad y $S S R$
\end{tabular}}} & \multicolumn{7}{|c|}{ Respuestas } \\
\hline & & \multirow{2}{*}{\multicolumn{2}{|c|}{ Valores personales }} & & & & & \\
\hline \multirow[t]{7}{*}{$\begin{array}{l}31 . \quad \text { ¿Estás de acuerdo en que?: } \\
\text { (Una respuesta para cada inciso) }\end{array}$} & & & & Acuerdo & Igual & Desacuerdo & $\begin{array}{l}N S \\
N R\end{array}$ & Comentario \\
\hline & \multicolumn{3}{|c|}{$\begin{array}{l}\text { 31.1 Los hombres deben ser } \\
\text { vírgenes hasta el matrimonio }\end{array}$} & & & & & \\
\hline & \multicolumn{3}{|c|}{$\begin{array}{l}31.2 \text { Las mujeres deben ser vírgenes } \\
\text { hasta el matrimonio }\end{array}$} & & & & & \\
\hline & & \multicolumn{2}{|c|}{$\begin{array}{l}\text { 31.3 Las mujeres solteras tengan } \\
\text { hijos }\end{array}$} & & & & & \\
\hline & & \multicolumn{2}{|c|}{$\begin{array}{l}\text { 31.4 Las parejas vivan juntas antes } \\
\text { de casarse }\end{array}$} & & & & & \\
\hline & \multicolumn{3}{|c|}{$\begin{array}{l}31.5 \text { La mujer decida el número de } \\
\text { hijos y el periodo entre cada } \\
\text { embarazo }\end{array}$} & & & & & \\
\hline & \multicolumn{3}{|c|}{$\begin{array}{l}\text { 31.6 Una mujer puede usar el } \\
\text { método anticonceptivo que quiera }\end{array}$} & & & & & \\
\hline \multicolumn{9}{|l|}{ V.5 Aborto Inducido } \\
\hline \multirow{5}{*}{$\begin{array}{l}\text { 32. ¿Cuál es tu opinión sobre el } \\
\text { aborto inducido? (elige sólo una opción) } \\
\text { (Una sola respuesta) }\end{array}$} & 1 & \multicolumn{7}{|c|}{ Debe ser prohibido en todos los casos } \\
\hline & 2 & \multirow{2}{*}{\multicolumn{7}{|c|}{ Debe ser permitido en algunas circunstancias ¿Cuáles? }} \\
\hline & 3 & & & & & & & \\
\hline & 4 & \multicolumn{7}{|c|}{ No se } \\
\hline & 5 & \multicolumn{7}{|c|}{ No respondió } \\
\hline \multicolumn{9}{|l|}{$\begin{array}{l}\text { 33. ¿Si una mujer en tu comunidad } \\
\text { necesita obtener un aborto, a donde va? }\end{array}$} \\
\hline \multirow{2}{*}{$\begin{array}{l}\text { 34. ¿Has oído hablar de } \\
\text { cytotec/misoprostol }\end{array}$} & 1 & $\mathrm{Si}$ & \multirow{2}{*}{\multicolumn{6}{|c|}{ Comentarios ¿qué has oído? }} \\
\hline & 2 & No & & & & & & \\
\hline
\end{tabular}




\begin{tabular}{|c|c|c|c|c|c|c|c|c|}
\hline Preguntas & Respuestas & & & & & & & \\
\hline VI IGUALDAD ENTRE HOMBRES Y M & JERES & & & & & & & \\
\hline 35. En tu comunidad las mujeres $\mathbf{y}$ & & $S i$ & $\mathrm{No}_{i} \mathrm{Pc}$ & qué? & & & No se & $N R$ \\
\hline hombres jóvenes ¿reciben el mismo & En la casa & & & & & & & \\
\hline trato? & En la escuela & & & & & & & \\
\hline respuesta para cada inciso) & En la vida cotidiana & & & & & & & \\
\hline & En el trabajo & & & & & & & \\
\hline & En las actividades religiosa & & & & & & & \\
\hline & En el sistema político & & & & & & & \\
\hline VI.1 Relaciones intrafamiliares y roles de & énero & & & & & & & \\
\hline 36. ¿Estás de acuerdo en que? & & & Acuerdo & Igual & Desacuerdo & $N S / N R$ & Comentc & \\
\hline (Una respuesta para cada inciso) & $\begin{array}{l}\text { 36.1 La mujer pueda escoger sus amistades } \\
\text { aunque al esposo/pareja no le gusten }\end{array}$ & & & & & & & \\
\hline & 36.2 El hombre debe administrar el dinero & & & & & & & \\
\hline & $\begin{array}{l}\text { 36.3 La mujer casada puede escoger su propio } \\
\text { plan de vida }\end{array}$ & & & & & & & \\
\hline & $\begin{array}{l}\text { 36.4 La mujer soltera puede escoger su propio } \\
\text { plan de vida }\end{array}$ & & & & & & & \\
\hline & $\begin{array}{l}\text { 36.5 La mujer debe responsabilizarse del } \\
\text { cuidado de los hijos (as) }\end{array}$ & & & & & & & \\
\hline & $\begin{array}{l}\text { 36.6 Es obligación de la mujer tener relacione } \\
\text { sexuales con su pareja/novio aunque ella no } \\
\text { quiera }\end{array}$ & & & & & & & \\
\hline & $\begin{array}{l}36.7 \text { Estás de acuerdo en que la mujer u } \\
\text { hombre expresen libremente su preferencia } \\
\text { sexual (hetero o gay) }\end{array}$ & & & & & & & \\
\hline
\end{tabular}




\begin{tabular}{|c|c|c|c|c|c|c|c|c|c|c|c|c|c|c|}
\hline \multirow{3}{*}{$\begin{array}{l}\text { Preguntas } \\
37 . \quad \text { En tú experiencia, con tu pareja o } \\
\text { familia } \\
\text { respuesta para cada inciso) }\end{array}$} & \multicolumn{14}{|c|}{ Respuestas } \\
\hline & & & \multicolumn{3}{|c|}{ Pareja } & \multicolumn{3}{|c|}{ Papá } & \multicolumn{3}{|c|}{ Mamá } & \multicolumn{3}{|l|}{ Tú } \\
\hline & & & $\mathrm{Si}$ & No & $\begin{array}{l}\text { NS } \\
\text { NR }\end{array}$ & $\mathrm{Si}$ & No & $\begin{array}{l}\mathrm{NS} \\
\mathrm{NR}\end{array}$ & $\mathrm{Si}$ & No & $\begin{array}{l}\text { NS } \\
\text { NR }\end{array}$ & $\mathrm{Si}$ & No & $\begin{array}{l}\text { NS } \\
\text { NR }\end{array}$ \\
\hline & & $\begin{array}{l}\text { Puedes escoger tus } \\
\text { stades aunque a tu pareja o a } \\
\text { padres no les gusten }\end{array}$ & & & & & & & & & & NA & NA & NA \\
\hline & & $\begin{array}{l}\text { Puedes salir con tus } \\
\text { stades sin pedir permiso a tu } \\
\text { ja o a tus padres }\end{array}$ & & & & & & & & & & NA & NA & NA \\
\hline & & $\begin{array}{l}\text { Tú, tu pareja o padres se } \\
\text { onsabilizan de todos los } \\
\text { os de la familia }\end{array}$ & & & & & & & & & & & & \\
\hline & & $\begin{array}{l}\text { Quién (es) administra(n) el } \\
\text { ro de tu casa }\end{array}$ & & & & & & & & & & & & \\
\hline & & $\begin{array}{l}\text { Quién (es) toma (n) las } \\
\text { siones importantes de tu } \\
\text { ilia }\end{array}$ & & & & & & & & & & & & \\
\hline & & $\begin{array}{l}\text { Quién (es) se responsabiliza } \\
\text { del cuidado de sus hijos(as) } \\
\text { iene) y/o hermanos (as) }\end{array}$ & & & & & & & & & & & & \\
\hline \multicolumn{15}{|l|}{ VII. VIOLENCIA BASADA EN GÉNERO } \\
\hline \multirow{6}{*}{$\begin{array}{l}\text { 38. En tu percepción/experiencia } \\
\text { ¿qué tan frecuente es la violencia (golpes, } \\
\text { amenazas, forzadas a tener relaciones } \\
\text { violación... ) hacia mujeres/niñas en tu } \\
\text { comunidad? (Una sola respuesta) }\end{array}$} & \multicolumn{3}{|c|}{ Frecuencia } & \multicolumn{11}{|c|}{ Comentarios } \\
\hline & 1 & \multicolumn{2}{|l|}{ Muy frecuente } & & & & & & & & & & & \\
\hline & 2 & \multicolumn{2}{|l|}{ Más o menos frecuente } & & & & & & & & & & & \\
\hline & 3 & \multicolumn{2}{|l|}{ No muy frecuente } & & & & & & & & & & & \\
\hline & 4 & \multicolumn{2}{|l|}{ No es un problema para nada } & & & & & & & & & & & \\
\hline & 5 & \multicolumn{2}{|l|}{ No se } & & & & & & & & & & & \\
\hline
\end{tabular}




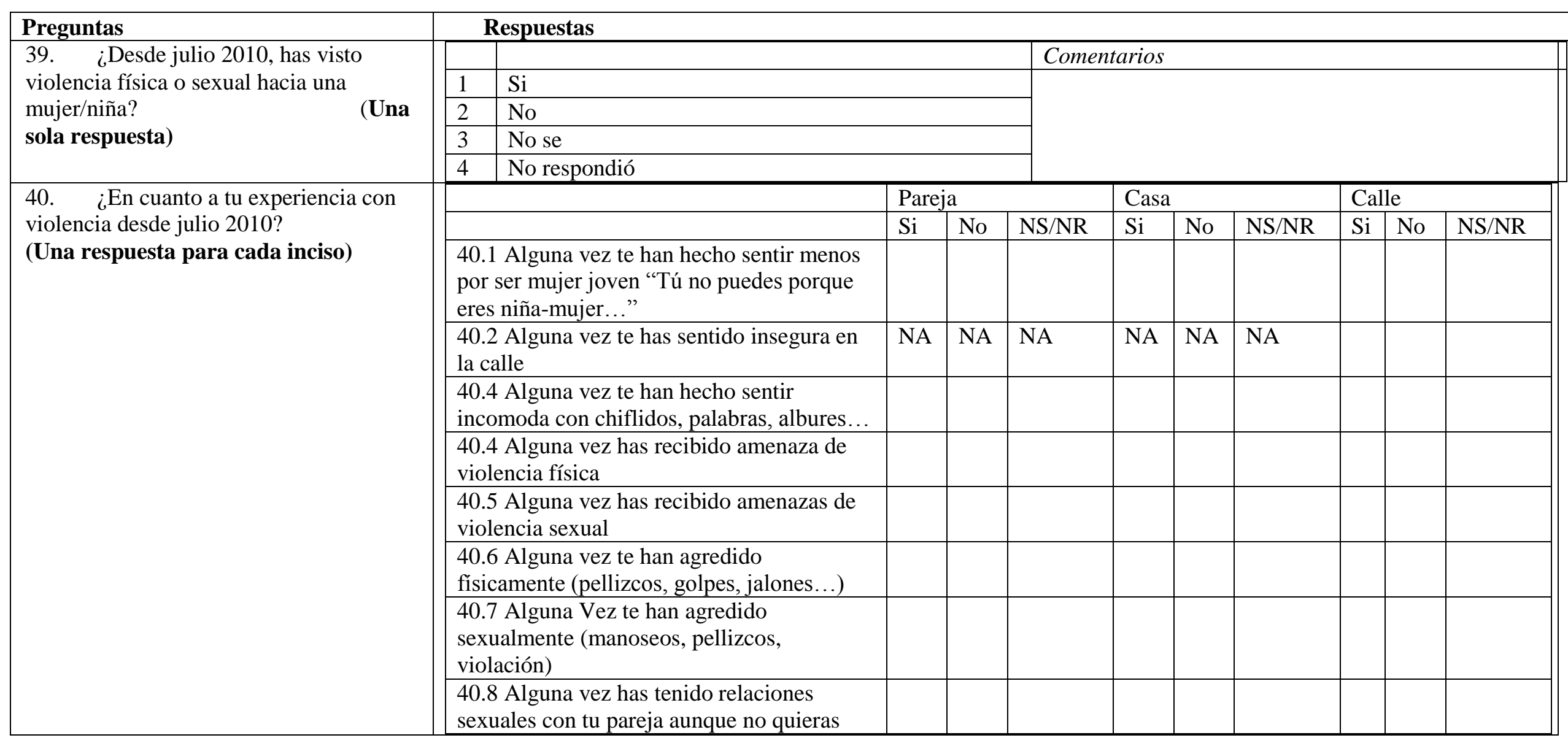




\begin{tabular}{|l|}
\hline Preguntas \\
\hline $41 . \quad$ Desde junio 2011, en tu \\
comunidad, ¿hay servicios que atiendan a \\
mujeres que han experimentado violencia \\
física, emocional, sexual y/o económica? \\
(Una sola respuesta)
\end{tabular}

\section{DERECHOS HUMANOS}

42. ¿Cuáles son los derechos

humanos que conoces?

(Puede haber más de una respuesta)

43. ¿Crees que la aplicación de derechos humanos podría causar problemas con los usos y costumbres en tu comunidad? ¿de qué forma? sola respuesta)

(Una

44. ¿Desde julio 2011 te has sentido discriminada (por ser mujer, mujer indígena, joven)? (Si la respuesta es sí, platícame un poco como fue)

(Una sola respuesta)

\begin{tabular}{||l|l|l||}
\hline \multicolumn{2}{|l|}{ Respuestas } \\
\hline & \multicolumn{1}{|c|}{ Comentarios } \\
\hline 1 & $\mathrm{Si}$ & \\
\hline 2 & No & \\
\hline 3 & No se & \\
\hline 4 & No respondió & \\
\hline
\end{tabular}

\begin{tabular}{|c|c|c|}
\hline 1 & \multicolumn{2}{|c|}{ Derecho a la libertad de pensamiento y religión } \\
\hline 2 & \multicolumn{2}{|c|}{ Derecho a la salud } \\
\hline 3 & \multicolumn{2}{|c|}{ Derecho a la igualdad } \\
\hline 4 & \multicolumn{2}{|c|}{ Derecho a la no discriminación } \\
\hline 5 & \multicolumn{2}{|c|}{ Derecho a la vida } \\
\hline 6 & \multicolumn{2}{|c|}{ Derecho a la libertad de opinión y expresión de ideas } \\
\hline 7 & \multicolumn{2}{|c|}{ Derecho a casarte y a decidir el número de hijos que deseas } \\
\hline 8 & \multicolumn{2}{|l|}{ Otro especifica } \\
\hline & & Comentarios si si de qué forma \\
\hline 1 & $\mathrm{Si}$ & \\
\hline 2 & No & \\
\hline 3 & No se & \\
\hline 4 & No respondió & \\
\hline & & Comentarios \\
\hline 1 & $\mathrm{Si}$ & \\
\hline 2 & No & \\
\hline 3 & No se & \\
\hline 4 & No respondió & \\
\hline
\end{tabular}




\section{Anexo B: \\ Consentimiento informado líderes}

Hola __estamos llegando a la recta final del proceso de monitoreo y evaluación de Movil.com, en nombre del Population Council quiero agradecer tú participación a lo largo de este par de años en éste proceso. Iniciamos el levantamiento de la línea final, para la cual estamos solicitando nuevamente tu colaboración en responder un cuestionario y una entrevista, así como en concertar citas con autoridades y tus aliados

La entrevista y el cuestionario exploran tus conocimientos, percepciones, opiniones y experiencias durante los dos años de trabajo en Movil.com, acerca de tu trabajo, el de tus aliados, el de la Casa de la Mujer y el del Population Council, así como el impacto que el programa ha tenido en tu comunidad. No es un examen, todas las respuestas son buenas siempre que sean sinceras. El objetivo de hacerte estas preguntas es aprender más acerca de la puesta en marcha de Movil.com para poder apoyarlas y lograr que pueda lograr sus metas.

Vamos a grabar la entrevista, ten la seguridad de que todo lo que platiquemos será privado y confidencial. En ningún lado se asocia tu nombre a tus respuestas.

Me gustaría que respondieras a todas las preguntas que puedas, y si es necesario tomar una pausa solo avísame y terminaremos después. Tu participación es completamente voluntaria y si en algún momento te sientes incomoda con alguna pregunta, puedes decidir responder a esa pregunta con la grabadora apagada o no responderla.

Cuando termine el levantamiento de la línea final, puedes hacerme todas las preguntas que quieras

\section{¿Estás de acuerdo en participar en la línea final?}

Si: No:

Fecha:

Firma:

Si tienes preguntas adicionales acerca de esta investigación, puedes contactar a Annik Sorahindo o a Xipatl Contreras en el Population Council (55-5999-8657 o 55, asorahindo@popcouncil.org; xcontreras@ popcouncil.org ) o a alguna trabajadora de GESMUJER. 